Cahiers de recherches médiévales

Journal of medieval studies

$18 \mid 2009$

Le système d'enseignement occidental $\left(\mathrm{Xl}^{\mathrm{e}}-\left.\mathrm{XV}\right|^{\mathrm{e}}\right.$ siècle)

\title{
Un baiser entre ciel et terre
}

Mouvance générique et exégèse dans le commentaire du Cantiques cantiques de Maître Eckhart

Julie Casteigt

\section{(2) OpenEdition}

\section{Journals}

Édition électronique

URL : https://journals.openedition.org/crm/11702

DOI : $10.4000 / \mathrm{crm} .11702$

ISSN : 1955-2424

Éditeur

Honoré Champion

Édition imprimée

Date de publication : 20 novembre 2009

Pagination : 217-238

ISSN : $1272-9752$

Référence électronique

Julie Casteigt, « Un baiser entre ciel et terre », Cahiers de recherches médiévales [En ligne], 18 | 2009,

mis en ligne le 15 décembre 2012, consulté le 15 décembre 2022. URL : http://

journals.openedition.org/crm/11702 ; DOI : https://doi.org/10.4000/crm.11702 
La " mouvance " des genres littéraires au Moyen Âge

sous la direction de Florence Bouchet 


\section{rig}

\section{La «mouvance» des genres littéraires au Moyen Âge}

Au Moyen Âge, les critères d'analyse des œuvres littéraires proposés par les accessus ad auctores hérités des grammairiens de l'Antiquité tardive ne prennent pas en considération le genre de l'œuvre considérée. Les arts poétiques des $\mathrm{XII}^{\mathrm{e}}$ et $\mathrm{XIII}^{\mathrm{e}}$ siècles n'ont pas davantage élaboré une poétique des genres médiévaux puisqu'ils compilaient les classifications antiques et proposaient essentiellement des éléments de rhétorique appliqués à la versification. Considérant vers 1200 les grands domaines de la création littéraire au début de la Chanson des Saisnes, Jean Bodel ne les envisage pas en termes de genres mais de «materes » (de France, de Bretagne et de Rome). Le vocabulaire des genres littéraires, tant en ancien qu'en moyen français, n'est d'ailleurs pas exempt d'imprécision ou d'instabilité. Du latin à l'ancien français puis au moyen français, les «translations» et mises en prose d'œuvres narratives occasionnent divers transferts génériques. Quant aux recueils manuscrits de textes médiévaux, ils ne tirent généralement pas leur cohérence d'une stricte homogénéité générique. Autant d'indices (parmi d'autres) qui doivent inciter les médiévistes à relativiser une approche moderne parfois trop étroitement générique: en clin d'œil à Paul Zumthor, le déplacement de la notion de «mouvance» du texte au genre invite à interroger la plasticité des genres médiévaux à travers tous les phénomènes observables de transfert, d'interférences, d'hybridité. Poser la question de la pertinence des genres pour l'écriture des œuvres médiévales, c'est aussi s'intéresser à leur réception, par rapport à un horizon d'attente en perpétuelle redéfinition.

L'enquête proposée se veut ouverte: du Moyen Âge central au Moyen Âge tardif, des domaines d'oc et d'oïl à d'autres littératures européennes. Les cinq articles du présent dossier, issus d'une journée d'étude qui s'est tenue à l'Université de Toulouse-Le Mirail le 7 novembre 2008 sous l'égide de l'IRPALL ${ }^{1}$, entendent contribuer à un champ de réflexion en pleine expansion au sein des études médiévales ${ }^{2}$.

Florence Bouchet

\footnotetext{
${ }^{1}$ Institut de Recherche Pluridisciplinaire en Arts, Lettres et Langues, axe $4:$ « Littératures du domaine européen » (dir. D. Lacroix).

${ }^{2}$ Cette manifestation s'inscrivait dans un projet tri-annuel impliquant les autres Universités du Sud-Ouest: colloques «Les genres en question au Moyen Âge» (Bordeaux, 8-9 novembre 2007), «Les genres au Moyen Âge: la question de l'hétérogénéité » (Pau, 12-13 novembre 2009).
}

Cahiers de Recherches Médiévales, 18, 2009 



\section{酶RM}

\section{Les mutations de l'alba dans la poésie des troubadours}

Abstract: The corpus of the albas supplies data that is extensive enough to allow one to outline the history of the genre which will be approached through the question of 'designation', the specific contribution of Guiraut Riquier, and the structure of the poems that have survived.

Résumé: Le corpus des albas fournit un nombre d'indices suffisamment important pour que l'on puisse dessiner les grandes lignes de l'histoire du genre que nous aborderons à travers la question de la désignation, l'apport spécifique de Guiraut Riquier et la morphologie des pièces conservées.

Dans sa récente édition du corpus des albas occitanes ${ }^{1}$, Christophe Chaguinian revient sur une question à laquelle il avait déjà consacré un article en $2007^{2}$, où il entend aller au-delà de la constatation que les albas de séparation se rattachent «peu ou prou» à l'idéologie de la fin'amor ${ }^{3}$. Il se demande si l'on a affaire à des interférences registrales qui auraient ajouté une «teinte courtoise» au « genre traditionnel », ou si le genre - qu'il limite en fait de façon implicite à l'aube de séparation -, n'est pas plutôt «le résultat d'une réflexion des troubadours » qui ferait de l'alba de séparation "un genre troubadouresque à part entière », s'ouvrant au XIII ${ }^{\mathrm{e}}$ siècle à des thématiques nouvelles. Qu'il s'agisse d'un genre troubadouresque ne nous semble guère poser de problèmes, une fois pris en compte les arguments de P. Bec pour qui la tradition manuscrite «si chiche quant aux genres popularisants » nous a conservé un nombre assez considérable de textes de ce genre, dont plus des deux tiers sont attribués à des troubadours de renom, parmi lesquels Giraut de Bornelh, Raimbaut de Vaqueiras, Bertran d'Alamanon, Guiraut Riquier et Cerveri de Girona ${ }^{4}$ : la question pertinente serait plutôt de savoir quelle est la place que le genre occupe dans la théorie des genres lyriques des troubadours au Moyen Âge. Si l'on se rappelle que plusieurs de ces troubadours se voient attribuer des textes relevant et de la pastorela et de l'alba, à savoir Cadenet, Guilhem d'Autpol, Giraut de Bornelh, Guiraut Riquier et Cerveri de Girona, on est en droit de penser que le sort de ces deux genres est plus ou moins mêlé comme nous tentons de le montrer ailleurs ${ }^{5}$.

\footnotetext{
${ }^{1}$ Les Albas occitanes, étude et édition par Ch. Chaguinian, transcription musicale et étude des mélodies par J. Haines, Paris, Champion, 2008.

${ }^{2}$ «L'alba dans le système des genres troubadouresques. Réflexions sur le rapport des troubadours à la production non troubadouresque », Cahiers de Civilisation Médiévale, 50, 2007, p. 131-47 (dorénavant «Réflexions »).

${ }^{3}$ Les Albas occitanes, p. 34-42.

${ }^{4} \mathrm{P}$. Bec, La lyrique française au moyen âge (XII ${ }^{e}-X I I I^{e}$ siècles) : contribution à une typologie des genres poétiques médiévaux, vol. I, Paris, Picard, 1977, p. 91-92 et 94-95.

${ }^{5} \mathrm{Cf}$. D. Billy, «Des origines populaires de l'alba », à paraître
}

Cahiers de Recherches Médiévales, 18, 2009 
Le questionnement de Ch. Chaguinian nous semble en fait soulever quelques problèmes : soit les premières albas comme celle de Giraut de Bornelh se trouvent en amont de cette 'réflexion' et ne peuvent alors en aucun cas s'inscrire dans ce 'résultat' dont parle le critique (constitueraient-elles alors un pré-genre ?); soit ces mêmes albas sont le résultat d'une réflexion qui aurait déjà eu lieu en amont. Mais quels seraient alors la nature et le contenu de cette 'réflexion'" ? Ce terme nous paraît bien peu approprié pour référer au travail d'un troubadour composant une œuvre quelconque qu'il entendrait inscrire dans ce que nous préférerions appeler une orientation ou une mouvance générique préexistante plutôt que dans un genre pleinement constitué. Mais il n'est pas davantage apte à rendre compte du travail cumulatif de plusieurs générations de troubadours qui se verrait ainsi interprété comme la construction d'une réflexion intellectuelle cohérente : le genre consiste en effet en une collection d'œuvres plus ou moins disparates, composées à des moments historiques bien différents, étalés sur deux siècles, dans un contexte culturel qui évolue considérablement de la première moitié du XII à l'orée du XIV ${ }^{\mathrm{e}}$, et chaque nouveau texte est susceptible d'apporter ou non une modification de quelque importance pouvant avoir une incidence sur le genre lui-même à travers la perception qu'en ont les auditeurs et plus particulièrement les entendens et celle qu'en ont les troubadours eux-mêmes. En d'autres termes, est-ce qu'une focalisation sur le genre pris dans son ensemble est véritablement productive? Quel intérêt peut avoir le portrait-robot que l'on peut dresser à partir de l'intersection des différents textes qui le constituent? N'y a-t-il pas plutôt diverses représentations du genre à différents moments de son histoire, que des ruptures historiques, idéologiques, sociologiques ou/et culturelles ont pu ponctuer, et qu'une perspective panchronique viendrait effacer au profit d'une représentation moderne sans doute bien commode, mais en fait quelque peu trompeuse?

Nous voulons profiter de l'exposé de Ch. Chaguinian pour faire part de quelques réflexions susceptibles d'éclairer l'histoire du genre, en mettant de côté les aspects typologiques qui nous semblent pourtant révéler une chronologie interne relative où se laissent déjà deviner diverses époques de l'évolution du genre ${ }^{7}$. Si Elizabeth W. Poe croit pouvoir évoquer « our inability to determine the origins and internal history of the Old Provençal dawn song $»^{8}$, nous croyons pour notre part disposer au contraire d'un nombre d'indices important qui nous permet de jeter quelques lumières sur cette évolution. Nous exposerons ici les autres éléments qui nous ont paru pouvoir éclairer l'histoire du genre, avec la question lexicologique de la représentation du genre qu'implique le recours à une désignation spécifique, le rôle de Guiraut Riquier dans cette histoire, et enfin les mutations du genre qui apparaissent à travers l'étude des caractéristiques formelles des pièces qui nous sont parvenues. On sait que le genre a subi une intégration précoce dans le cadre de l'idéologie courtoise (et peut-être est-il né dans son sein) avant de connaître une série de mutations qui se traduisent au niveau textuel par l'utilisation de thèmes

\footnotetext{
${ }^{6}$ Dans ses «Réflexions » cit., p. 136 (v. aussi p. 135, n. 16 et 17), Chaguinian parlait d' «un travail de réécriture en profondeur », mais cette notion nous paraît également inappropriée.

${ }^{7} \mathrm{Cf}$. «Des origines populaires de l'alba » cit.

${ }^{8}$ "New Light on the 'Alba' : A Genre Redefined», Viator, 15, 1984, p. 139-150, à la p. 143.
} 
nouveaux au détriment de celui, fondamental, de la séparation des amants9. L'étude formelle met en évidence une intégration progressive dans le cadre de l'esthétique même du trobar, achevant de couper le genre des origines popularisantes qu'on lui suppose et qui se limitent peut-être à des motifs ou à des rythmes musicaux et à des formes poétiques étrangères à la lyrique d'art dont témoigne en particulier l'utilisation du refrain dans les pièces de la première génération.

\section{Désignation et mutation du genre}

En ce qui concerne la désignation du genre au moyen d'une étiquette propre, en l'occurrence 'alba', il convient de remarquer que l'auto-désignation est absente des albas de séparation: on ne la trouve que dans l'alba formelle 'érotique' d'Uc et l'alba religieuse de Guilhem d'Autpol ${ }^{10}$. L'apparition de l'étiquette dans les rubriques des chansonniers concerne par contre surtout des albas de séparation, mais elle est naturellement décalée dans le temps: il s'agit des albas ses titol du chansonnier $C$ copié à Narbonne au $\mathrm{XIV}^{\mathrm{e}}$ siècle, et de Reis glorios dans le chansonnier $T$ copié au $\mathrm{XV}^{\mathrm{e}}$ siècle dans le Nord de l'Italie. On n'a pas non plus manqué d'invoquer la vida de Raimon de Las Salas où le terme ne se voit associé à aucune pièce en particulier, dans deux manuscrits relativement tardifs $(I K)$, copiés à la charnière des $\mathrm{XIII}^{\mathrm{e}}$ et $\mathrm{XIV}^{\mathrm{e}}$ siècles $^{11}$. L'alba religieuse de Cerveri est également dotée de la même étiquette dans le chansonnier $S g$ copié en Catalogne dans la première moitié du $\mathrm{XV}^{\mathrm{e}}$ siècle, ainsi que Eras diray, pièce parodique transmise par le seul $\mathrm{VeAg}$ dont la copie, de main catalane, date du premier quart du $\mathrm{XV}^{\mathrm{e}}$ siècle.

Ces éléments tendent à nous montrer que, jusqu'à preuve du contraire, la conscience affirmée d'un genre spécifique n'apparaît chez les troubadours qu'une fois que le contenu primitif a cédé la place à des thématiques nouvelles, ou peut-être plus exactement lorsqu'il a commencé à se diversifier: le genre qui n'était jusqu'alors qu'une pratique textuelle particulière dont l'homogénéité suffisait à assurer la reconnaissance, acquiert alors une nouvelle identité avec un statut à part entière qui lui vaudra d'apparaître dans le répertoire évoqué par Guiraut Riquier dans sa supplique au roi d'Aragon. La traditionnelle alba de séparation est encore assez bien représentée dans le premier tiers du XIII ${ }^{\mathrm{e}}$ siècle, et, au-delà de cette période, seul Us cavaliers de Bertran d'Alamanon s'inscrit bien encore dans cette tradition, du moins si l'on en croit l'attribution de $C$. Celle-ci se trouve en effet

\footnotetext{
${ }^{9}$ Nous évoquons ce problème du point de vue des motifs utilisés dans «Des origines » cité, où nous plaidons pour l'inscription du genre dans le cadre troubadouresque où il a dû être conçu.

${ }^{10}$ Le cas de $S$ 'anc fuy belha évoqué par E. W. Poe dans «La transmission de l'alba en ancien provençal », Cahiers de Civilisation Médiévale, XXXI, 1988, p. 323-45, à la p. 342, est en effet à rejeter; cf. D. Billy, «Le traitement théorique de l'alba dans la Doctrina de compondre dictats et la question de l'alborada", à paraître dans Revue de Linguistique Romane.

${ }^{11}$ Il est intéressant de noter que la vida n'est pas conservée dans $C R$ qui nous a transmis l'alba à lui attribuée, même si C. Pulsoni se montre indécis sur l'attribution dans "Dieus aydatz $(409,2) »$, Studi di Filologia romanza offerti a Valeria Bertolucci Pizzorusso, Pisa, 2007, vol. II, p. 1307-28.
} 
concurrencée par celle de $K p$ copié dans le Nord de la France, qui l'assigne à Gaucelm Faidit, troubadour actif dans les années $1185-1220^{12}$. Si l'on voit réapparaître les éléments primitifs de l'alba de séparation à la fin du XIII siècle ou à l'orée du XIV', c'est dans Eras diray dont le caractère parodique indique un net démarquage du genre tel qu'il était encore pratiqué dans la première moitié du XIII ${ }^{\mathrm{e}}$ siècle ${ }^{13}$. Cette nette régression du genre primitif nous semble trouver dans la Doctrina de trobar une certaine confirmation: dans ce traité en effet, l'alba de séparation n'est pas désignée sous le terme d'alba mais sous celui de gayta, nom occitan du guetteur, comme si la première étiquette n'était plus associée à cette époque (et dans le milieu de l'auteur du traité) au genre primitif qui serait alors tombé en désuétude. Pour l'auteur de la Doctrina, l'étiquette alba semble par contre désigner l'alba 'érotique' formelle qui pourrait bien représenter pour lui la forme contemporaine que le genre avait revêtu. On peut naturellement se demander pourquoi sa définition laisse complètement dans l'ombre le cas de l'alba religieuse. On rappellera tout d'abord que cette dernière n'accorde plus au mot alba qu'un sens métaphorique (l'éveil spirituel), ce qui pouvait justifier une conception plus restrictive du genre que celle qu'en a Ch. Chaguinian, mais on peut plus simplement penser que l'auteur du traité n'avait en vue que la pratique profane du genre. Seuls les rubricateurs des chansonniers dont la copie est ultérieure, soit ceux de $S g$ et de $\mathrm{VeAg}$ dans la tradition catalane, utilisent 'alba' pour désigner des pièces de toute sorte, y compris religieuses (Cerveri), ce qui renvoie à un sens générique de 'pièce dont les couplets se terminent sur le mot alba'.

\section{Le rôle de Guiraut Riquier}

Une attention toute particulière doit être accordée au rôle que Guiraut Riquier a pu jouer dans l'évolution du genre, car son œuvre semble bien marquer une nouvelle étape dans sa perception (qui n'est peut-être rien d'autre que le genre luimême). Le troubadour de Narbonne avait en effet quant à lui une véritable réflexion sur le trobar, au niveau tant de la fonction du troubadour que du statut des genres et de la part de l'invention dans son travail. C'est en effet Guiraut Riquier qui adresse une supplique au roi d'Aragon, réelle ou fictive, peu importe, pour établir une hiérarchie au sein de sa profession (1274-1275), où Alphonse le Sage accorde le titre de trobador aux inventores qui savent composer coblas, baladas, dansas (ou dansas doblas), sirventes, albas et partimens ${ }^{14}$; ce statut était intermédiaire entre le joglar

\footnotetext{
${ }^{12}$ Il peut d'ailleurs très bien se faire que les deux attributions soient également erronées (il n'y a au demeurant, nous semble-t-il, guère d'albas attribuées dont l'attribution ne soit pas contestable...).

${ }^{13}$ Sur l'originalité de son contenu, voir A. Alberni, «Deux albas catalanes anonymes du XVI siècle ", L'Espace lyrique méditerranéen au moyen âge: nouvelles approches, textes réunis par D. Billy, F. Clément et A. Combes, Toulouse, P.U.M., 2006, p. 265-89, aux p. 269-70 ; sur son caractère parodique, cf. D. Billy, «Le traitement théorique de l'alba » cit.

${ }^{14}$ Cf. J. Linskill, Les Épîtres de Guiraut Riquier, troubadour du XIII siècle, s.1., 1985, p. 230, v. 246-322 et 356-367. Le qualificatif de doblas accolé à dansas n'a pas été élucidé, et nous ne savons pas exactement ce qu'il était censé concerner. Peut-être les strophes fortement charpentées de quelques dansas de Cerveri sont-elles à l'origine de cette expression ? Il ne
} 
(simple interprète) et le doctor de trobar (troubadour d'élite qui se fait remarquer par son talent et son enseignement), ce qui revient à faire de l'alba un genre de bonne tenue mais sans doute dépourvu de caractère édifiant ${ }^{15}$. Cependant, rien ne dit si l'interlocuteur royal de Guiraut pensait à la seule alba de séparation, à des albas formelles dont Guiraut donne lui-même deux témoignages, l'un profane, l'autre religieux, aux seules pièces profanes ou encore à l'ensemble des manifestations du genre. Les genres de prédilection du doctor de trobar étaient le vers et la canso, avec mention indéfinie, novas mises à part, d'autres genres (autres trobars) : on ne peut donc exclure l'idée qu'un troubadour de cette classe pût également pratiquer le genre de l'alba. Or, Guiraut Riquier est précisément dans ce cas, lui qui prétendait au titre le plus élevé de cette hiérarchie de son métier, et il paraît symptomatique de constater qu'il ne nous a pas laissé d'albas de séparation mais uniquement des albas formelles qui ont par conséquent rompu avec le caractère popularisant qu'on s'entend à accorder aux premières.

C'est également Guiraut qui renouvelle la théorie des genres en créant sous le nom de $\operatorname{vers}^{16}$ un genre moral qu'il plaçait au même niveau d'exigences que la canso; c'est lui qui renouvelle la pratique de la pastorela en concevant un cycle tournant autour d'un même personnage féminin dont il suit l'évolution d'âge en âge, avec une visée édifiante ; c'est lui enfin qui s'exerce à plusieurs variations autour du genre de l'alba avec ses deux albas dites 'formelles', l'une 'érotique' (1257), présentée sous la rubrique «alba», l'autre religieuse (1266), présentée sous la rubrique «alba de la maire Dieu », et entre-temps sa 'serena' qui prend le contrepied du motif principal (1263). Les pages que D. Rieger a consacrées à cet aspect nous dispensent d'insister sur cette mutation que Guiraut a imprimée au genre dans une période d'une dizaine d'années ${ }^{17}$. Ces pièces présentent une nette orientation tournée vers la lyrique courtoise avec des formes qui ne doivent pourtant pas grand chose à l'esthétique de la canso. On ne peut dès lors que se demander si ce n'est pas Guiraut lui-même qui est responsable de cette mutation du genre que l'on peut également observer, dans sa variante profane, dans Per grazir la bon'estrena. A en croire $\mathrm{Ch}$. Chaguinian qui l'attribue à Uc de la Bacalaria sur la foi du ms. $C$, cette dernière pièce remonterait à la fin du $\mathrm{XII}^{\mathrm{e}}$ ou au début du $\mathrm{XIII}^{\mathrm{e}}$, ce qui retirerait à Guiraut une partie du rôle que nous lui prêtons, mais cette hypothèse se trouve contredite par la table du chansonnier qui l'attribue à un certain «Guillem de la Bacalaria », en accord avec le chansonnier $R$ ( $« \mathrm{G}$. de la Bacalaria $»^{18}$ ), et l'éditeur

semble pas en tout cas s'agir de pièces qui doubleraient le nombre de couplets si l'on s'en tient aux témoignages conservés.

${ }^{15}$ Dans ses «Réflexions », p. 145, Chaguinian se contente de voir dans ces passages un 'indice' ou une 'preuve' de la codification du genre chez les troubadours.

${ }^{16}$ Guiraut donne à ce terme qui désignait à l'origine toute composition lyrique, une nouvelle motivation sur la base du latin verus.

${ }^{17}$ D. Rieger, «Zur Stellung des Tagelieds in der Trobadorlyrik», Zeitschrift für romanische Philologie 87 (1971), p. 223-232 ; trad. it. «La posizione dell'alba nella lirica trobadorica », La lirica, éd. L. Formisano (Strumenti di filologia romanza, dir. C. Di Girolamo), Bologna, Il Mulino, 1990, p. 157-169.

${ }^{18}$ Sur l'interprétation de l'initiale, voir les remarques de C. Pulsoni dans son Repertorio delle attribuzioni discordanti nella lirica trobadorica, Modena, Mucchi, 2001, p. 79. 
donne lui-même les raisons qui auraient pu inciter le copiste de $C$ à substituer Uc à Guilhem : si donc ce Guilhem dont nous ne savons rien était effectivement l'auteur de la pièce, rien n'empêcherait de lui donner une datation beaucoup moins reculée dans le temps.

\section{La question formelle}

3.1. Elizabeth W. Poe a évoqué un aspect particulièrement important du corpus qui a des conséquences directes sur les hésitations des copistes dans l'attribution des quelques pièces qui n'ont pas été laissées dans l'anonymat ${ }^{19}$ :

C'est parce qu'elles ont tendance à être transmises séparément du corpus des poèmes d'un troubadour particulier et parce qu'elles manifestent de façon naturelle un style et un ton les distinguant des autres genres, que les albas présentent des problèmes extraordinaires d'attribution.

Cette facilité que les albas ont à se dérober à l'auctoritas des troubadours montre à quel point la définition du genre comme 'troubadouresque' est simplificatrice et fallacieuse, ces textes affichant en général un caractère étranger à l'esthétique et à la thématique du trobar qu'on ne peut expliquer que de deux façons : soit par une origine extra-troubadouresque, peut-être pré-troubadouresque comme on s'entend à le reconnaître, soit par une imprégnation d'éléments popularisants. Dès lors, c'est bien la question de l'appropriation du genre par les troubadours qui se pose, et dont nous avons pu, sur le plan thématique, mesurer l'ampleur et la portée ${ }^{20}$. L'examen formel va maintenant nous permettre d'apporter des précisions sur cette intégration progressive du genre primitif de l'alba dans le cadre du système des genres plus spécifiquement troubadouresques.

3.2. Un examen superficiel met très vite en évidence des ruptures au sein du corpus. La première oppose des pièces monométriques : quatre à décasyllabes plus une (Qui velha) à hexasyllabes, et d'autres où une polymétrie plus ou moins libre se manifeste ${ }^{21}$. Le sous-corpus de pièces à décasyllabes se divise en deux selon la longueur de la strophe. D'une part En un vergier dont la forme comme la dimension réduite (un quatrain $10 \mathrm{aaaB}$ ) est étrangère au 'grand chant courtois' et rappelle nettement le quintil de Reis glorios, seule pièce polymétrique à recourir au décasyllabe, soit concrètement dans la partie libre du couplet, le refrain étant un hexasyllabe $\left(\mathrm{a}^{10} \mathrm{a}^{10} b^{10} b^{10} C^{6}\right)$. D'autre part les autres pièces à décasyllabes qui utilisent par contre des strophes d'au moins sept vers (Bernart de Venzac, Peire Espanhol et Cerveri $^{22}$ ), celle de Guilhem d'Autpol une de onze vers, pièce dont la longueur et l'arrangement des rimes rappellent nettement l'esthétique de Bertran

\footnotetext{
${ }^{19}$ Dans «La transmission de l'alba en ancien provençal » cité.

${ }^{20}$ Voir «Des origines populaires de l'alba » cité.

${ }^{21}$ On pourrait discuter du cas de Us cavaliers et de Per grazir dont le couplet est monométrique (heptasyllabes dans les deux cas) au contraire du refrain. Rappelons toutefois que cette pièce initie la mutation du genre.

${ }^{22}$ Le dernier décasyllabe est divisé par une rime batelée : $10 a b b a \operatorname{ccc}^{4} d^{6}$.
} 
Carbonel: toutes sont des albas religieuses. Il convient d'ajouter que ces quatre pièces ont toutes de cinq (Bernart de Venzac, Peire Espanhol) à six (Guilhem d'Autpol, Cerveri) couplets, qu'elles utilisent la technique des coblas unissonans et sont accompagnées d'une ou deux tornadas, toutes caractéristiques qui signalent une intégration parfaite dans le cadre de l'esthétique courtoise. Il n'est en outre pas inutile de remarquer que la strophe de deux de ces albas suggère la possibilité d'un contrafactum: celle de Peire de Venzac et celle de Cerveri pourraient dériver respectivement d'une canso de Raimon de Miraval et d'une autre d'Arnaut de Maruelh $^{23}$. Il ne fait pour nous pas de doute que ces pièces reposent sur un détournement du genre traditionnel de l'alba, où seul le mot-clé utilisé comme motrefrain terminal sert d'indicateur générique. Les seules aubes religieuses qui ne répondent pas à cette interprétation sont celle, polymétrique, que l'on attribue à Falquet de Romans, sur laquelle nous reviendrons, et Qui velha de Guiraut Riquier, seule pièce composée uniquement d'hexasyllabes, ce qui n'est pas du tout commun dans l'esthétique courtoise. Cette dernière pièce qui utilise une strophe de quinze vers n'est composée que de quatre couplets, est dépourvue de tornadas et utilise un refrain, soit trois caractéristiques qui signalent la nette intention du troubadour narbonnais de se démarquer de l'esthétique courtoise, en dépit de l'utilisation de coblas unissonans: sa démarche est par conséquent opposée à celles de Bernart de Venzac, de Peire Espanhol, de Guilhem d'Autpol ou de Cerveri : Guiraut Riquier maintient un lien formel avec la tradition de l'alba de séparation.

3.3. La seconde rupture apparaît entre les pièces dotées d'un refrain (neuf) et les autres. En effet, le refrain est étranger au 'grand chant courtois' comme nous venons de le dire. Tout d'abord, le refrain cesse d'être autonome dans trois pièces, dont l'une présente ordinairement un refrain non $\operatorname{lié}^{24}$; dans les deux autres, toutes deux de Guiraut Riquier, l'une 'érotique' (Ab plazen), l'autre religieuse (Qui velha), il s'agit d'une proposition coordonnée («e dezir vezer l'alba») ou d'un syntagme pronominal constitué d'un démonstratif suivi d'une relative («selha qu'a peccadors / vius penedens es alba»). L'autonomie du refrain semble bien avoir joué un rôle essentiel dans les premières albas de séparation. On remarque d'autre part que, dans les pièces avec refrain, le mot alba n'apparaît qu'à l'intérieur des vers, à l'exception d'Us cavaliers qui daterait du XIII' siècle (Bertran d'Alamanon est né vers 1210).

L'alba attribuée à Falquet de Romans est particulièrement intéressante, car elle est la seule pièce religieuse du corpus à présenter un refrain parfaitement autonome où le mot-clé n'occupe pas la position finale, et où la venue de l'aube a une présentation purement objective, avec une valorisation positive, dont seuls les couplets proprement dits permettent d'interpréter la fonction symbolique ${ }^{25}$ :

La nueg vay e-l jorn[s] ven ab clar cel e cere, mas l'alba no's rete: ans ven bel' e complia.
La nuit s'en va et le jour vient

dans un ciel clair et serein, mais l'aube ne tarde pas: elle vient au contraire, belle et parfaite.

\footnotetext{
${ }^{23}$ Cf. Chaguinian, op. cit., p. 263 et 334-36.

${ }^{24}$ Il s'agit de Reis glorios où la dernière reprise du refrain s'accompagne d'une modification textuelle et de son intégration au couplet.

${ }^{25}$ Cf. Jeanroy, Les origines..., op. cit., p. 82.
} 
L'utilisation du mot alba à la fin du dernier vers semble bien résulter du développement d'une nouvelle technique, celle du mot-refrain, que l'on trouve dans presque toutes les pièces dépourvues de refrain au sens strict, à l'exception de $\mathrm{Ab} l a$ genser qui n'utilise d'ailleurs pas une seule fois le mot-clée ${ }^{6}$, sans parler, naturellement, des deux strophes isolées, encore que Drutç qui vol se termine également sur $a l b a^{27}$. Or, la technique du mot-refrain est typiquement troubadouresque, de même que celle du rim espars que constitue presque toujours le mot-clé lorsqu'il apparaît à la rime, en liaison avec l'isolement lexical de ce mot dont la terminaison est à peu près unique ${ }^{28}$, ce qui explique du reste que, dans les refrains, on le trouve généralement au sein des vers. Dans deux pièces, le mot est répété en fin de vers au sein de la strophe, deux fois dans Us cavaliers qui est la plus tardive, quatre fois dans l'alba de Raimbaut de Vaqueiras (Gaita be $)^{29}$, dont deux dans le refrain, et où l'on ne peut par conséquent pas parler de rim espars, mais de ce que la tradition galégo-portugaise théorisera sous le nom de dobre dont seul Jaufre Rudel parmi les troubadours nous a laissé une autre illustration (Lanquan li jorn). Dans cette pièce, la reprise terminale du mot-refrain terminal fait l'objet d'une double répétition, ponctuée par un $o c$ d'insistance :

$\begin{array}{ll}\text { Joc novel } & \text { C'est d'un jeu nouveau } \\ \text { mi tol l'alba, } & \text { que me prive l'aube, } \\ \text { l'alba oc, l'alba. } & \text { l'aube, oui, l'aube. }\end{array}$

Ces données permettent d'esquisser une évolution du genre, avec d'abord l'emploi d'un refrain autonome pour aboutir avec Raimbaut de Vaqueiras, puis Cadenet et Bertran d'Alamanon à un simple mot-refrain, technique dont on retrouve la trace dans le couplet isolé Drutç qui vol et qui réapparaîtra dans l'alba parodique occitano-catalane Eras diray pour s'en tenir au domaine de l'alba de séparation, avec des nuances typologiques que nous examinons ailleurs ${ }^{30}$.

\footnotetext{
${ }^{26}$ Élément qui, parmi d'autres, a amené Poe à voir dans cette pièce une parodie improvisée par un copiste, "The Lighter Side of the Alba: Ab la genser que sia», Romanistisches Jahrbuch, 36, 1985, p. 87-103 ; voir les critiques de Chaguinian, op. cit., p. 195-96. On pourrait tout aussi bien imaginer que la pièce ait été amputée d'un refrain liminaire, sans rappel en fin de strophe dans la source du ms., mais nous ne voyons pas de raison majeure de douter de l'authenticité de cet état.

${ }^{27}$ Le cas de Quan lo rossinhols est difficile à interpréter. Le mot-clé est intégré dans le cri du guetteur rapporté à la fin: «Drutz, al levar, / qu'ieu vey l'alba e-l jorn clar. » Ce discours rapporté est introduit par le verbe escrida que l'on rattache aux premiers mots rapportés, mais on a au v. 1 la forme escria qui suggère de décomposer l'avant-dernier vers en deux vers plus courts; on aurait ainsi $a^{7} a^{7} a^{7} b^{3} b^{7} a^{2} c^{4} c^{7}$ (si le couplet est un fragment, ces deux vers pouvaient servir de refrain).

${ }^{28}$ Encore faut-il signaler l'ingéniosité dont feront preuve les auteurs catalans d'un échange de coblas à rimes rares conservé dans le petit chansonnier de Ripoll, en tirant parti de leur langue avec les dérivés verbaux enalbar et esxalbar, les adjectifs féminins calba (ao. calva) et balba et les noms propres Gualba et Vilalba.

${ }^{29}$ Rappelons ici que Dieus aydatz utilise alba à trois reprises au sein du refrain.

${ }^{30} \mathrm{Cf}$. notre article «Des origines populaires de l'alba » à par., $\S 3$.
} 
L'utilisation du mot en fin de refrain ou à défaut en fin de couplet est à peu près constante dans les albas formelles, seule Vers Dieus de Falquet de Romans faisant exception. Dans la dernière alba 'érotique' formelle $E$ ! quant m'es greu, transmise par $\mathrm{VeAg}$, on observe un ton nettement courtois, comme dans les pièces d'Uc de la Bacalaria (?) et de Guiraut Riquier, avec de plus la figure du descortes «qui m'ha repres / de vos amar» et celle de l'envegos falç e lausenger. Mais à leur différence, l'aube n'y joue plus le moindre rôle dramatique, et sa venue est pour le moins forcée :

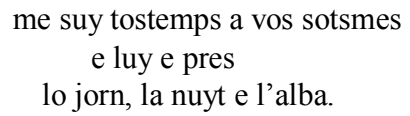

haver l'enten,

belha, presan, prous e valen, qui manta gen

desir' aver un' alba.

(II, 17-19) et je me suis toujours soumis à vous, que ce soit auprès de vous ou éloignée, le jour, la nuit ou bien à l'aube.

j'entends l'avoir, belle, digne d'éloges, bonne et noble, elle que maintes personnes voudraient avoir un jour à l'aube. ${ }^{31}$

Il n'en reste pas moins que la forme ne doit rien aux modèles de la canso, témoignant d'une volonté de démarcation censée sans doute la rattacher à la tradition popularisante de l'alba de séparation. Dans Eras diray qui date de la même époque et emprunte le même modèle strophique, plus proche de l'alba de séparation dont elle est une parodie, l'emploi du mot-refrain est plus conforme à l'utilisation ancienne $\mathrm{e}^{32}$ :

$$
\begin{gathered}
\text { «Via sus, cavalhiers guerrers, } \\
\text { que lausangiers } \\
\text { no.us assauton en l'alba. » }
\end{gathered}
$$

(I, 17-19)

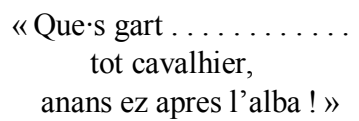

(II, 17-19)

\author{
En avant, cavalier guerrier! \\ que les médisants \\ ne vous surprennent pas à l'aube!
}

qu'il se garde ............ tout cavalier, avant et après l'aube!

\footnotetext{
${ }^{31}$ L'interprétation du passage pose problème, bien que Chaguinian et Alberni s'entendent sur ce point. Dans Et ades sera l'alba. Angoisse de l'aube. Recueil des chansons d'aube des troubadours, Montpellier, Centre d'Études occitanes, 2005, p. 73, Gouiran donne semble-t-il une interprétation métaphorique : «je désire qu'elle soit belle, estimable, de haut mérite et de valeur, car beaucoup de gens désirent avoir une aube. »

${ }^{32}$ Cité d'après Alberni, art. cit., p. 282-83. Nous considérons cependant comme Chaguinian que les vers II 17-19 constituent bien un discours rapporté et non une proposition complétive en raison du traitement parallèle dans les autres couplets.
} 


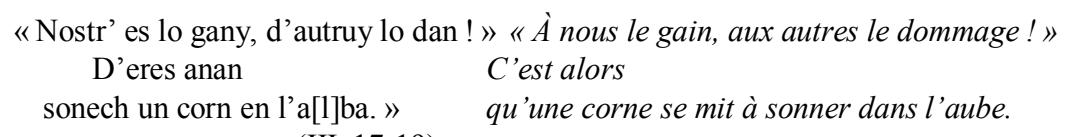
(III, 17-19)

3.4. Une troisième rupture concerne le nombre de couplets. On sait que le modèle de la canso ne descendait jamais au-dessous de cinq, et qu'elle dépassait peu souvent six. De ce point de vue, la majorité des albas de séparation sont en-dessous de cette norme, dont quatre ont trois couplets et deux n'en ont qu'un (fragments?), et seules l'alba attribuée à Bertran d'Alamanon, Ab la genser et En un vergier correspondent au canon de la canso, celle de Giraut de Bornelh allant jusqu'à sept couplets, encore qu'il convienne de tenir compte d'une certaine variation dans la tradition manuscrite de celles de Giraut et de Cadenet. Les formes strophiques utilisées dans ces pièces n'ont par contre pas grand chose à voir avec les formes pourtant extrêmement variées pratiquées dans la canso, et surtout, elles utilisent un refrain, à l'exception de $\mathrm{Ab}$ la genser. Ce qui nous frappe le plus est cependant le cas des albas 'érotiques' formelles qui ont toutes un nombre de couplets inférieur à cinq, et dont la strophe à refrain indique pour deux d'entre elles une nette volonté de démarcation de l'orbite de la canso. Si E! quant m'es greu n'en a que deux (et pas de refrain au sens strict), celle de Guiraut Riquier et celle attribuée à Uc de la Bacalaria en ont plus précisément quatre, ce qui, avec leur refrain, les fait correspondre à la définition que la Doctrina de compondre dictats donne de la retronxa $a^{33}$ :

E deus saber que deu haver quatre cobles, e so novell tota vegada. E deus saber que per ço ha nom retronxa car lo refray de cada una de les cobles deu esser totz us.

Et l'on doit savoir qu'elle doit avoir quatre couplets et un air nouveau. Et l'on doit savoir qu'on l'appelle retronxa pour ce que le refrain de chacun des couplets doit être le même.

Cet aspect est d'autant plus intéressant si l'on se rappelle qu'aucune alba de séparation n'a quatre couplets ${ }^{34}$.

3.5. La quatrième rupture concerne la présence ou non de tornadas. Nous avons déjà vu que les pièces religieuses à strophes longues de décasyllabes en étaient toutes pourvues. On peut naturellement imaginer que ces appendices dont on connaît la volatilité ont parfois pu se perdre dans les méandres de la tradition

${ }^{33}$ Éd. J. H. Marshall, The 'Razos de tobar' of Raimon Vidal and associated texts, London, Oxford University Press, 1972, p. 96.

${ }^{34}$ Guiraut nous a laissé trois retroenchas selon le nom que leur donne la rubrique du chansonnier $R$ (dont deux en heptasyllabes, l'autre, No cugey mais, en décasyllabes). Cependant une seule d'entre elles (No cugey mais) a bien quatre couplets, les deux autres en ont cinq. 
manuscrite ${ }^{35}$, mais le croisement avec d'autres données formelles nous paraît justifier leur absence. La presque totalité des albas 'érotiques' en sont dépourvues, ce qui semble significatif d'une volonté de se démarquer là encore de l'esthétique courtoise, y compris lorsque Uc de La Bacalaria et Guiraut Riquier orientent la thématique amoureuse dans une optique idéaliste plus clairement courtoise.

Une seule alba de séparation en est dotée: celle de Cadenet, pourtant pourvue d'un nombre de couplets et d'un réseau (trois coblas singulars) qui renvoient plutôt à une tradition non courtoise, mais dont le mot-refrain renvoie par contre lui aussi, comme les tornadas, à la lyrique d'art. S'anc fui belha apparait ainsi comme une composition hybride où le troubadour n'entend pas davantage renoncer aux charmes de la forme popularisante qu'à ceux de l'esthétique courtoise dans un équilibre qui a dû contribuer à sa réussite, tout comme la place qui y est faite au personnage de la mal mariée, qui n'apparaît jamais dans les autres pièces du corpus. La seule alba religieuse dépourvue de tornadas a, nous l'avons vu, un nombre de couplets inférieur à celui requis dans le cadre de la canso: celle de Guiraut Riquier. Celle de Falquet de Romans, Vers Dieus, el vostre nom e de sancta Maria, est problématique ${ }^{36}$; analyse :

$$
\begin{array}{rlll}
\text { I-II } & a^{12} a^{12} a^{12}-\mathrm{b}^{6} \mathrm{~b}^{6} \mathrm{~b}^{6} a^{6}-\mathrm{b}^{6} \mathrm{~b}^{6} \mathrm{~b}^{6} a^{6} & \mathrm{C}^{6} \mathrm{C}^{6} \mathrm{C}^{6} A^{6} & \mathrm{a}: i a, \mathrm{~b}: a t z, \mathrm{c}: e \\
\text { III-IV } & d^{12} d^{12} d^{12}-\mathrm{c}^{6} \mathrm{c}^{6} c^{6} d^{6}-\mathrm{c}^{6} c^{6} c^{6} d^{6} & \mathrm{C}^{6} \mathrm{C}^{6} \mathrm{C}^{6} A^{6} & \mathrm{~d}: \text { enda } \\
\text { V } & d^{12} d^{12} d^{12}-\mathrm{c}^{6} \mathrm{c}^{6} \mathrm{c}^{6} d^{6} & \mathrm{C}^{6} \mathrm{C}^{6} \mathrm{C}^{6} A^{6} &
\end{array}
$$

La reprise des rimes dans $\mathrm{V}$ suggère qu'il s'agit bien ici d'une forme de tornada, comme le pensent la plupart des éditeurs à la suite d'Appel, d'autant plus que le contenu peut passer pour une conclusion. Il faut cependant savoir que, dans la chanson courtoise des trouvères, lorsque la pièce a un nombre impair de couplets (soit en pratique 5 ou 7), les coblas doblas peuvent très bien s'organiser en $2+3$ ou $2+2+3$ couplets, de façon à éviter l'isolement du couplet final, mais ce phénomène demeure exceptionnel chez les troubadours ${ }^{37}$. La structure de Vers Dieus est parfaitement originale, et c'est naturellement dans la poésie des trouvères, beaucoup plus ouverte aux refrains, que l'on peut trouver des formes analogues, bien que la structure ternaire qui commence la strophe et le redoublement dans le couplet du

\footnotetext{
${ }^{35}$ Rappelons que celles de Cadenet sont présentes dans $A D G I K$ mais absentes de CEPR (Sg en garde cependant la trace). Par contre, leur absence dans le chansonnier de Guiraut nous paraît délibérée en raison de la rigueur avec laquelle celui-ci a été compilé.

${ }^{36}$ D. Billy, «Contribution à l'étude du chansonnier de Colin Muset», Romania, 125, 2007, p. 306-41, aux p. 314-15 (notre analyse est malheureusement erronée au niveau du refrain des couplets III-V, de même l'incipit qui est celui du troisième couplet, ce qui, je le reconnais, est un comble !) Nous adoptons ici le type de présentation retenu par Chaguinian, éd. cit., p. 275, qui applique l'ordre alphabétique de bout en bout, ce qui permet de préserver la cohérence du refrain.

${ }^{37}$ Voir Bertran de Born PC 80,9, mais aussi Guilhem IX PC 183,1 et Jaufre Rudel PC 262,5 (avec des permutations dans ces deux cas). Pour les trouvères, voir R. Dragonetti, La Technique poétique des trouvères dans la chanson courtoise. Contribution à l'étude de la rhétorique médiévalle [sic], Bruges, 1960, p. 447.
} 
module de quatre hexasyllabes soient propres à notre pièce ${ }^{38}$. Cette pièce n'est conservée que dans trois chansonniers qui appartiennent à une même tradition $(C R f)$, et l'on ne peut écarter l'hypothèse d'une lacune, même si le sens de V paraît satisfaisant en l'état actuel: nous dirions même que cette complétude apparente pourrait être la raison qui aurait provoqué l'omission des quatre vers manquants, identiques du point de vue formel aux quatre précédents (sans parler du refrain). On ne peut manquer de se souvenir ici des réticences de Madeleine Tyssens à admettre l'hypothèse de John H. Marshall concernant l'existence d'un hétéromorphisme motivé par le caractère modulaire des strophes qui caractérise précisément notre pièce $^{39}$.

L'originalité de cette composition mérite également que l'on s'attarde sur l'aspect historique. L'activité de Falquet de Romans à qui la pièce est attribuée est antérieure à $1230^{40}$. Il s'agirait donc de l'alba religieuse la plus ancienne avec Lo pair' $e \cdot l$ filh que $C R$ s'entendent à attribuer à Bernart de Venzac, actif avant 1210 , mais Ch. Chaguinian, au terme d'une discussion assez serrée de la question, en est venu à conclure que la pièce n'était vraisemblablement pas de lui, ouvrant la voie à une datation postérieure ${ }^{41}$ :

Le passage en revue des arguments, tant favorables que contraires à Bernart, nous semble défavorable à ce dernier et nous sommes enclin à voir en ce texte une œuvre $\mathrm{du}$ treizième siècle.

Nous irions même plus loin tout en rappelant qu'il ne s'agit là que d'une conjecture: toutes les autres albas religieuses présentent les traits généraux de la canso, et il en va de même de Lo pair' e'l filh qui semble bien se rattacher directement à cette nouvelle orientation du genre qui se manifeste sans doute après 1230, puisque la plus ancienne qui soit plus ou moins datable, Esperansa de totz ferms esperans est attribuée par le seul chansonnier $C$ à Guilhem d'Autpol (ce qui soulève certes des réserves) qui fut seigneur entre 1231 et 1289 . La seule exception, pour le moins notable, est la pièce de Guiraut Riquier, Qui velha, datée de 1266 , dont, nous l'avons vu, la structure répond de façon aussi exacte que possible à la définition que la Doctrina de compondre dictats donne de la retronxa. Par ailleurs, la présence d'un refrain dans l'alba de Falquet nous autoriserait à évoquer la possibilité de l'influence des trouvères, de même que la répétition d'un même module rimico-métrique (de quatre vers) au sein du couplet. Cette perspective ne donne malheureusement pas de réponse satisfaisante : d'une part la structure ternaire

\footnotetext{
${ }^{38}$ Nous songeons plus précisément à une chanson pieuse, anonyme, Chanter vous vueil de la vierge Marie (RS 1182), dont la strophe $\left(a^{10} a^{10} b^{6} b^{6} b^{6} a^{6} C^{6} C^{6} C^{6} A^{6}\right)$ résulte en fait d'une légère altération d'un modèle emprunté à Richart de Semilli (vers 5 et $9: b^{7}$ ).

${ }^{39}$ M. Tyssens, "Chansons hétéromorphiques?», Cultura Neolatina, XLVIII, 1988, p. 113 41 ; J. H. Marshall, «Textual Transmission and Complex Musico-metrical Form in the Old French Lyric », Medieval French Studies in Memory of T.B.W. Reid, Londres : Anglo-Norman Text Society, 1984, p. 119-48.

${ }^{40}$ Cf. R. Arveiller et G. Gouiran, L'œuvre poétique de Falquet de Romans, troubadour, Aixen-Provence, 1987, p. 143-44.

${ }^{41}$ Op. cit., p. 262.
} 
de la partie frontale est plutôt exceptionnelle mais se retrouve dans d'autres albas; d'autre part, le refrain reproduit la moitié de la cauda qui est constituée de deux parties identiques, alors que, comme l'illustre le cas du virelai, lorsqu'un refrain est en cause et qu'il reproduit la partie finale du couplet, c'est la cauda tout entière qu'il reproduit. On ne peut par ailleurs manquer de faire le rapprochement avec Qui velha de Guiraut Riquier, seule pièce à employer systématiquement l'hexasyllabe (dont l'alexandrin n'est d'une certaine façon que le redoublement), mais la comparaison s'arrête là. Tout ceci confirme l'extrême originalité de la pièce.

3.6. La question de la structure des strophes est naturellement importante. Nous avons déjà évoqué le quintil de Reis glorios et le quatrain de En un vergier, tous deux conclus sur un refrain autonome. Les autres pièces ont souvent une partie frontale étrangère à la tradition de la canso: S'anc fui belha, Us cavaliers, Quan le rossinhols et $\mathrm{Ab}$ la genser commencent toutes avec trois vers féminins homorimes, comme Vers Dieus, avec des heptasyllabes féminins dans les trois premières, des hexasyllabes dans $A b$ la genser et des alexandrins dans Vers Dieus ${ }^{42}$. Une autre forme également fréquente est composée de pedes particuliers composés de trois vers masculins isométriques en aabaab, avec des octosyllabes dans les deux pièces catalanes anonymes (Eras diray et E! quant m'es greu), de versification négligée et en rapport de contrafacture, des trisyllabes dans Ab plazen de Guiraut Riquier et des hexasyllabes dans Qui velha du même troubadour, seule composition religieuse du corpus à commencer ainsi. Cette dernière pièce se détache par conséquent tout comme Vers Dieus des autres albas religieuses ${ }^{43}$ :

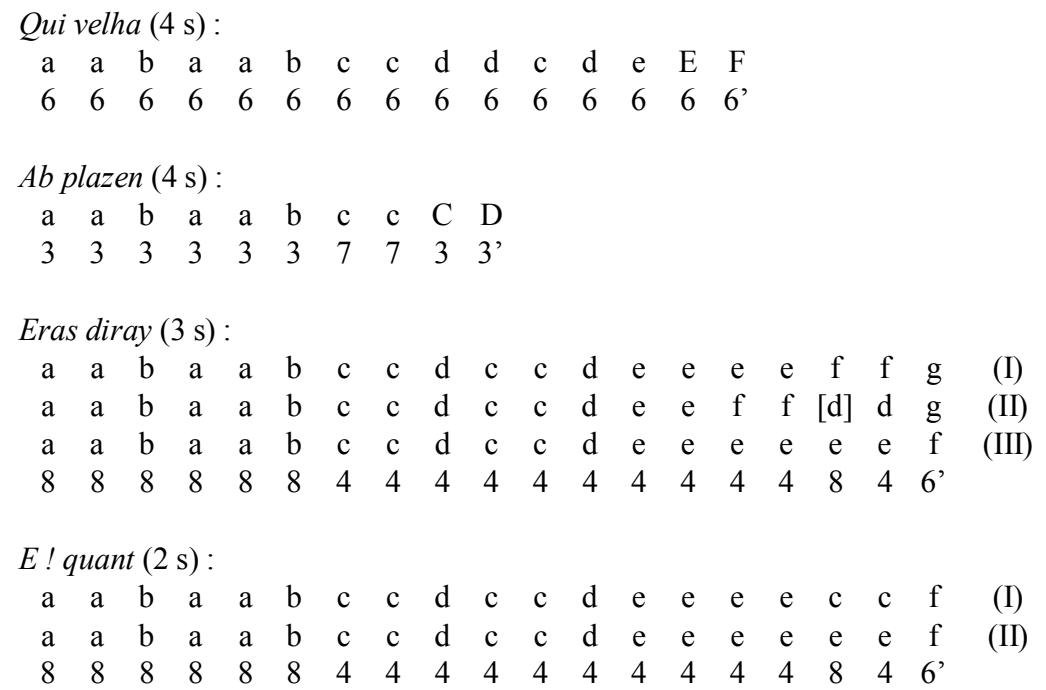

${ }^{42}$ Cf. G. Monari, «Son d'alba. Morfologia e storia dell'alba occitanica », Critica del Testo, VIII /2, 2005, p. 669-763, aux p. 756-57.

${ }^{43} \mathrm{~s}=$ coblas singulars. 
La sur-représentation de ce type de pedes ternaires dans un corpus aussi petit que celui des albas indique nettement une communauté d'inspiration esthétique que l'on retrouve dans une cobla anonyme qui se démarque par l'emploi du pentasyllabe et l'utilisation d'un refrain onomatopéique ${ }^{44}$, autre élément qui signale une esthétique étrangère aux standards troubadouresques, Folcher, considrer (sic) (PC 461,123a) :

$$
\begin{array}{cccccccccccccccc}
\mathrm{a} & \mathrm{a} & \mathrm{b} & \mathrm{a} & \mathrm{a} & \mathrm{b} & \mathrm{c} & \mathrm{c} & \mathrm{b} & \mathrm{c} & \mathrm{c} & \mathrm{b} & \mathrm{D} & \mathrm{D} & \mathrm{E} & \mathrm{F} \\
5 & 5 & 5 & 5 & 5 & 5 & 5, & 5, & 5 & 5, & 5, & 5 & 5 & 5 & 1 & 8
\end{array}
$$

On ne peut non plus oublier que Guiraut utilise une structure analogue à celle de Qui velha, mais sans refrain (5 aabaabbccdd), dans une canso par ailleurs régulière bien que constituée de vers inhabituellement courts (six couplets plus deux tornadas) de 1255 , soit un an avant son alba religieuse ${ }^{45}$. Il est également intéressant de trouver chez Peire Cardenal une formule affine dans des coblas (BdT 335,35 : Lo segle vei camjar) dont la structure est très proche de celle de Qui velha:

$$
\begin{array}{ccccccccccc}
a & a & b & a & a & b & b & b & a & a & b \\
6 & 6 & 6 & 6 & 6 & 6 & 6 & 6 & 6 & 6 & 6
\end{array},
$$

Le satiriste s'était inspiré comme souvent d'un modèle qui a eu un incontestable succès chez les troubadours puisqu'on en trouve des variations jusque chez Gui d'Ussel, dans des coblas, chez un Fraire Menor ${ }^{46}$ et chez Bertran d'Alamanon, dans un sirventes (Lo segles m'es camjatz), variations que John $\mathrm{H}$. Marshall, reprenant les notes de Frank M. Chambers, a pu rattacher à une pastourelle en langue mixte, L'autrier mi'ere levaz $(\mathrm{R} 935=B d T 461,148)$ dont la forme est proche de trois chansons satiriques lorraines que l'on a pu attribuer avec des réserves variables à Colin Muset ${ }^{47}$.

La plupart des autres pièces commencent avec des pedes de forme classique, soit à rimes alternées, forme moins prisée dans le cadre de la canso mais, sans doute de façon significative, davantage dans l'alba; soit avec des rimes embrassées ${ }^{48}$. Il

\footnotetext{
${ }^{44}$ «Varalalito / varalalito / deu ! / varalatitondeyna. »; éd. H. Suchier, «Provenzalische Verse aus Nünberg », Zeitschrift für romanische Philologie, XV, 1891, p. 511-4, à la p. 513. Frank $(109: 1)$ donne un hexasyllabe pour le dernier vers qui a au moins une syllabe de plus, sans doute deux.

${ }^{45}$ Dans Ab pauc er decazutz (BdT 248,2) : 6 aabaabbccdd.

${ }^{46} \mathrm{Cf}$. L. Selaf, «Frère mineur ou frère cadet ? Cor ay voluntatz : rapports d'imitation d'une chanson religieuse provençale », Revue des Langues Romanes, CXII, 2008, p. 61-72.

${ }^{47}$ F. M. Chambers, «Imitation of Metrical Form in Peire Cardenal », Romance Philology, XXXII, 1978, p. 18-48, aux p. 36-38; J. H. Marshall «Pour l'étude des contrafacta dans la poésie des troubadours », Romania, 101, 1980, p. 289-335, aux p. 304-9; pour Colin Muset, voir D. Billy, «Contribution à l'étude du chansonnier de Colin Muset» cit., p. 306-41, aux p. 307-10.

${ }^{48} \mathrm{La}$ seule pièce qui commence d'une autre façon est Dieus aydatz avec des pedes quaternaires de petits vers tout à fait inhabituels, en $\mathrm{a}^{3} \mathrm{a}^{3} \mathrm{~b}^{3} \mathrm{c}^{5}$ (voir cependant les modules constitutifs de la strophe VII du descort de Guiraut de Calanson BdT 243,1: $\mathrm{a}^{4} \mathrm{a}^{4} \mathrm{~b}^{2} \mathrm{c}^{6}$ ).
} 
s'agit d'une part de Gaita be $\left(\mathrm{a}^{3} \mathrm{~b}^{6} \mathrm{a}^{3} \mathrm{~b}^{6}\right)$, du couplet didactique Drutç qui vol $\left(\mathrm{a}^{8} b^{7} \mathrm{a}^{8} b^{7}\right)$, de l'alba d'Uc de La Bacalaria (7 abab) et des albas religieuses Lo pair' e.l filh (10 abab) et Or leves (10 abab); d'autre part des albas religieuses de Guilhem d'Autpol (10 abba) et Cerveri (10 $a b b a)$. Il nous semble ainsi que l'on peut identifier deux courants d'inspiration dans le cadre de l'alba religieuse où dominent ces formes classiques: celui qu'illustrent les albas de Falquet et de Guiraut qui semblent suivre dans les grandes lignes des modèles français ou plus exactement une esthétique française, et celui des autres troubadours qui semblent partir d'une structure de canso qu'ils modifient par la seule insertion du mot-refrain ' $a l b a$ ' en fin de strophe, avec des modèles strophiques beaucoup plus conformes aux standards troubadouresques de l'époque : frons à rimes embrassées, évitement (sauf chez Peire Espanhol) des rimes multiples, chaque rime (sauf le rim espars final) ayant deux occurrences au sein du couplet, disposition simple des différentes rimes contrairement à ce qui se pratiquait en général à l'époque classique.

3.7. Le type de réseau de rimes est un critère naturellement important, mais qui n'a manifestement pas la même portée. Composées de coblas singulars, trois aubes de séparation seulement n'ont pas recours à un quelconque réseau, parmi lesquelles En un vergier et celle de Cadenet, la troisième (qui est aussi la dernière en date), Eras diray, présentant, on l'a vu, un caractère parfaitement atypique. Il paraît par contre très intéressant de constater que les albas 'érotiques' formelles sont toutes trois à coblas singulars et qu'elles utilisent seulement deux à quatre strophes, affichant ainsi une rupture formelle radicale d'avec les canons de la canso, contrairement à la plupart des aubes religieuses. Avec ses cinq coblas unissonans, l'aube de Bertan d'Alamanon affiche par contre son rattachement à ces standards troubadouresques à la fois par le réseau et par le nombre de couplets. Des pièces restantes $^{49}$, seules Reis glorios et $A b$ la genser se signalent par une recherche évidente, avec rigueur pour la première (sept coblas doblas), avec une relative liberté pour la seconde dont l'originalité (rappelons l'absence de refrain comme du mot $a l b a$ ) se trouve là encore confirmée; mots-rime des 5 couplets (ordre du ms.) :

$\begin{array}{lllll}\text { sia } & \text { jazia } & \text { maldia } & \text { tenia } & \text { via } \\ \text { aibia } & \text { adormia } & \text { Maria } & \text { auciria } & \text { amia } \\ \text { dia } & \text { tendia } & \text { dia } & \text { tenria } & \text { venia } \\ \text { solamen } & \text { plazenmen } & \text { ay } & \text { argen } & \text { ai } \\ \text { rizen } & \text { sen } & \text { esmay } & \text { viven } & \text { esmay } \\ \text { dia } & \text { via } & \text { amia } & \text { sia } & \text { vilania }\end{array}$

La première rime ia est constante, mais la seconde fait l'objet d'une alternance incertaine entre en et ai (Ch. Chaguinian intervertit les couplets III et IV) : cette recherche est néanmoins altérée par des rims tornatz qui constituent un vice dans la lyrique d'art (sia I 1 et IV 5 ; dia I 3 et IV 3 ; amia III 5 et V 2$)^{50}$. La

\footnotetext{
${ }^{49}$ Les pièces composées de couplets isolés sont bien entendu hors concours.

${ }^{50}$ Quoi qu'en ait Chaguinian, p. 200-201, qui s'appuie sur l'autorité de N. Smith. Les vers III 4-5 et V 4-5 sont identiques (en fait, seule rime en -ai), reprise qui peut s'expliquer dans le cadre d'un changement de voix comme c'est ici le cas.
} 
forme strophique adoptée n'est pas sans rappeler une ballette française du chansonnier d'Oxford ${ }^{51}$ :

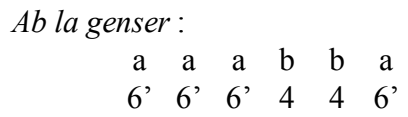

Belle et bone mi proie (RS 1750):

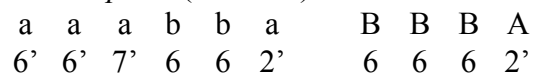

On constate ainsi que les albas de séparation témoignent de deux options, avec une référence formelle, souvent précoce, à l'esthétique du trobar ou au contraire son gommage avec des coblas singulars qui confèrent à la pièce une simplicité supplémentaire rappelant les origines modestes supposées du genre, ou du moins les modèles formels dont il s'inspirait tout d'abord. Les albas 'érotiques' formelles sont par contre toutes dépourvues de réseau rimique, tandis que les pièces religieuses recourent à des coblas unissonans sauf dans un cas, avec les coblas doblas de Vers Dieus.

\section{Synthèse}

La codification du genre que décrit Ch. Chaguinian n'a certainement pas été le résultat d'une 'réflexion', mais plutôt celui d'une adaptation à l'univers courtois, soit d'un genre prétroubadouresque ou paratroubadouresque dont nous ne connaissons rien, soit plus vraisemblablement de matériaux lyriques divers heureusement combinés. Cette adaptation paraît achevée dès les premiers témoignages, soit semble-t-il à une époque où le système des genres articulé sur la canso, le sirventes et la tenso, est en train de se constituer sur les vestiges du vers polyvalent des premières générations attestées. Un réexamen du corpus sous l'angle formel permet de préciser cette évolution qui tire l'alba de ses origines pré- ou paratroubadouresques supposées vers les standards formels de la canso, jusqu'à ce qu'elle en perde sa nature première de chant de séparation des amants à l'aube. L'aube de séparation est assortie de motifs courtois dès ses premières attestations. Les formes primitives, dotées d'un refrain autonome, utilisant des vers courts mélangés ou des strophes courtes de décasyllabes, où une certaine coquetterie se manifeste à travers l'utilisation de réseaux de rimes liant les couplets entre eux, coquetterie qui trahit l'appartenance de leurs auteurs à l'aire courtoise, ont progressivement fait place à des pièces de plus en plus marquées par l'esthétique du trobar, renonçant ainsi au refrain autonome pour lui substituer la reprise en fin de strophe du mot-refrain 'alba': aux côtés du thème de la mal mariée qui apparaît essentiellement dans l'alba de Cadenet, nous verrions volontiers dans les traits formels primitifs les véritables indices d'une inspiration populaire.

${ }^{51}$ Voir le texte dans The Old French Ballette: Oxford, Bodleian Library, MS Douce 308, éd. E. Doss-Quinby et S. N. Rosenberg, mélodies éd. E. Aubrey, Genève, Droz, 2006, n 172 , p. 482-83. 
Vient un moment où le genre trouve une désignation technique que l'abandon de ces formes primitives a très vraisemblablement préparée, et cette mutation n'apparaît dans les textes qu'avec Per grazir la bon' estrena attribuée à Uc de la Bacalaria, qui procède à une variation importante en faisant de la nuit le temps de l'absence qui rend l'aube désirable, et en rompant ainsi d'avec l'alba de séparation. La seconde moitié du XIII ${ }^{\mathrm{e}}$ siècle est marquée par deux étapes distinctes, qui ont au demeurant parfaitement pu coexister, avec d'une part les expériences de Guiraut Riquier, d'autre part la transposition dans le cadre de la chanson pieuse où, en dehors de Guiraut et de Falquet de Romans, le trait formel qui signait le genre de l'alba, à savoir la réitération finale du mot-clé (employé désormais de façon métaphorique), se trouve seul retenu dans un cadre strophique qui n'est plus désormais que celui de la chanson courtoise, dans les formes plus ou moins standardisées qu'elle pouvait prendre à l'époque. On assiste ici à la captation du genre primitif pour servir la poésie religieuse dont la vogue s'était singulièrement développée dans la seconde moitié du XIII ${ }^{\mathrm{e}}$ siècle après que l'Inquisition se fut durablement implantée.

Les innovations ou mutations successives ne semblent pas s'accompagner de l'abandon des pratiques anciennes qui ont pu coexister tout au long de l'histoire du trobar. Il n'est cependant pas impossible que l'aube de séparation ait été marginalisée sinon délaissée dans la seconde moitié du XIII ${ }^{\mathrm{e}}$ siècle à la faveur d'une réactualisation plus conforme aux schèmes courtois conventionnels. Le caractère parodique d'Eras diray, qui renoue avec le genre primitif à l'orée du $\mathrm{XIV}^{\mathrm{e}}$ siècle, semble aller dans ce sens : le genre primitif était sans doute perçu à cette époque comme un genre ancien fondé sur un scénario dont on pouvait tirer sujet à plaisanterie. Comme nous pensons l'avoir démontré ailleurs, la distinction de deux genres distincts dans la Doctrina de compondre los dictatz semble bien témoigner de cette mutation, alba désignant selon toute vraisemblance l'alba 'érotique' formelle tandis que l'alba de séparation perd son étiquette traditionnelle pour se voir désignée du nom du guetteur, personnage emblématique du genre $(\text { gayta })^{52}$.

Dominique Billy

Université de Toulouse-Le Mirail, CLLE-ERSS

${ }^{52} \mathrm{Cf}$. «Le traitement théorique de l'alba » cité. 


\section{Annexe 1 : Caractéristiques formelles}

Les pièces sont réunies en trois blocs qui suivent le classement de Ch. Chaguinian: albas de séparation (A), albas formelles 'érotiques' (B), albas religieuses $(\mathrm{C})$.

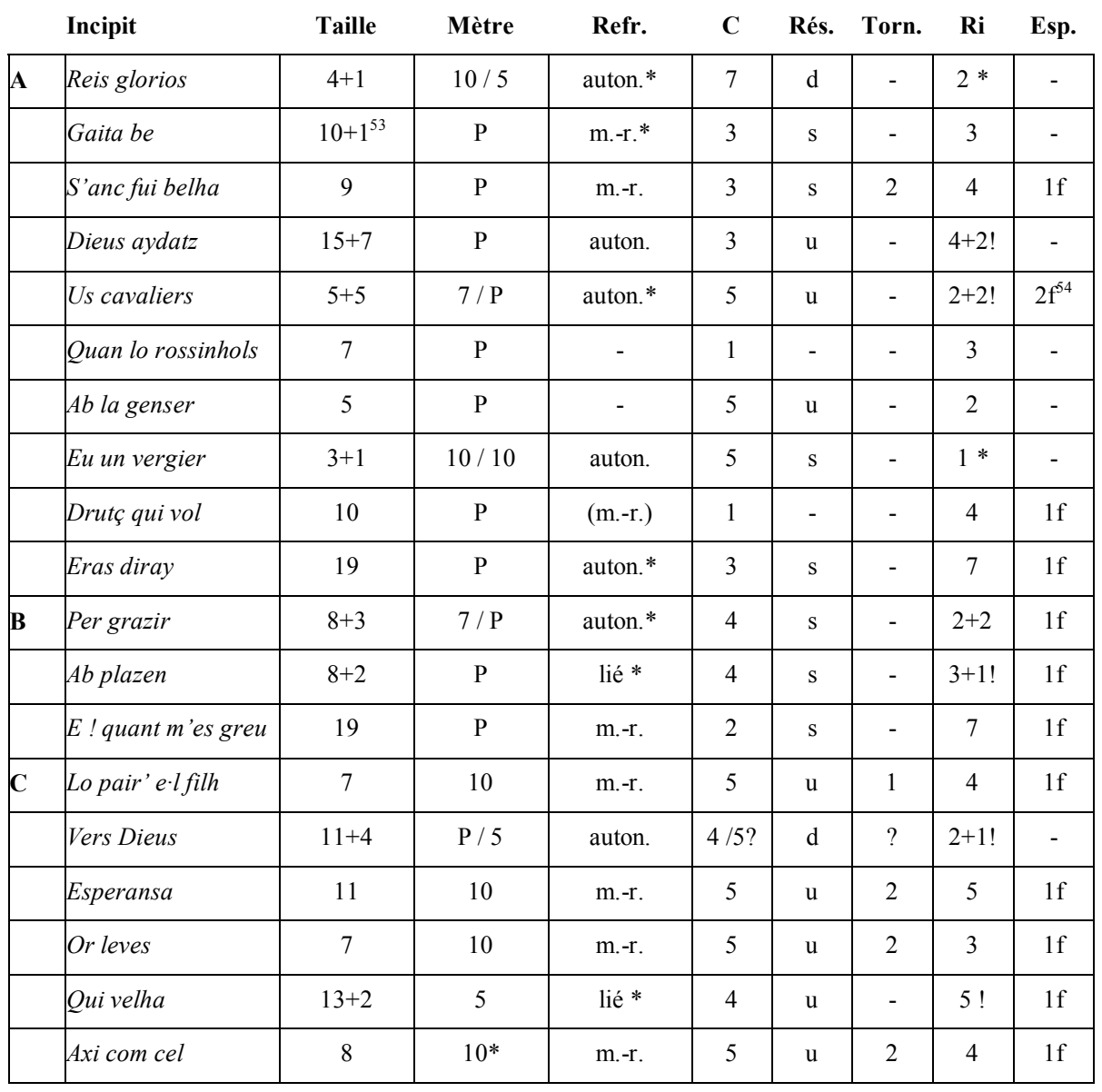

${ }^{53}$ Nous considérons comme Frank que la pièce a un vers de moins que ce qu'indique Chaguinian.

${ }^{54}$ Il n'y a vraisemblablement qu'un rim espars. Le découpage adopté par Chaguinian (comme d'autres éditeurs) vise en effet seulement à dégager un heptasyllabe en accord avec le mètre des couplets : «Sus ! qu'ieu vey lo jorn venir / apres l'alba. » Outre qu'un découpage après jorn serait plus respectueux de la syntaxe et que l'interjection Sus! pourrait aussi bien être traitée de façon isolée comme Ay et Via!, nous trouverions plus satisfaisant de ne pas dissocier la dernière proposition. 
Taille : nombre de vers de la strophe (pièces 'avec refrain') ou de la partie libre de la strophe (pièces 'à refrain'), plus nombre de vers du refrain.

Mètre : $\mathbf{P}=$ polymétrique. La barre penchée isole le refrain éventuel à droite lorsqu'il est différencié du point de vue examiné.

Refr.: auton. : refrain autonome (pièces 'avec refrain'). - lié : prolonge la strophe (pièces 'à refrain'). - m.-r. : mot-refrain (toujours «alba ») ${ }^{55} ; *$ : indique que la strophe ou le refrain éventuel se termine toujours sur le mot alba

C : nombre de couplets.

Rés. : type de réseau rimique (d : coblas doblas ; $\mathbf{s}$ : singulars ; u : unissonans).

Torn. : nombre de tornadas.

Ri : nombre de rimes dans la strophe ou sa partie libre, suivi après le signe $+d u$ nombre de rimes nouvelles éventuellement ajoutées par le refrain (c'est le premier couplet qui sert de référence), sans compter le mot-refrain alba éventuel. $-\mathbf{x}$ ! le refrain partage en outre certaines rimes avec la partie libre. $-\mathbf{x} *$ : le refrain est un vers indépendant qui ne rime pas dans la strophe (rim espars).

Esp. : présence de rims espars; $\mathbf{f}$ indique une position finale dans la strophe (ce qui est toujours le cas).

${ }^{55}$ Le mot-refrain n’est que virtuel lorsque la pièce est réduite à un couplet (BdT 461,99a). 
Annexe 2: Concordances

\begin{tabular}{|c|c|c|c|}
\hline Incipit & BdT & BdT & Incipit \\
\hline Ab la genser que sia & 451,3 & 71,2 & Lo pair' e-l filh (Bernart de Venzac) \\
\hline Ab plazen (Guiraut Riquier) & 248,3 & 75,23 & Us cavaliers (Bertran d'Alamanon) \\
\hline Axi com cel (Cerveri) & $434 \mathrm{a}, 8$ & 105,14 & S'anc fui belha (Cadenet) \\
\hline Dieus aydatz (Raimon de Las Salas) & 409,2 & 155,15 & Vers Dieus (Falquet de Romans) \\
\hline Drutç qui vol & $451,99 \mathrm{a}$ & 205,1 & Esperansa (Guilhem d'Autpol) \\
\hline E! Quant m'es greu & 451,113aа & 242,54 & Reis glorios (Giraut de Bornelh) \\
\hline En un vergier & 451,113 & 248,3 & Ab plazen (Guiraut Riquier) \\
\hline Eras diray & $451,25 \mathrm{a}$ & 248,70 & Qui velha (Guiraut Riquier) \\
\hline Esperansa (Guilhem d'Autpol) & 205,1 & 342,1 & Or leves sus (Peire Espanhol) \\
\hline Gaita be (Raimbaut de Vaqueiras) & $392,15 \mathrm{a}$ & $392,15 \mathrm{a}$ & Gaita be (Raimbaut de Vaqueiras) \\
\hline Lo pair' e-l filh (Bernart de Venzac) & 71,2 & 409,2 & Dieus aydatz (Raimon de Las Salas) \\
\hline Or leves sus (Peire Espanhol) & 342,1 & $434 \mathrm{a}, 8$ & Axi com cel (Cerveri) \\
\hline Per grazir (Uc de la Bacalaria) & 449,3 & 449,3 & Per grazir (Uc de la Bacalaria) \\
\hline Quan lo rossinhols & 451,203 & 451,113 & En un vergier \\
\hline Qui velha (Guiraut Riquier) & 248,70 & $451,113 \mathrm{aa}$ & E! Quant m'es greu \\
\hline Reis glorios (Giraut de Bornelh) & 242,54 & 451,203 & Quan lo rossinhols \\
\hline S'anc fui belha (Cadenet) & 105,14 & $451,25 \mathrm{a}$ & Eras diray \\
\hline Us cavaliers (Bertran d'Alamanon) & 75,23 & 451,3 & Ab la genser que sia \\
\hline Vers Dieus (Falquet de Romans) & 155,15 & $451,99 a$ & Drutç qui vol \\
\hline
\end{tabular}

BdT : numéro dans la Bibliographie der Troubadours d'A. Pillet et H. Carstens, Halle, 1933. 


\section{㮣M}

\section{Un petit traictié bon à tout faire : réflexions sur la mouvance générique à la fin du Moyen Âge}

Abstract: This article studies the generic polyvalence inherent in the term «traictie » in the 14th and 15th centuries in France. The first part highlights the variety of texts that can be called "traictiés », and analyses the fundamental mechanisms of such writings. The second part reassesses the Quadrilogue invectif of Alain Chartier (1422).

Résumé : Cet article étudie la polyvalence générique inhérente au mot «traictié » aux XIV et $X V^{e}$ siècles français. Une première approche de corpus met en lumière la variété des textes auxquels le terme "traictié" s'applique et en analyse les ressorts fondamentaux. Une seconde partie propose une mise au point sur le Quadrilogue invectif d'Alain Chartier (1422).

« Roman », « dit», «dictié»... l'indétermination du métalangage littéraire médiéval est bien connue. Elle est perceptible dans la période des commencements de la littérature en ancien français, mais perdure bien après. Les arts poétiques médiévaux des $\mathrm{XII}^{\mathrm{e}}-\mathrm{XIII}^{\mathrm{e}}$ siècles compilent les classifications antiques et proposent essentiellement des éléments de rhétorique appliqués à la versification, ce qui ne suffit évidemment pas à fonder une poétique des genres littéraires. À la fin du Moyen Âge, la complexification des formes littéraires et le passage de l'ancien au moyen français ne sont pas pour clarifier la terminologie'. Le cas du mot "traictié » et des textes qu'il désigne est à cet égard significatif. Alors que les dictionnaires étymologiques attribuent généralement la première occurrence du terme à Nicole Oresme, vers 1370, Sylvie Lefèvre a relevé quelques exemples dès le milieu du XII ${ }^{\mathrm{e}}$ siècle $^{2}$. Néanmoins le terme prolifère véritablement à partir du $\mathrm{XIV}^{\mathrm{e}}$ siècle, dans des textes fort divers, ce qui soulève des questions sur la pertinence de la notion de genre et peut nous éclairer sur la pratique de la littérature à la fin du Moyen Âge. Je

\footnotetext{
${ }^{1}$ Même les tentatives laborieuses de définition des formes lyriques opérées par les arts de seconde rhétorique sont loin d'être satisfaisantes: l'effort taxinomique n'est pas toujours abouti ni respecté dans la pratique par les poètes. Les flottements terminologiques perdurent (par exemple, Villon annonce au v. 973 du Testament sous le terme de «lai » le rondeau qui suit aux v. 978-989, Poésies, éd. J. Dufournet, Paris, GF Flammarion, 1992). Cf. E. Langlois (éd.), Recueil d'arts de seconde rhétorique, Genève, Slatkine Reprints, 1974 ( $1^{\mathrm{e}}$ éd. : Paris 1902). G. Lote dénonce les imperfections de ces arts de seconde rhétorique, "Quelques remarques sur l'Art de dictier d'Eustache Deschamps », Mélanges de philologie romane et de littérature médiévale offerts à Ernest Hopffner, Paris, Les Belles Lettres, 1949, p. 361-367.

${ }^{2} \mathrm{~S}$. Lefèvre, «Du tractatus au traité : transfert en langue vulgaire d'un genre scientifique ?», Le Moyen Âge et la science. Approche de quelques disciplines et personnalités scientifiques médiévales, dir. B. Ribémont, Paris, Klincksieck, 1991, p. 31-46.
}

Cahiers de Recherches Médiévales, 18, 2009 
concentrerai ma réflexion sur un échantillonnage non exhaustif mais suffisamment étendu pour être significatif ${ }^{3}$.

\section{Éléments généraux de définition}

Notons pour commencer que le terme «traité» brille par son absence aussi bien dans l'Essai de poétique médiévale de Zumthor ${ }^{4}$ que dans la somme collective consacrée aux Poétiques de la Renaissance ${ }^{5}$, qui englobe le $\mathrm{XV}^{\mathrm{e}}$ siècle. A priori, il n'y a pas d'existence générique du «traictié ». Sémantiquement, ce n'est certes pas vers la définition moderne du mot («Ouvrage didactique, où est exposé d'une manière systématique un sujet ou un ensemble de sujets concernant une matière ${ }^{6} \gg$ ) qu'il faut d'emblée se diriger. Les $\mathrm{XII}^{\mathrm{e}}-\mathrm{XIII}{ }^{\mathrm{e}}$ siècles ont donné le jour à plusieurs ouvrages que la critique moderne nomme spontanément «traités » (par exemple $L a$ Somme de Roi de frère Laurent) alors qu'ils n'étaient à leur époque pas ainsi désignés. Au contraire, les œuvres plus tardives nommées «traités » ne répondent pour la plupart pas à notre conception du traité.

L'âge scolastique a connu les tractatus latins, à orientation didactique et religieuse. N'oublions pas le lien du tractatus avec la littérature homilétique: l'homilia grecque fut traduite par tractatus popularis avant d'être nommée sermo ${ }^{7}$. Claude Gauvard présente les tractatus du Moyen Âge tardif comme des écrits politiques engagés qui se démarquent des «lourds traités théoriques hérités de la tradition du speculum ou de la summa ${ }^{8} »$. En particulier sous les règnes de Charles VI et de Charles VII (soit entre 1380 et 1461),

Le réel est abordé de plein fouet dans des œuvres littéraires d'un type nouveau que sont les tractatus. Ils se différencient des traités théoriques [...] par leur moindre longueur; mais il s'agit aussi d'une différence de nature. [...] ce sont de petits écrits de doctrine inspirés par l'événement, tout en ayant valeur de principe permanent ${ }^{9}$.

\footnotetext{
${ }^{3}$ Voir Annexe en fin d'article. Je laisse de côté le champ de la langue d'oc, qu'il faudrait pourtant explorer car il a le mérite de l'antériorité dans l'emploi du mot, témoin, dès la fin du $\mathrm{XIII}^{\mathrm{e}}$ siècle, le Perilhos tractat d'amor de donas de Matfre Ermengau (= v. 27791-31933 du Breviari d'Amor). Cf. V. Galent-Fasseur, «Une expérience avec la lyrique: le Perilhos Tractat d'amor de donas de Matfre Ermengau», Perspectives médiévales, suppl. au $\mathrm{n}^{\circ} 28$ (L'expérience lyrique au Moyen Âge), 2002, p. 169-192. Cependant la notion de traité semble être portée plutôt par le mot ensenhamen; cf. Don A. Monson, Les ensenhamens occitans. Essai de définition et de délimitation du genre, Paris, Klincksieck, 1981.

${ }^{4}$ P. Zumthor, Essai de poétique médiévale, Paris, Seuil, 1972.

${ }^{5}$ Poétiques de la Renaissance, dir. P. Galand-Hallyn et F. Hallyn, Genève, Droz, 2001.

${ }^{6}$ Définition du Petit Robert.

${ }^{7}$ Cf. C. A. Robson, «Sermons et sermonnaires », Dictionnaire des Lettres françaises. Le Moyen Âge, dir. G. Hasenohr et M. Zink, Paris, LGF, 1992, «La Pochothèque », p. 1377.

${ }^{8}$ «Christine de Pizan et ses contemporains : l'engagement politique des écrivains dans le royaume de France aux $\mathrm{XIV}^{\mathrm{e}}$ et $\mathrm{XV}^{\mathrm{e}}$ siècles », Une femme de lettres au Moyen Âge. Études autour de Christine de Pizan, dir. L. Dulac et B. Ribémont, Orléans, Paradigme, 1995, p. 106. ${ }^{9}$ Ibid., p. 108.
} 
Et Gauvard de citer les noms d'Étienne de Conty, de Jean de Montreuil, de Nicolas de Clamanges et de Jean Dubois. Les tractatus de Jean de Montreuil sont particulièrement intéressants dans la mesure où, certains d'entre eux étant rédigés en partie en latin et en partie en français, ils peuvent constituer un pont avec la veine vernaculaire des «traictiés ». On voit alors fleurir en français, aux $\mathrm{XIV}^{\mathrm{e}}-\mathrm{XV}^{\mathrm{e}}$ siècles, toutes sortes de traités doctrinaux ou techniques (guerre, médecine, chasse, fauconnerie, astrologie, héraldique, tournois, etc. $)^{10}$, qu'on écartera néanmoins de la suite pour concentrer l'analyse sur des œuvres relevant davantage de la fiction, ou tout au moins d'une forme d'élaboration littéraire.

Lorsque le mot «traictié» se répand dans les textes en langue d'oïl, c'est, en particulier à la fin du Moyen Âge, clairement sous le signe de la disparate, aussi bien formelle que thématique, comme en témoigne mon corpus d'étude. Antoine de La Sale, annonçant à son destinataire Jean d'Anjou « quatre beaux traitiez » $\left(n^{\circ} 5\right)$, lui offre d'un même élan linguistique des œuvres bien différentes par le sujet, le ton et la manière: Jehan de Saintré, Floridan et Elvide, un extrait des Chroniques de Flandres, Paris et Vienne; en l'occurrence, M. Quereuil traduit «traitié» par « récits ». On trouvera aussi bien désignés sous ce terme de «traictié» : des romans (Comte d'Artois, Floriant et Florete, Mélusine), dont certains voisinent avec le genre historique de la chronique (Gilles de Chin, Seigneurs de Gavre); des débats allégoriques (Quadrilogue invectif, Procès d'Honneur féminin, Pas de la Mort); des récits didactiques (Jouvencel) ou édifiants (Mortifiement de vaine plaisance); des exposés didactiques (Neuf Preues); des dits à insertions lyriques (Remède de Fortune) ou mêlant poèmes et lettres en prose (Voir Dit); des manuels de « seconde rhétorique » (Art de Rhétorique, Traité de rhétorique). Encore n'est-ce là qu'un classement approximativement formulé et non exhaustif. Le champ du "traictié» s'élargit encore si l'on considère les emplois du verbe «traictier $\rangle^{11}$ : glose encyclopédique (Échecs amoureux moralisés), traité politique (Corps de policie), récit de vie allégorique (Abuzé en court), roman inspiré de la légende antique ${ }^{12}$ (Roman de Troyle), dérimage compilatoire de chansons de geste (Guillaume d'Orange en prose), biographie chevaleresque (Faits de Boucicaut).

On le voit, le sujet d'une œuvre ne détermine pas sa nature de «traictié», puisque plusieurs de mes exemples sont des réécritures avouées dont l'hypotexte n'était pas désigné comme «traictié». Formellement, la prose domine sur les vers sans exclure ces derniers (j'y reviendrai). Semble pouvoir être nommé «traictié » tout écrit qui, comme l'exprime le verbe, traite d'un sujet quelconque sous une forme ou une autre. Tel ou tel glossaire d'édition glosera ainsi le terme par « composition littéraire », sans autre précision. Par sa généralité même, le «traictié » est à la croisée des genres littéraires. Certains auteurs éprouvent le besoin de préciser leur choix d'écriture en complétant le mot par un adjectif qualificatif («traictié narratif», $n^{\circ} 6$ ) ou par un complément de nom («traictié de l'ystoire », $n^{\circ} 9$ ) : dans l'un et l'autre cas, c'est la catégorie du récit qui ressort. Le style, quand il est

\footnotetext{
${ }^{10}$ Cf. P. Contamine, «Les Traités de Guerre, de Chasse, de Blason et de Chevalerie », La Littérature française aux XIV et XV siècles (Grundriß der romanischen Literaturen des Mittelalters, VIII /1), dir. D. Poirion, Heidelberg, Carl Winter, 1988, p. 346-367.

${ }^{11}$ Deuxième partie de l'Annexe (à partir du n ${ }^{\circ} 20$ ).

${ }^{12}$ Via le Filostrato de Boccace dont il est une «translation ».
} 
précisé, peut être « ruide et commun » $\left(\mathrm{n}^{\circ} 10\right)$ ou «tres piteux et plaisant $»\left(\mathrm{n}^{\circ} 23\right)$; l'impact sur le lecteur est recherché, qu'il s'agisse de l'édifier ou de le séduire.

Ajoutons à ces premières observations le fait que l'emploi du mot «traictié » n'est nullement stable. On peut le trouver tantôt dans l'incipit, tantôt dans l'explicit de l'œuvre, plus rarement dans les deux. Dans le discours de l'auteur, "traictié» entre régulièrement en équivalence avec d'autres termes, eux aussi très généraux, qui peuvent se substituer à lui : «hystoire $\rangle^{13}$, « escript», « œuvre $\rangle^{14}$, «dittié $\rangle^{15}$, «livre $»^{16}$. Pour ce dernier, Marie-Claude de Crécy fait observer que la dénomination «livre de», concurrente de «traité », procède vraisemblablement de « la traduction des traités latins où le titre était donné par la préposition suivie de l'objet du traité ${ }^{17}$ » (exemple: le Livre de viellesse, traduction par Laurent de Premierfait du De Senectute de Cicéron).

Venons-en à la définition (la seule formulée, semble-t-il, dans un texte du $\mathrm{XV}^{\mathrm{e}}$ siècle) fournie par les Règles de la seconde rhétorique $\left(\mathrm{n}^{\circ} 17\right)$. Définition embarrassée, s'il en est : le propos part de « correlacion », passe par « compilacion », pour aboutir enfin à «traitié »... et revenir à «correlacion»! En cette période de transition linguistique qu'est celle du moyen français, la définition univoque du terme est d'autant moins possible que celui-ci embrasse diverses acceptions qui, «d'autre part», n'ont rien à voir avec l'objet littéraire qu'on tente de cerner: «traitié de mariage ou de marchié », sans oublier l'accord négocié qu'est le traité militaire $^{18}$. Toutefois cette définition quelque peu laborieuse se noue autour d'une idée essentielle : " chose extraite d'escripture et mise par forme de traitié ». C'est là que réside l'explication du caractère composite du «traitié», qui le rend rebelle à l'identification générique. Le «traitié» se présente ici comme un écrit second procédant d'un ou de plusieurs écrits antérieurs et dont le genre n'est nullement spécifié. C'est le principe de la compilation, si généreusement pratiquée au Moyen Âge: Christine de Pizan, dans le Livre des fais et bonnes meurs du sage roy Charles $V$, évoque «toutes les materes, de quoy le traittié de [sa] compilacion est

\footnotetext{
${ }^{13}$ Jehan de Saintré, éd. Blanchard, p. 34.

${ }^{14}$ Quadrilogue invectif, éd. E. Droz, p. 66.

${ }^{15}$ Mortifiement de vaine plaisance, éd. Lyna, p. 60.

${ }^{16}$ L'Advisement de Memoire et Entendement de Gauvain Candie se désigne d'abord comme un «petit traictié» (ms B.R.B. 10984-1985, fo 1) puis comme simple «livre» (v. 1714, $\left.\mathrm{f}^{\circ} 63 \mathrm{v}\right)$. Cf. C. Thiry, «Débats et moralités dans la littérature française du $X V^{\mathrm{e}}$ siècle: intersection et interaction du narratif et du dramatique, Le Moyen Français, 19, 1986, p. 229. Comme le montre $\mathrm{C}$. Thiry, ce texte est d'autant plus problématique qu'on hésite à le définir comme récit ou comme moralité.

${ }^{17}$ Vocabulaire de la littérature du Moyen Âge, s.1., Minerve, 1997, p. 199-200. Inversement, plusieurs traités scientifiques rédigés en latin par Nicole Oresme conservent dans leur titre le moule ancien : De proportionibus proportionum, De moneta; Oresme a aussi composé des traités en français : Livre de divinacions, Traité de la sphère.

${ }^{18}$ Froissart semble jouer de cette multiplicité de sens dans le prologue du livre IV des Chroniques, où il évoque la «noble matiere» de son livre, «laquelle traitte et propose les fais et les advenues des guerres de France et d'Angleterre [...], si comme il appert clerement par les traittiés qui sont clos jusques au jour de la presente date» (éd. Ainsworth et Varvaro, Paris, LGF, 2004, p. 344).
} 
composé $»^{19}$; Jean Molinet, dans le prologue de ses Chroniques (ap. 1474), classe dans « la menue lettre» (la littérature) «les beaux volumes et traictiez coulourez de rhetorique, que les vrais historiographes et collecteurs de leurs gestes $[i$.e. des conquérants] ont compilez a grant diligence $»^{20}$.

L'étymologie, soulignée par la graphie «traictié », confirme ce lien à un ou plusieurs écrits antérieurs. Le substantif adapterait en français le latin tractatus (participe passé du verbe tractare, dérivé de tractum, supin de trahere: " tirer »), à moins qu'il ne procède directement du verbe «traiter/traitier» issu de tractare $^{21}$. Ainsi, d'une part, le «traictié» soumet, par le biais de l'analyse ou de la fiction, un objet (histoire, matière) à la pensée (il «traite de »); d'autre part, le principe de son écriture est l'extraction, il «trait», il tire sa matière d'un écrit préalable. C'est en ce sens que l'auteur du Gilles de Chin a «voulu transmuer de rime en prose» son « traittiet» $\left(\mathrm{n}^{\circ} 4\right)$, à partir d'un roman en vers du XIII ${ }^{\mathrm{e}}$ siècle; qu'Antoine de La Sale propose à son lecteur princier, entre autres «traitiez», « une adicion [qu'il a] traitte des Cronicques de Flandres $»^{22}$ ou que Jean d'Arras a fait « le traictié de l'ystoire» de Mélusine à partir, dit-il, de « croniques » $\left(\mathrm{n}^{\circ} 9\right)$. Evrart de Conty rédige en prose son commentaire des Échecs amoureux écrits, eux, en vers. C'est probablement une raison pour laquelle la prose prédomine : le «traictié » participe du processus des mises en prose, tendance lourde de l'écriture au $\mathrm{XV}^{\mathrm{e}}$ siècle (particulièrement en milieu bourguignon). Ceci n'oblitère pas la possibilité, pour l'auteur des Règles de la seconde rhétorique $\left(\mathrm{n}^{\circ} 16\right)$, de définir de façon plus restrictive une autre forme de «traitié » versifié, caractérisé par son thème («traitiez d'amours ») et par sa forme (quatrains d'alexandrins), à l'instar du Testament de Jean de Meung. Mais mon corpus fait apparaître d'autres formes versifiées de «traictié»: dit octosyllabique à insertions lyriques (Remède de Fortune), huitains carrés (Pas de la Mort) ${ }^{23}$.

Le geste esquissé par le verbe «traictier» n'est pas non plus sans rappeler celui qui présidait à la collecte d'extraits (excerpta, du verbe excerpere, " arracher ») dans les florilèges scolastiques, toujours avidement lus à la fin du Moyen Âge. D'où le caractère éventuellement mêlé du «traictié». Evrart de Conty loue l'auteur des Échecs amoureux pour ce qu' «avec l'amoureuse matiere [il] entremella et adjousta pluseurs choses estranges qui profitent grandement a traictier des meurs » $\left(\mathrm{n}^{\circ} 20\right)$. D'où peut-être aussi l'idée que tous ces «petit[s] traictié[s]» (c'est le qualificatif privilégié : $\left.\mathrm{n}^{\circ} 1,2,6,7,15,18\right)$ sont des concentrés, des condensés de matière, un peu à la manière revendiquée par les encyclopédistes qui aspirent à combiner le bref

\footnotetext{
${ }^{19}$ Éd. S. Solente, Paris, Champion, 1936, t. I, p. 191. Sur la compilation chez Christine de Pizan, cf. J. Blanchard, «Compilation et légitimation au $\mathrm{XV}^{\mathrm{e}}$ siècle », Poétique, 74, 1988, p. 139-157 ; B. Ribémont, «Christine de Pizan, Isidore de Séville et l'astrologie : compilation et 'mutacion' d'un discours sur les arts libéraux », Désireuse de plus avant enquerre... Actes du colloque international Christine 2006, dir. L. Dulac, A. Paupert, C. Reno et B. Ribémont, Paris, Champion, 2008, p. 303-314.

${ }^{20}$ Cité dans Textes d'étude (ancien et moyen français), éd. de R.-L. Wagner renouvelée par O. Collet, Genève, Droz, 1995, p. 357.

${ }^{21}$ C'est l'avis de S. Lefèvre, art. cit., p. 41.

${ }^{22}$ Jehan de Saintré, éd. Blanchard, p. 34.

${ }^{23} \mathrm{~N}$ 'oublions pas non plus que Villon désigne son Lais, composé de quarante huitains carrés, comme « ce présent traitié » (v. 195).
} 
et le long, à réaliser une summa brevi ${ }^{24}$, pour la plus grande commodité de leurs lecteurs. Sébastien Mamerot y insiste particulièrement: il veut «redduyre en ung petit traictié » son sujet pour le donner à «congnoistre en brief» à son protecteur $\left(n^{\circ} 15\right)$.

Cet effort de concision se conjugue à un effort de structuration du propos, menant au sens moderne de «traité » en tant qu'étude méthodique d'un sujet donné. Marie-Claude de Crécy a raison de relever que la récurrence du mot aux $\mathrm{XIV}^{\mathrm{e}}$ et $\mathrm{XV}^{\mathrm{e}}$ siècles correspond au moment «où la vulgarisation et la diffusion des connaissances s'associent avec le souci de les organiser ${ }^{25} »$. Plusieurs de nos «traictiés» revendiquent ainsi une nette structure démonstrative: Jouvencel (tripartition d'inspiration aristotélicienne), Livre $d u$ corps de policie $\left(\mathrm{n}^{\circ} 21\right)$ triparti suivant «trois differences d'estas» (princes, chevaliers et nobles, peuple), Abuzé en court dont «le commencement, le moien et la fin» $\left(\mathrm{n}^{\circ} 22\right)$ concourent à un seul et même but. Pour plusieurs de nos candidats à l'appellation «traictié », le recours au cadre allégorique est un autre moyen efficace de se doter d'une cohérence démonstrative (Quadrilogue invectif, Mortifiement de vaine plaisance, Procès d'Honneur féminin, Pas de la Mort, Abuzé en court); l'imagerie allégorique aide à la mémorisation du propos.

C'est que, en définitive, l'impact sur le lecteur (fugacement évoqué plus haut) est primordial, et c'est par lui qu'on s'oriente vers l'acception moderne du mot « traictié ». En effet, la quasi totalité de nos exemples explicite l'ambition d'instruire le lecteur, de lui être d'une quelconque manière profitable, et il n'est pas rare que l'auteur s'adresse directement à lui aux seuils de l'œuvre. À cet égard, les Evangiles des Quenouilles se bornent à renverser ironiquement ce topos $\left(\mathrm{n}^{\circ} 7\right)$. Si la définition univoque du genre «traictié » reste problématique à nos yeux de modernes, c'est parce que la visée didactique (éthique, plus largement) prévaut souvent, au Moyen Âge, sur les critères d'appréciation strictement thématiques ou formels. L'adjectif «present» qui régulièrement désigne le «traictié» $\left(\mathrm{n}^{\circ} 4,6,10\right)$ ou le «livre» qui «traicte de» $\left(\mathrm{n}^{\circ} 20,24,25\right)$ n'agit pas en simple renforcement du déictique; il s'offre en miroir au lecteur pour sa vie présente, hic et nunc, car il s'agit, fondamentalement, de «traictier de vertu au proufit d'ordre de vivre », selon la belle formule de Christine de Pizan ( $\left.{ }^{\circ} 21\right)$.

\section{Le Quadrilogue invectif}

Développons à présent l'examen d'un texte du corpus dont je prépare l'édition: le Quadrilogue invectif d'Alain Chartier. J'ai déjà eu l'occasion, dans l'introduction à ma traduction de cette œuvre qui m'est chère, de statuer sur sa nature «polymorphe $»^{26}$. Je vais revenir sur certains aspects et tâcher de les approfondir, à la lumière, entre autres, des manuscrits que je suis en train de lire en

\footnotetext{
${ }^{24}$ Cf. B. Ribémont, «Christine de Pizan écrivain didactique », Christine de Pizan. Une femme de science, une femme de lettres, dir. J. Dor et M.-É. Henneau, Paris, Champion, 2008, p. 7577.

${ }^{25}$ M.-C. de Crécy, op. cit., p. 199.

${ }^{26}$ A. Chartier, Le Quadrilogue invectif, traduit et annoté par F. Bouchet, Paris, Champion, 2002, p. 26-29.
} 
vue de l'édition. On vérifiera ainsi à quel point ce «traictié » apparemment simple peut fonctionner comme un carrefour de genres littéraires de l'époque.

On a vu que Chartier ne désigne son texte comme «traictié » que dans les pages liminaires, alors qu'il emploie d'autres mots en conclusion. Les divers manuscrits examinés conservent en tout cas le terme, la variation jouant seulement sur l'adjectif qualificatif: «petit traict(i)é» $(\mathrm{BnF}$ fr. 126, fr. 1125); "present traictié» (BnF fr. 1124, fr. 1133, fr. 19127, fr. 24440); "premier traictié» (BnF fr. 24441 ; ce manuscrit présente, à la suite du Quadrilogue, le Livre de l'esperance, inachevé et qui, dans plusieurs manuscrits, était intitulé Traité de l'esperance). Plus largement, Chartier apparut vite à sa postérité comme un auteur «éthique » et donc comme un auteur de traités. C'est ce que proclame en 1526 le libraire parisien Galliot du Pré à la fin du préambule de son édition des Faictz et dictz de feu de bonne memoire maistre Alain Chartier ${ }^{27}$ :

Ne mettez donc en nonchaloir ou oublyance cestuy livre contenant plusieurs traictiez de matiere diverse puisque vous en pouez mieulx valloir au moyen que vous aurez ung conducteur et charretier propice qui tresbien vous conduyra en vertu et iustice de bonne vie.

Bien que notre auteur se dise «lointaing immitateur des orateurs ${ }^{28}$ » et emprunte nombre d'exemples à la tradition classique et à la Bible, il faut préciser que le Quadrilogue invectif n'est pas la réécriture d'un texte antérieur; son canevas est original.

En mettant aux prises France et ses trois enfants, le Peuple, le Chevalier et le Clergé, notre texte s'inscrit dans la tradition littéraire du débat ${ }^{29}$, extrêmement nourrie depuis le XIII ${ }^{\mathrm{e}}$ siècle scolastique. On pense aussi au théâtre, le propos et le choix de quatre personnages typologiques nous orientant plus précisément vers le genre de la moralité ${ }^{30}$. Il n'est pas indifférent de savoir que France devient un personnage de théâtre récurrent; $\mathrm{C}$. Beaune ${ }^{31}$ cite plusieurs pièces de la seconde moitié du XV $\mathrm{XV}^{\mathrm{e}}$ siècle. Le Quadrilogue invectif, écrit en 1422, pourrait constituer un avant-courrier de ce phénomène. Il ne faut certes pas trop vite confondre mise en scène écrite d'un échange oral et texte réellement destiné à la performance théâtrale. De fait, l'appréciation des critiques peut varier du tout au tout. Paul Zumthor estime que

\footnotetext{
${ }^{27}$ Id., Faictz et dictz de feu de bonne memoire maistre Alain Chartier, imprimé à Paris par Antoine Couteau, 1526.

${ }^{28}$ Quadrilogue invectif, éd. cit., p. 1.

${ }^{29}$ Cf. E. Cayley, Debate and Dialogue. Alain Chartier in his cultural context, Oxford University Press, 2006.

${ }^{30}$ Je laisse de côté les cas où «moralité » entre en concurrence avec d'autres dénominations («jeu », « sottie », etc.). L'interférence du débat, de l'allégorie et du théâtre n'a pas échappé à F. Rouy (L'esthétique du traité moral d'après les auvres d'Alain Chartier, Genève, Droz, 1980, chap. II) ni à C. Thiry (art. cit.).

${ }^{31}$ C. Beaune, Naissance de la nation France, Paris, Gallimard, 1985, p. 316.
} 
d'Alain Chartier à Jean Molinet, le débat semble n'être plus qu'un type-cadre : sa fonction est purement textuelle et n'a rien à voir avec quelque forme que ce soit de spectacle $^{32}$.

Armand Strubel avance quant à lui que

la dramatisation de la métaphore traduit une tentation permanente de l'allégorie : conduire l'analogie jusqu'à la représentation, faire voir ce qui n'est que langage ${ }^{33}$.

La théâtralité serait ainsi l'aboutissement naturel du scénario allégorique. De fait, la psychomachie se transpose aisément sur scène, en combats ou en affrontements verbaux de toutes sortes : procès, altercation, etc.

En ce qui concerne le Quadrilogue invectif, les huit miniatures du manuscrit $\mathrm{BnF}$ fr. 19127 pourraient fournir quelques indices d'une théâtralité possible. Au $f^{\circ} 9 v$, France se trouve seule au centre d'une sorte de salle capitulaire de cloître. Puis la salle se remplit avec l'arrivée des trois enfants ( $\left.f^{\circ} 19\right)$, image à partir de laquelle chaque nouvelle prise de parole est illustrée, ce qui donne : Peuple ( $\left.\mathrm{f}^{\circ} 19\right)$, Chevalier $\left(f^{\circ} 24 v\right)$, Peuple $\left(f^{\circ} 35 v\right)$, Chevalier ( $\left.f^{\circ} 39\right)$, Ecclésiastique ${ }^{34}\left(f^{\circ} 43\right)$, Chevalier $\left(f^{\circ} 60 v\right)$, France $\left(f^{\circ} 63\right)$. France est toujours debout, ainsi que celui qui s'adresse à elle, au centre de l'image ${ }^{35}$ (de l'aire de jeu ?), tandis que ceux qui se taisent sont assis, en position de spectateurs. Peut-on voir dans ce programme iconographique un dispositif scénique? La question est difficile à trancher.

La rubrique écrite en latin dans deux manuscrits ${ }^{36}$ indique plus nettement une possible réception du Quadrilogue comme texte théâtral: Incipit Quadrilogium invectivum et comicum ad morem Gallicorum correctionem (BnF fr. 126, fr. 1124). L'adjectif comicum désigne en effet ce qui est relatif au théâtre ${ }^{37}$ (plus spécialement à la comédie ${ }^{38}$ ). Certes cette rubrique, loin d'être systématique, n'est pas le fait de

\footnotetext{
${ }^{32}$ P. Zumthor, Essai de poétique médiévale, op. cit., p. 430.

${ }^{33}$ A. Strubel, Renart, la Rose et le Graal. La littérature allégorique en France au XIII siècle, Paris, Champion, 1989, p. 49.

${ }^{34}$ Telle est la dénomination du Clergé dans ce ms.

${ }^{35}$ Seul fait exception le Peuple, dont le texte dit expressément qu'il «gisoit reversé sur la terre » et donc couché au $\mathrm{f}^{\circ} 19$, puis décentré sur la droite au $\mathrm{f}^{\circ} 35 \mathrm{v}$. Faut-il y voir une volonté de singulariser le Peuple, voire de le juger? Difficile à dire !

${ }^{36}$ J'écarte le BnF fr. 19127, pour le coup, qui ne donne que le début de la rubrique : Incipit Quadrilogium invectivum. Je précise que je n'ai pu consulter que $7 \mathrm{mss}$ sur la cinquantaine de mss existants du Quadrilogue invectif.

${ }^{37}$ L'adjectif «comique » a conservé cette acception jusque dans la langue classique (cf. L'illusion comique de Corneille, Le Roman comique de Scarron).

${ }^{38}$ Là se pose un nouveau problème de distinction des genres. L'on sait bien que par suite d'une mésinterprétation du latin comedia, la "comedie » ne concernait pas le théâtre au Moyen Âge. Au XIII ${ }^{\mathrm{e}}$ siècle, Jean de Garlande désigne par ce terme une œuvre littéraire plaisante qui commence dans la tristesse et finit dans la joie; c'est encore ce qu'indique Jacques Legrand au début du XV $\mathrm{XV}^{\mathrm{e}}$ : comedie c'est une poetrie la quelle au commencement parle moult tristement, et a la fin joieusement» (Archiloge Sophie, éd. Beltran, Paris, Champion, 1986, p. 151). On ne saurait ramener le Quadrilogue invectif à cette conception
} 
l'auteur lui-même; il reste intéressant qu'un lecteur du texte (en l'occurrence le copiste litteratus du Quadrilogue dans les manuscrits considérés) ait jugé bon de prolonger le titre de l'œuvre pour faire apparaître cette dimension théâtrale éventuelle.

L'identification générique du texte est donc peut-être moins affaire d'écriture que de réception. Il reste tout à fait possible de voir dans le Quadrilogue invectif un texte hybride, qui pouvait être soit lu soit reçu dans le cadre d'une représentation ${ }^{39}$. Un exemple un peu plus tardif cautionne cette possibilité, celui de La Condamnation de Banquet de Nicolas de La Chesnaye ${ }^{40}$. Le prologue de cette moralité composée entre 1503 et 1507 est on ne peut plus explicite :

Et pour ce que telles œuvres que nous appelons jeux ou moralitez ne sont tousjours facilles a jouer ou publiquement representer au simple peuple, et aussi que plusieurs ayment autant en avoir ou ouyr la lecture comme veoir la representacion, j'ay voulu ordonner cest opuscule en telle façon qu'il soit propre a demonstrer a tous visiblement par personnages, gestes et parolles sur eschaffault ou autrement, et pareillement qu'il se puisse lyre particulierement ou solitairement par maniere d'estude, de passetemps ou bonne doctrine ${ }^{41}$.

Si l'on se souvient que le prologue du Quadrilogue s'ouvre sur une adresse aux différents estats de la société française ("princes» et «nobles», «clers» et « peuple françois »), on peut alors concevoir que la réception du texte variait selon l'appartenance sociale du lecteur (ou spectateur?). En d'autres termes, l'identification générique du texte est tributaire de l'horizon d'attente du public. Le dauphin Charles, patron de Chartier, et son entourage princier pouvaient lire l'œuvre

médiévale de la «comedie » car le débat, autoritairement interrompu par France, ne s'achève pas véritablement dans la joie. Jean-Claude Mühlethaler ( «'Incipit Quadrilogium invectivum et comicum ad morum Gallicorum correctionem'. Dalla definizione della satira all'uso degli animali nella letteratura impegnata ai tempi di Carlo VI: Alain Chartier e Eustache Deschamps ", L'immagine riflessa, N.S, VII/2, 1998, p. 311-313) interprète le passage de l'invectivum au comicum comme celui de l'invective à la satire, mais on pourrait opposer que J. Legrand tient la comédie et la satire pour deux «manieres de poetrie » distinctes (Archiloge Sophie, ibid.). C'est pourquoi l'adjectif comicum me semble plutôt avoir son sens théâtral général dans la rubrique du Quadrilogue invectif. Il y a bien, au demeurant, passage de l'invective à la satire, comme nous le verrons plus loin.

${ }^{39}$ La présente analyse m'amène à nuancer ce que j'écrivais dans un ancien article : «le terme traictié signale bien un texte destiné à la lecture individuelle ; la représentation du débat entre France et ses enfants sera d'ordre mental et se jouera dans l'esprit du lecteur. » («L'écrivain et son lecteur dans le prologue et l'épilogue du Quadrilogue invectif d'Alain Chartier », Bien dire et bien aprandre, 19, 2001, p. 27). L'on a pu objecter la longueur des harangues de chaque participant au Quadrilogue comme obstacle à la performance théâtrale ; mais c'est peut-être une perception moderne : le public médiéval des jongleurs et des prédicateurs était habitué plus que nous à une communication orale longue.

${ }^{40}$ Père ou fils? On ne sait pas!

${ }^{41}$ Nicolas de La Chesnaye, La Condamnation de Banquet, éd. J. Koopmans et P. Verhuyck, Genève, Droz, 1991, p. 63. 
comme un petit miroir du prince; les clercs pouvaient y lire un produit dérivé du genre satirique des «états du monde»; les classes populaires, peut-être touchées par une représentation du texte, pouvaient l'entendre comme une moralité ou comme un sermon. De fait, les manuscrits du Quadrilogue invectif, de facture soignée ou plus rudimentaire, illustrés ou pas, donnant le seul Quadrilogue ou d'autres œuvres, semblent bien avoir été destinés à des usagers de statuts disparates. Ainsi, le BnF fr. 126 contient six œuvres dont l'ensemble constitue une sorte de miroir du prince : une première partie comprend trois textes politiques ou philosophiques (Le Régime des princes, les traductions par Laurent de Premierfait du De Senectute de Cicéron et du De Amicitia); la seconde partie (ajoutée postérieurement) offre trois œuvres de «maistre Alain » (Quadrilogue invectif, Dialogus familiaris amici et sodalis, Traité de l'esperance).

Toutes ces réceptions possibles, qui témoignent de la diversification du lectorat à la fin du Moyen Âge, privilégient néanmoins une dimension particulière de l'œuvre. C'est peut-être pourquoi Chartier insiste, à la fin du prologue, sur la nécessité de lire intégralement le Quadrilogue:

Si ne vueille aucun lire l'une partie sans l'autre, afin que l'en ne cuide pas que tout le blasme soit mis sur ung estat ${ }^{42}$.

Précisément parce que la lecture sélective avait cours à côté de la lecture cursive, certains devaient être tentés d'isoler (grâce aux rubriques qui les désignent dans les manuscrits) les propos du personnage correspondant à leur propre « estat». Toutefois le message voulu par l'auteur n'est perceptible que dans la complétude contradictoire du débat, au demeurant autoritairement arrêté (sans être tranché) par France, comme s'il fallait au moins respecter formellement la brièveté inhérente au «traictié».

Enfin, la tonalité satirique du Quadrilogue invectif ramène encore celui-ci à un genre par définition mêlé, composite. L'adjectif «invectif» fait référence au genre de l'invective, genre antique répertorié dans les arts poétiques médiévaux: l'invectio est l'une des sept espèces de poèmes inventoriés par Vincent de Beauvais; Jean de Garlande en fait aussi état dans sa Poetria, parallèlement à la satire. À son tour, Jacques Legrand, vers 1400, situe ainsi les choses dans 1'Archiloge Sophie:

invection c'est aucun dit qui reprent aucune chose de mauvaise entencion; et satire c'est quant la reprehension se fait de bonne entencion ${ }^{43}$.

Ceci nous amène à dépasser les indications explicites de Chartier dans le prologue $\mathrm{du}$ Quadrilogue invectif et à distinguer deux niveaux d'analyse : dans la fiction du Quadrilogue, l'échange discursif serait spécifiquement «invectif» dans la mesure où tel ou tel débateur inculpe l'autre en cherchant à le dominer, fût-ce au prix de la mauvaise foi - il faut toutefois réserver un statut particulier au Clergé, évident porteparole de Chartier. Au niveau extradiégétique, la visée de Chartier (l'intentio auctoris, pour reprendre l'une des catégories des accessus ad auctores) est

${ }^{42}$ Quadrilogue, éd. cit., p. 5.

${ }^{43}$ Ibid., p. 151. 
clairement satirique car animée d'une louable intention, comme le rappelle la dernière phrase :

Car je afferme loiaument que l'esmouvement de cest œuvre est plus par compassion de la necessité publique que par presumption d'entendement et pour profiter par bonne exhortacion que pour autrui reprendre ${ }^{44}$.

Ces deux niveaux ne s'opposent pas: il reste clair que la mise en scène de l'invective à quatre voix est un outil pour l'admonestation de Chartier ${ }^{45}$. Comme le spécifie J.-C. Mühlethaler,

Dans la satire médiévale le blâme est presque toujours explicite [...]. Le recours à l'invectio reste d'habitude ponctuel : elle est mise au service de la reprehensio, de la dénonciation des vices causa correctionis et more magistri, à la manière du maître ${ }^{46}$.

L'originalité du Quadrilogue invectif est d'avoir donné à l'invectio une dimension structurelle.

\section{Conclusion}

Cette petite mise au point sur le statut du «traictié» ne saurait, en définitive, être systématique. On pourrait certainement invoquer des contreexemples aux tendances que j'ai pu dégager d'un corpus d'analyse nécessairement restreint, mais c'est la preuve de la polyvalence même du «traictié». Si le terme n'est pas absolument nouveau, il correspond visiblement à une mode littéraire à partir des années 1350 et plus encore au $\mathrm{XV}^{\mathrm{e}}$ siècle- en ce sens aussi l'on peut parler de «present traictié». C'est un terme polysémique, qui obéit à une vocation éthique (castigat docendo mores) plutôt qu'à une norme formelle ou à une identité thématique : en ce sens, s'il définit un genre, ce ne peut être qu'un genre ouvert. Un terme, enfin, qui désigne un texte ostensiblement tourné vers ses destinataires, à une époque où le lectorat s'étoffe et se diversifie ${ }^{47}$. Le modelage des esprits, ambition à peine voilée des «traictiés», est un enjeu culturel et politique fort en ces temps de crise et de perte (donc de redéfinition) des repères, enjeu dont la destination plurielle du Quadrilogue invectif est un éloquent témoin.

Florence Bouchet Université de Toulouse (UTM) PLH : Patrimoine, Littérature, Histoire (EA n 4153$)$

\footnotetext{
${ }^{44}$ Ibid., p. 66.

${ }^{45}$ Vers 1427, Chartier use de l'invective en latin à des fins polémiques : Ad ingratum amicum, Ad invidum et detractorem; cf. R. Meyenberg, Alain Chartier prosateur et l'art de la parole au XV siècle, Berne, Francke, 1992, p. 21-22, 35.

${ }^{46}$ Fauvel au pouvoir : lire la satire médiévale, Paris, Champion, 1994, p. 406.

${ }^{47} \mathrm{Cf}$. F. Bouchet, Le discours sur la lecture en France aux XIV et XVe siècles : pratiques, poétique, imaginaire, Paris, Champion, 2008.
} 


\section{ANNEXE Corpus d'étude}

[1] Et je, meu de compassion, pour ramener a memoire l'estat de nostre infélicité et a chascun ramentevoir ce qui lui en touche, ay composé ce petit traictié que je appelle Quadrilogue, pour ce que en quatre personnages est ceste œuvre comprise, et est dit invectif en tant qu'il procede par maniere d'envaïssement de paroles et par forme de reprendre. (Alain Chartier, Quadrilogue invectif, éd. Droz, Paris, Champion, 1950, p. 5).

[2] Et atant prent fin cestuy petit traittié que l'istorien recommande en la doulce correction dez lisans et escoutans [...] (Roman du comte d'Artois, éd. Seigneuret, Genève, Droz / Paris, Minard, 1966, p. 153).

[3] Or pry je aux lisans qu'en ce qu'ilz trouveront a amender en cestuy traictié que benignement ilz amendent ou corrigent et prennent en gré l'istoire ainsi parfaicte qu'elle pourra estre et comme ilz pourront veoir au lire. (Roman de Floriant et Florete en prose, éd. Lévy, Ottawa, Éditions de l'Université d'Ottawa, 1983 , p. 83).

[4] Pour ce que la mémoire des hommes deffault et passe par terminacion de vye et que touttes choses se délaissent et oublient qui ne les rédige et met par escript, doncques adfin que les haulx et courageux fais de nos anchiens prédécesseurs ne soient estains mais aumentés et ramenteus pour donner example aux nobles et vertueux hommes du temps présent, ay voulu transmuer de rime en prose chest présent traittiet ou quel fait mencion des haultes proeces que jadis fist un noble chevalier, lequel en son temps fu nommés messire Gilles de Chin, natif de Tournesis. (Chronique du bon chevalier messire Gilles de Chin, éd. Chalon, Mons, Typographie de Hoyois-Derely, 1837, p. 1).

[5] Après mes treshumbles et tresobeissantes recommandacions, pour obéir a vos prières, qui me sont entiers commandemens, me suis delitté a vous faire quatre beaux traitiez en deux livres, pour les porter plus aisiement [...] (Antoine de La Sale, Jehan de Saintré, éd. Blanchard, Paris, LGF, 1995, p. 34).

[6] $\mathrm{Si}$ ay proposé à l'aide de Dieu escripre et compiler ung petit traictié narratif, pour donner cueur et voulenté à tous hommes, especiallement à ceulx qui sieuvent les adventures merveilleuses de la guerre, de tousjours bien faire et acroistre leur honneur et hardement de mieulx en mieulx. [...] Si ay proposé en oultre de deviser mon livre en trois principales parties selon les trois manieres de vivre par le phyllosophe moral, qui sont monostique, yconomique et pollitique [...]. Et après, au plaisir de Dieu, en chascune de ces trois principales parties sera la chose distinguée par certains chappitres, comme il apparra plainement aux lisans et bien entendans ce present traittié. (Jean de Bueil, Le Jouvencel, éd. Favre et Lecestre, Paris, Renouard, t. I, 1887, p. 15-16). 
[7] Vous, messeigneurs et dames, qui cest petit traittié lirez ou avez leut, prenez le en passe temps d'oiseuse, je vous prie, et n'ayez regart a aucune chose qui dedens y soit escripte quant a aucun fruit ou substance de vérité, ne d'aucune bonne introduction. (Les Evangiles des Quenouilles, éd. Jeay, Paris, Vrin/ Montréal, Presses universitaires, 1985, p. 117).

[8] [...] me suis mys cy a faire ung traittié entre l'ame dévote et le cuer plain de toute vanité pour plus esmouvoir les lisans a bien faire et parfaitement sur toutes choses amer nostre vray rédempteur [...] (René d'Anjou, Le Mortifiement de vaine plaisance, éd. Lyna, Bruxelles, Euvre Nationale pour la Reproduction des Manuscrits à Miniatures de Belgique, 1926, p. 2).

[9] Et m'en a comandé a faire le traictié de l'ystoire qui cy après s'ensuit, et je commanceray de cuer diligent. [...] car certainement je l'ay fait au plus justement que j'ay peu selon les croniques que je cuide estre vrayes. (Jean d'Arras, Mélusine, éd. Vincensini, Paris, LGF, 2003, p. 112).

[10] Les haulx et corrageux fais de nos anchiens predecesseurs, escrips pour exemple et mémoire a la loenge d'iceulx, ramainent a la cognoissance de mon debileté et obscurcy entendement une matere laquelle sera discutée en ruide et commun stile ou procès de ce present traittyé. (Histoire des seigneurs de Gavre, éd. Stuip, Paris, Champion, 1993, p. 1).

[11] Mais en la fin de ce traitié/ Que j’ay compilé et traitié/Vueil mon nom et mon seurnom mettre [...] (Guillaume de Machaut, Le Remede de Fortune, dans Euvres, éd. Hœpffner, Paris, Firmin-Didot, t. II, 1911, p. 156).

[12] Le Voir Dit veuil je qu'on appelle / Ce traitié que je fais pour elle, / Pour ce que ja n'i mentirai. (Guillaume de Machaut, Le Livre du Voir Dit, v. 518-520, éd. Imbs et Cerquiglini-Toulet, Paris, LGF, 1999, p. 74).

[13] Prenez en gré ma petite labeur:/ [...]/ Mais s'il y a aucun mot mal dicté, / Je vous supply, pour Dieu, qu'on me pardonne, / [...]./ Vous, Dames, dont, en qui honneur foisonne, / Le tel traittié vostre Advocat direz: / Tout plaisamment, s'il vous plaist, le lirez. (Pierre Michault, Le Procès d'Honneur Féminin, dans Euvres poétiques, éd. Folkart, Paris, UGE, 1980, p. 67-68).

[14] Dois tu oublier ou que soye / Ce traictié qui tant point et mort / Que fist Amé de Montjesoye, / Plus riche que d'or ne de soye, / Du merveilleux Pas de la Mort? (Olivier de La Marche, Le Chevalier deliberé, éd. Carroll, Tempe, Arizona Center for Medieval and Renaissance Studies, 1999, p. 56-58).

[15] Par ce que le tres noble et tres loable desir et vouloir de vous mon tres doubté seigneur, monseigneur Loys de Laval, [...] a esté et est de sçavoir [et] congnoistre en brief les principaux fais des .ix. dames et princesses dictes Preues, et aussi de la Pucelle, décorees par les anciens selon leur sexe a l'exemple des Neuf Preux tres renommés et de Bertrand du Ghesquin, les fais desquelz ont esté par moy, 
Sebastien Mamerot, [...] redigiez de nouvel en ung volume ou traictié par moy compendieusement composé l'an precedent, je me suis, en cestuy mois de janvier mil cccc soixante et ung, [...] mis en peine de redduyre en ung petit traictié par la maniere que vostre noble seigneurie me commanda proceder ou principal livre des Neuf Preux [...]. [...] je me suys efforcé couchier a mon pouvoir la vérité et en brief selon aulcuns tres anciens volumes qui me ont este très difficiles a trouver et conjoindre avec les communs [...] (Sébastien Mamerot, Petit traictié des Neuf Preues, transcrit par M. Lecourt, Romania, 37, 1908, p. 532-33).

[16] Après sont aultres faiz de ceste rime alexandrine, et en fait on tout communément diz de Vies de sains, ou aucuns traitiez d'amours, et se mettent 4 et 4 , a l'exemple du Testament maistre Jehan de Meun [...] (Les Règles de la seconde rhétorique, dans Recueils d'arts de seconde rhétorique, éd. Langlois, Genève, Slatkine Reprints, 1974, p. 28).

[17] Correlacion est chose coppiée, ou chose en codicille par cahyers, ou chose arguée entre clers ; [...]. Compilacion est chose extraite d'escripture et mise par forme de traitié. Traitié est une maniere de correlacion; et d'autre part est traitié de mariage ou de marchié. (ibid, p. 50).

[18] [...] je vous envoie ce petit traittié de rethorique, tout chaudement forgié et fait a vostre contemplation, ouquel vous trouverez patrons, exemples, couleurs et figures de dittiers et tailles modernes qui sont maintenant en usage [...] (Jean Molinet, L'Art de Rhétorique, dans Recueils d'arts de seconde rhétorique, op. cit., p. 215).

[19] Pluseurs balades baladans, / Virlais, fatras d'aultre fachon / Ont en leur ait les bien rimans, / Dont point je ne fais mension./ Se j'en dis mon intention, Pardonés moi se j'ay failly, / Je n'ay fait ce traictiét se non / Pour apprendre ung mien amy. (Traité de rhétorique anonyme, dans Recueils d'arts de seconde rhétorique, op. cit., p. 264).

[20] Et affin que ce livre rimé fut plus agréablement et plus generalment receu de tous, jones et anciens, l'aucteur avec l'amoureuse matière entremella et adjousta pluseurs choses estranges qui profitent grandement a traictier des meurs et au gouvernement de nostre vie humaine, affin que ceulx qui y regardent, avec la recreacion et le delit qu'ilz y pourront prendre, aucun profit en puissent rapporter. (Evrart de Conty, Livre des Eschez amoureux moralisés, éd. Guichard-Tesson et Roy, Montréal, CERES, 1993, p. 2).

[21] Ainsi doncques nous avons a traictier de vertu au proufit d'ordre de vivre en trois differences d'estas par laquelle dicte vertu vie humaine doit estre ruillee en toutes œuvres et sans qui ne peut homme a honneur ataindre [...] (Christine de Pizan, Livre du corps de policie, éd. Kennedy, Paris, Champion, 1998, p. 2). 
[22] Si me suis pensé, ouvrant ceste inventive, que assez estoit convenable et consonante a la matiere dont a ce present livre vueil traictier, combien que le commencement, le moien et la fin d'icelluy soient touchant au gouvernement et ordre a la personne vivant en court, tant pour la purification de l'ame comme a pouoir avoir en ce monde provision honneste et seure [...] (L'Abuzé en court, éd. Dubuis, Genève, Droz, 1973, p. 2-3).

[23] Et traicte celui livre en stille tres piteux et plaisant la façon et maniere comment Troyle, filx au roi Priant, s'enamoura de la belle Criseida pendant le temps que les grecs tenoient Troye assegee, et comment elle changea son amour vers la fin, en le mettant en oubli pour Dyomedos de Grece. (Louis de Beauvau, Roman de Troyle, éd. Bianciotto, Rouen, Publications de l'Université de Rouen, 1994, vol. II, p. 560).

[24] [...] de plus gente matiere n'a ce present livre tractié en chappitre qui qu'il soit que il fera de Vivien [...] (Guillaume d'Orange en prose, éd. Wahlund, p. 64, citée par F. Suard, Guillaume d'Orange. Étude du roman en prose, Paris, Champion, 1979, p. 154).

[25] [...] mais de l'une parlerons plus avant au propos que nous voulons traictier, c'est assavoir de Chevalerie, en la louant en la personne d'un vaillant et noble chevalier [...] : c'est mon seigneur messire Jehan le maingre, dit Bouciquaut, mareschal de France et gouverneur de Jannes, en laquelle reverence et honneur, pour les dessertes de ses bienfais, sera, au plaisir de Dieu, traictié et parfaict ce present livre [...] (Le Livre des fais du bon messire Jehan le Maingre, dit Bouciquaut, éd. Lalande, Genève, Droz, 1985, p. 7-8). 



\title{
rid
}

\section{Un baiser entre ciel et terre : mouvance générique et exégèse dans le commentaire du Cantique des cantiques de Maître Eckhart}

\begin{abstract}
Master Eckhart's commentary of the Song of the Songs concentrates on one only verse. But Eckhart mentions twice, in his Liber parabolarum Genesis, that he has written a complete commentary of the Song of the Songs. Moreover, there are many verses of the Song of the Songs in some of Eckhart's works. How shall we explain this fact? What can it teach us on the " moving " literary genres? I shall not adopt here a historical method which tends to explain the factual circumstances of the commentary on the Song of the Songs writing. But I shall follow a method which rests only upon the textual indications that we have at our disposal. My hypothesis is that the different forms of Eckhart's commentary on the Song of the Songs are linked to the literary genre and to the text of the Song of the Songs itself. The "moving" literary forms of his commentary on the Song of the Songs are in themselves Eckhart's act of interpretation of this text. Passing from a commentary as "island» (continuous commentary of the text) to a commentary as " archipelago " (network of verses which refer to one another through the different Eckhartian works) helps Master Eckhart to formulate more efficiently the principles of his "metaphysics of the kiss 》. Doing so, he puts into practice his hermeneutical hypothesis : the Song of the Songs is a midrash in which the prophetical Hebrew literature is written again. That is why Master Eckhart draws his inspiration from the way to communicate the truth that he finds in Maimonides' Dux Perplexorum. That is, he suggests the principles of a metaphysics of the lover and the beloved's unio in actu by veiling them, in order to invite his reader to go beyond the limits of a metaphysics of the substances identified by their own nature.
\end{abstract}

Résumé : Le commentaire du Cantique des Cantiques de Maître Eckhart (dominicain rhénan 1260-1328) se réduit à l'exégèse d'un verset. Or, Eckhart a par deux fois signalé, dans son Livre des paraboles de la Genèse, avoir composé un commentaire complet du Cantique. De plus, de nombreux versets du Cantique apparaissent dans certaines ouvres de Maître Eckhart notamment. Comment expliquer ce fait? Qu'a-t-il à nous enseigner sur la mouvance des genres? En adoptant une méthode d'interprétation des indices textuels dont nous disposons, et non pas une méthode historique cherchant à expliquer les circonstances factuelles de la rédaction du commentaire eckhartien du Cantique des Cantiques, je ferai ici l'hypothèse que les différentes formes prises par les exégèses des versets du Cantique ne sont pas sans rapport avec le texte et le genre littéraire mêmes $d u$ Cantique, si bien que cette mouvance de la forme exégétique $d u$ Cantique des Cantiques constitue en elle-même un acte d'interprétation de Maître Eckhart. J'essaierai de montrer que le passage d'une forme "insulaire" (commentaire continu de l'œuvre) à une forme "en archipel» (réseaux de versets du Cantique des Cantiques renvoyant les uns aux autres à travers différentes ouvres eckhartiennes) permet à Maître Eckhart de formuler plus efficacement les principes d'une "métaphysique du baiser», mettant ainsi en pratique son hypothèse herméneutique: le Cantique des Cantiques apparaît comme une réécriture midrashique de la littérature prophétique hébraïque. C'est pourquoi Maître Eckhart s'inspire du mode de communication de la vérité qu'il a trouvé dans le Guide des égarés de Maïmonide pour suggérer, en les voilant, les fondements d'une métaphysique de l'union en acte de l'amant et de l'aimé, afin

Cahiers de Recherches Médiévales, 18, 2009 
d'inviter son lecteur à aller au-delà d'une métaphysique des substances séparées par leur nature respective.

Pourquoi avoir choisi le commentaire du Cantique des Cantiques de Maître Eckhart pour parler de la mouvance des genres ? Le texte exégétique du dominicain rhénan, qui a vécu entre 1260 et 1328 , pose à plusieurs titres la question du bouleversement des frontières du genre littéraire.

En premier lieu, quant à son objet, le texte qu'il commente : le genre littéraire du Cantique des Cantiques a effectivement, au cours de l'histoire, fait l'objet de débats et a mis en question l'appartenance de ce texte au canon des Écritures. S'agitil, en effet, d'un cantique biblique, dans le sillage de la littérature sapientielle et prophétique d'Israël, ou bien plutôt d'un poème nuptial ou érotique ? Il appartient à chaque exégète, notamment à Maître Eckhart ${ }^{1}$, à la suite d'une longue tradition médiévale $^{2}$, de prendre position, dans son acte herméneutique, quant à l'appartenance générique du Cantique des Cantiques.

\footnotetext{
${ }^{1}$ Le commentaire du Cantique des Cantiques de Maître Eckhart ne fait pas, à ma connaissance, l'objet d'une étude qui lui soit spécifiquement consacrée dans le champ des recherches eckhartiennes. Sur l'herméneutique biblique de Maître Eckhart, en général, le lecteur se référera notamment à J. Koch, "Sinn und Struktur der Schriftsauslegungen », Meister Eckhart der Prediger. Festschrift zum Eckhart-Gedankjahr, hrsg. von U.M. Nix, R. Öchslin, Freiburg i. Br. /Basel /Wien, 1960, p. 73-103 et Kleine Schriften, 2 Bde, Bd. I, Storia e letteratura Bd. 127, Rom, 1973, p. 399-428; K. Weiss, «Meister Eckharts biblische Hermeneutik », La Mystique rhénane, 1963, Paris, p. 96-108.

${ }^{2}$ Maître Eckhart s'inscrit dans une très vaste tradition exégétique de commentaires médiévaux du Cantique des Cantiques, ceux de Bède (672-735), Alcuin (730-804), Haymon d'Auxerre (840-860), Bernard de Clairvaux (1090-1153), Guillaume de Saint-Thierry (1085-1148), ou des Exercices de Gertrude d'Helfta (1256-1302) par exemple : cf. R. Herde, Das Hohelied in der lateinischen Literatur des Mittelalters bis zum 12. Jahrhundert, Munich, Spolento, 1968 ; C. Spicq, Esquisse d'une histoire de l'exégèse au Moyen-Âge, Paris, Vrin, 1944 ; F. Ohly, Hohlied-Studien. Grundzüge einer Geschichte der Hohenliedauslegung des Abendlandes bis 1200, Wiesbaden, 1958 et de commentaires ressortissant à la tradition patristique, tels que ceux d'Apponius (aux dates encore incertaines), de Cyrille d'Alexandrie (376-444), de Grégoire de Nysse (331/341-394), de Grégoire le Grand (540-604), d'Hyppolite (170-235), d'Origène (185-253), de Théodore de Mopsueste (350-428), de Théodoret (393-458), dont le lecteur trouvera les références dans $\mathrm{Ch}$. Kannengiesser, Handbook of Patristic Exegesis. The Bible in Ancient Christianity, Leiden/Boston, Brill, 2006. Dans l'exégèse du verset $C t$ 1, 6 qui constitue le seul fragment qui nous soit parvenu du commentaire du Cantique des Cantiques que Maître Eckhart prétend avoir composé, les autorités citées explicitement sont : Augustin, Confessions, XI, c. 3, n. 5 ; De libero arbitrio, II, c. 16, n. 41 ; Thomas d'Aquin, Summa theologiae, II/IIae, q. 27, a. 1; Bernard de Clairvaux, Sermones super Cantica canticorum, Sermo 33, c. 1, n. 2. L'expositio altera super Canticum canticorum ainsi que l'œuvre qui lui est attribuée, intitulée Brevis commentatio in Cantici canticorum priora duo capita SS. Bernardi sermonibus contexta, semblent constituer une source d'inspiration implicite. Cependant, dans les limites imparties à ce texte, je n'examinerai pas le rapport du
} 
En deuxième lieu, le commentaire eckhartien du Cantique des Cantiques déconcerte le lecteur à la fois quant à sa forme et quant à son contenu. Il se présente, d'une part, comme un commentaire fragmentaire qui se concentre sur un seul verset du livre et, procédant par propositions brèves, il s'apparente davantage à une prise de notes qu'à une exégèse développée et argumentée. D'autre part, son explication du verset consiste à mettre en lumière l'impossibilité de répondre à la question que pose la fiancée du Cantique dans le verset en question - « Indique-moi, toi que mon âme aime, où tu reposes, où tu fais paître $<$ ton troupeau $>$ à midi, pour que je ne commence pas à errer $\rrbracket^{3}$. Ce commentaire insulaire, agrippé sur le roc de son unique verset, isolé des autres commentaires exégétiques eckhartiens par sa forme elliptique et son retrait doctrinal et herméneutique, semble mettre en scène sa disparition en tant que genre exégétique.

Or, il apparaît, en troisième lieu, que, loin d'avoir déserté l'œuvre latine de Maître Eckhart, le Cantique des Cantiques y fait de nombreuses apparitions, quarante-quatre, à ma connaissance, à l'occasion du commentaire d'autres versets. Ces résurgences dispersées dans les différents ouvrages exégétiques du maître thuringien esquissent une forme générique étonnante que l'on pourrait nommer « un commentaire en archipel $\gg^{4}$ assez cohérent du point de vue de son intention doctrinale et de ses citations concentrées sur certains versets.

L'hypothèse que je voudrais examiner ici est la suivante: la disparition du commentaire insulaire, comme l'Atlantide du commentaire biblique en forme d'exégèse, et sa résurgence en forme d'archipel dans l'œuvre latine du maître rhénan ne sont pas sans lien avec le genre littéraire du Cantique des Cantiques lui-même. $\mathrm{Au}$ contraire, il me semble que c'est parce qu'il prend une position très déterminée quant à la nature du Cantique que Maître Eckhart déploie une forme exégétique inattendue, disséminée, et une métaphysique adéquate au Cantique des Cantiques.

Voici le parcours que je propose pour vérifier cette hypothèse.

Quels sont, tout d'abord, les procédés formels et doctrinaux par lesquels Maître Eckhart semble tenter de retirer à toute saisie par le lecteur d'un commentaire du Cantique des Cantiques en forme exégétique?

De quel modèle littéraire de la tradition hébraïque Maître Eckhart s'inspire-til, ensuite, pour assigner au Cantique des Cantiques une appartenance générique et déplacer les frontières de son propre commentaire?

Quelle est, enfin, la géographie du commentaire en archipel et comment les lieux mêmes où émergent les citations du Cantique des Cantiques contribuent-ils à l'énonciation d'une métaphysique spécifique au Cantique des Cantiques, d'une

maître thuringien à cette tradition exégétique, afin de la déployer plus amplement dans une autre étude.

${ }^{3}$ Ct 1,6 selon Maître Eckhart : Indica mihi, quem diligit anima mea, ubi cubas, ubi pascas in meridie, ne vagari incipiam, selon Biblia sacra iuxta vulgatam versionem, adiuvantibus $\mathrm{B}$. Fischer, I. Gribomont, H.F.D. Sparks, W. Thiele, recensuit et brevi apparatu critico instruxit R. Weber, $4^{\mathrm{e}}$ éd. praeparavit R. Gryson, Stuttgart, Deutsche Bibelgesellschaft, ( $1^{\mathrm{e}}$ éd. 1969) 1994: Indica mihi quem diligit anima mea ubi pascas ubi cubes in meridie ne vagari incipiam.

${ }^{4}$ Je remercie Florence Bouchet de m'avoir suggéré cette appellation. 
métaphysique très audacieuse quant à la possibilité d'union entre l'amant et l'aimé, entre l'être humain et son principe divin?

\section{La disparition formelle et doctrinale annoncée d'un commentaire insulaire}

La question de l'identité générique du commentaire du Cantique des Cantiques de Maître Eckhart ne se poserait pas en ces termes, si par deux fois, il n'avait pas affirmé l'avoir effectivement composé.

Et par cela spécialement peut être exposé clairement ce livre des Cantiques tout entier, comme je l'ai remarqué là même ${ }^{5}$.

La concentration de ces annonces dans les deux paragraphes 139 et 152 qui semblent avoir été écrits d'un seul élan, dans le Livre des paraboles de la Genèse, indique, par la certitude de l'expression employée «comme je l'ai remarqué là même », l'émergence effective à un certain moment, dans l'esprit de Maître Eckhart, du projet d'écrire un tel commentaire ou peut-être même du fait de l'avoir réellement écrit.

Or, bien que Maître Eckhart paraisse l'affirmer, ce commentaire n'existe pas comme tel au sens strict. Ou, du moins, ce qui nous en est parvenu n'est qu'une page de notes à l'allure tachygraphique. Et, alors qu'au paragraphe $139^{6}$ du Livre des paraboles de la Genèse, il mentionnait l'existence d'un principe d'interprétation unificateur pour le livre du Cantique des Cantiques tout entier, le fragment de commentaire qui nous est parvenu se concentre sur un unique verset.

Voici un exemple de la forme elliptique du commentaire eckhartien du Cantique des Cantiques :

$\S 1$ : L'épouse, ayant tout laissé, cherche à apprendre du Verbe lui-même, en disant : «Indique-moi », c'est-à-dire dis-moi à l'intérieur, parce que, selon Augustin ${ }^{7}:$ «à l'intérieur au domicile de la cogitation » etc.

« Indique », parce que seules les forces intérieures ont plus de capacité.

\footnotetext{
${ }^{5}$ Maître Eckhart, Liber parabolarum Genesis, Bd. I/1, ed. K. Weiss, Stuttgart, Kohlhammer Verlag, 1964, [désormais noté : In Gen. II et LW I/1], In Gen. II, § 152, [LW I/1, 623, 4-5] : Ex quibus specialiter luculenter exponi potest litteraliter totus liber ille Canticorum, sicut ibidem notavi.

Cf. également In Gen. II, §139, [LW I/1, 607, 5-7] : Et super hac confabulatione supremi nostri, quod est imago dei, cum deo et dei cum illo videtur fundari et procedere totus liber Cantici canticorum.

${ }^{6}$ In Gen. II, § 139, [LW I/1, 607, 5-7]. Cf. supra.

7 Augustin, Conf. XI, c. 3, n. 5, Confessionum libri XIII, CCSL XXVII, ed. L. Verheijen O.S.A., Turnhout, Typographi Brepols, 1990, p. 196, 9-197, 15 : Intus utique mihi, intus in domicilio cogitationis nec hebraea nec graeca nec latina nec barbara ueritas sine oris et linguae organis, sine strepitu syllabarum diceret: "Verum dicit» et ego statim certus confidenter illi homini tuo dicerem: "Verum dicis 》. Cum ergo illum interrogare non possim, te, quo plenus uera dixit, ueritas, rogo, te, deus meus, rogo, parce peccatis meis, et qui illi seruo tuo dedisti haec dicere, da et mihi haec intellegere.
} 
«Indique », parce que les paroles (verba) extérieures sont déficientes.

En troisième lieu, «indique », pour que ce qui est très «indiqué », une fois transfusé dans les paroles (voces) extérieures, ne trompe pas, une fois couvert d'ombre.

«Toi, que mon âme aime »

$\S 2$ : Elle ne nomme pas, parce qu'elle sait qu'il excède tout nom.

En deuxième lieu, parce que, à la manière de tout amant, elle pense savoir de qui elle parle.

En troisième lieu, parce que l'amour n'a pas la raison de la nomination.

En quatrième lieu, parce que, étant toute pleine de dilection, elle ne sait pas parler de la dilection.

En cinquième lieu, parce qu'elle ne pense pas qu'il a un nom, puisque par lui-même tout entier, il est aimable (diligibilis) au-dessus de tout ${ }^{8}$.

Dans ces deux premiers paragraphes, le premier mouvement s'oriente vers l'intériorité de la connaissance qui seule permet d'atteindre le lieu du bien-aimé, par opposition aux facultés de perception externes et au langage proféré. Maître Eckhart ne développe pas son argumentation, mais renvoie seulement au livre XI des Confessions où Augustin décrit l'intériorité ou le «domicile de la cogitation» comme le lieu de la vérité où ni distinction des langues, ni séparation des syllabes ni articulation par le truchement d'organes n'ont cours. Le deuxième mouvement apparaît comme un pas plus radical dans l'advenue de la connaissance négative. La connaissance propre à l'amour n'est plus seulement une question de mode noétique intérieur. Mais, l'amour à plusieurs titres dépasse la connaissance : du point de vue de l'aimé, de l'amant et de la raison même de l'acte d'aimer. Lorsque la fiancée prie son bien-aimé de lui indiquer le lieu où il demeure, Maître Eckhart répond, en quelque sorte, en annulant la requête de deux manières. La première consiste à renvoyer à elle-même celle qui adresse la question à un autre. La seconde met en cause le fondement même du désir de connaître ce qui ressortit à l'amour.

À l'existence hypothétique du commentaire eckhartien du Cantique des Cantiques, s'ajoute, dès lors, son caractère exégétique problématique. Le lecteur attendrait d'un commentaire du verset $C t 1,6$ une indication quant à l'identité de

\footnotetext{
${ }^{8}$ Maître Eckhart, Expositio Cantici Canticorum cap. 1, 6, hrsg. und übersetzt von H. Fischer, Die Lateinischen Werke, Bd. II, Stuttgart, Kohlhammer, 1954-1992, [noté désormais : LW II], $\S 1-2$, [LW II, 637, 3-638, 2]: § 1: Sponsa omnibus dimissis ab ipsomet verbo quaerit experiri dicens : "indica mihi », id est intus dicas, quia secundum Augustinum "intus in domicilio cogitationis » etc.

"Indica », quia solae vires interiores plus capaces sunt.

"Indica», quia verba exteriora deficiunt.

Tertio "indica», ne illud indicatissimum in voces exteriores transfusum decipiat obumbratum. »

"Quem diligit anima mea ».

$\S 2$ : Non nominat, quia scit ipsum omne nomen excedere.

Secundo, quia more amantis omnis, de quo loquitur, putat scire.

Tertio, quia amor non habet rationem nominandi.

Quarto, quia tota plena dilectione nescit de dilectione loqui.

Quinto, quia non putat eum aliquod nomen habere, cum se toto sit super omnia diligibilis.
} 
l'époux promis à la fiancée et au lieu où il repose et où il paît son troupeau, afin d'éviter l'errance à laquelle le condamnerait une quête incertaine, semblable à celle de la fiancée. Or, Maître Eckhart livre le lecteur à un commentaire en éclats, à une série de pensées jaculatoires qui semblent viser, par leur forme elliptique et par leur intention, à l'égarer plutôt qu'à l'aider à s'orienter. Ce commentaire semble donc tenter de disparaître de plusieurs manières: d'abord, en énonçant de manière presque aphoristique l'ensemble des arguments concernant chaque terme à expliquer, comme s'il suffisait de les rappeler à la mémoire du lecteur; ensuite, cette exégèse biblique qui a recours à des auteurs philosophiques et théologiques (Augustin, dans le De libero arbitrio et les Confessions, et Thomas d'Aquin) se place d'une certaine manière en retrait de cette intention argumentative, en ne faisant qu'une brève allusion aux preuves invoquées sans les développer ; enfin, ce discours échappe à toute prise, en retirant aussitôt, selon la méthode de la connaissance négative ${ }^{9}$, ce qu'il vient de poser. Ainsi se présente-t-il comme un commentaire en négatif ou en creux par sa forme et son discours.

Or, si, par son existence en tant que corpus, par sa forme fragmentaire et son discours négatif, le commentaire insulaire du Cantique des Cantiques semble se retirer sous le pied du voyageur qui prétendrait l'y poser fermement, les références au Cantique des Cantiques abondent dans les autres commentaires exégétiques latins de Maître Eckhart.

Le problème de l'appartenance générique du commentaire du Cantique des Cantiques de Maître Eckhart apparaît donc dans les termes suivants : d'un côté, le lecteur est face à la chronique d'une disparition qui se montre en sa forme littéraire et s'énonce en son discours, de l'autre, il assiste à une prolifération disséminée, en forme d'expositions éparses à l'occasion d'autres versets, faisant ainsi apparaître un réseau fluvial d'affluents et de confluents abondants qui débordent le lit du genre exégétique, tel que Maître Eckhart l'a déployé dans ses autres commentaires latins.

Du point de vue de l'interprétation de ces commentaires tels que nous en disposons, comment rendre compte du passage de l'engloutissement de l'île à l'émergence de l'archipel?

\section{Un récit midrashique: double décision herméneutique quant au genre du Cantique des Cantiques}

Voici la ligne directrice d'interprétation que je propose et la raison du choix du commentaire eckhartien du Cantique des Cantiques pour évoquer la question de la mouvance des genres. Il n'est pas anodin que ce soit précisément en relation avec un tel objet de commentaire, à savoir le livre biblique du Cantique des Cantiques dont la question du genre est apparue si problématique au cours de l'histoire de son interprétation, que Maître Eckhart bouleverse les frontières du commentaire exégétique. Mon hypothèse, quant au passage de la forme fragmentaire du commentaire à l'archipel, est que cette mouvance eckhartienne du genre exégétique

\footnotetext{
${ }^{9}$ Sur la connaissance négative dans l'œuvre de Maître Eckhart, le lecteur pourra consulter notamment l'ouvrage de référence de V. Lossky, Théologie négative et connaissance de Dieu chez Maître Eckhart, Études de philosophie médiévale XLVIII, Paris, Vrin, 1960 (1 ${ }^{\mathrm{e}}$ édition), $2^{\mathrm{e}}$ édition augmentée d'une bibliographie par A. de Libera, Paris, Vrin, 1998.
} 
est la réponse littéraire et philosophique que lui inspire ce texte énigmatique du canon des Écritures.

Voici un bref rappel du débat ${ }^{10}$. Le Cantique, composé à l'époque persane vraisemblablement avant les réformes d'Esdras, autour de 444 dans le contexte de Néhémie, est classé parmi les livres sapientiaux, entre l'Ecclésiaste et la Sagesse. De plus, parmi les nombreuses occurrences du genre du «cantique » dans l'un et l'autre Testaments $^{11}$, le Cantique des cantiques présente la particularité de constituer tout un livre, et non pas seulement un passage. Le texte hébreu, ratifié par les anciennes versions, use, en outre, d'un superlatif pour qualifier ce livre, indiquant ainsi peutêtre, dans le genre du cantique, son excellence : le Cantique des Cantiques, comme l'on dit le Saint des saints ${ }^{12}$. Bien qu'il soit reconnu comme un écrit sacré, avant la tradition pharisienne, comme l'atteste la présence des quatre rouleaux de ce livre à Qumrân, l'assemblée de Yabné ${ }^{13}$, dès le premier siècle de l'ère chrétienne, doit, cependant, avec l'intervention de Rabbi Aquiba (50-135) notamment ${ }^{14}$, réglementer

\footnotetext{
${ }^{10}$ L'étude du Cantique des cantiques ici proposée s'inspire notamment de la lecture des commentaires contemporains suivants : La Sainte Bible, Le Cantique des cantiques, traduit par A. Robert, p.s.s., Paris, Cerf, 1951 ; A. Feuillet p.s.s., Le Cantique des cantiques. Étude de théologie biblique et réflexions sur une méthode d'exégèse, Lectio divina 10, Paris, Cerf, 1953 ; A. Robert p.s.s., R. Tournay o.p., A. Feuillet p.s.s., Le Cantique des cantiques. Traduction et commentaire, Études bibliques, Paris, Librairie Lecoffre, J. Gabalda et $\mathrm{C}^{\text {ie }}$ Éditeurs, 1963 ; R. J. Tournay, Quand Dieu parle aux hommes le langage de l'amour. Études sur le Cantique des Cantiques, Cahiers de la Revue Biblique, 21, Gabalda, 1982 ; A. Lys, Le plus beau chant de la création. Commentaire du Cantique des Cantiques, Lectio Divina 51, Paris, Cerf, 1968 ; J. Calloud, «Esquisse, Propositions pour une interprétation raisonnée du Cantique des Cantiques », Sémiotique et Bible, 65, mars 1992, p. 43-60 ; P . Beauchamp, L'Un et l'autre Testaments, 2. Accomplir les Écritures, Paris, Seuil, 1990, chap. 4, p. 159195 ; A.-M. Pelletier, Lectures du Cantique des Cantiques. De l'énigme du sens aux figures du lecteur, Analecta biblica 121, Rome, Editrice Pontificio Istituto biblico, 1989; Y.Simoens, Le Cantique des Cantiques comme livre de la plénitude. Une lecture anthropologique et théologique, Bruxelles, Lumen vitae, 1992.

${ }^{11}$ Cf. par exemple : Ex 15, 1; Dt 31, 30; 2 S22, 1 .

${ }^{12}$ Traité Yadaïm, 3, 5.

${ }^{13}$ Pour une information plus complète sur la canonicité du Cantique des Cantiques et la place de ce livre dans l'histoire complexe de l'établissement du canon des Écritures, cf. Ch. Théobald (dir.), Le canon des Écritures : études historiques, exégétiques et systématiques, Lectio divina140, Paris, Cerf, 1990, p. 140-142 ; A.-M. Pelletier, Lectures du Cantique des Cantiques, op. cit., p. 380 sq.

${ }^{14}$ Les chrétiens reçoivent l'interprétation allégorique des Juifs. Cependant, dès le cinquième siècle, Théodore de Mopsueste (Fragmenta in Canticum, Patrologia Graeca [désormais notée : PG]66, Paris, Migne, 1864, col. 699-700) soutient que le Cantique des cantiques n'est qu'un épithalame relatif au mariage de Salomon avec la fille du roi d'Égypte, c'est-à-dire, du point de vue littéraire, d'un chant d'amour profane. Il est condamné par le second Concile de Constantinople (533). Cf. A.-M. Pelletier, Lectures du Cantique des Cantiques, op. cit., p. 322 sq. Certains interprètes, comme K. Budde, H. Gunkel, W. O. E. Oesterly-T. H. Robinson, s'inspirent des remarques de J. G. Wetzstein sur le folklore nuptial du Hauran syrien pour lire le Cantique des Cantiques comme une collection de chants de noces qui
} 
son usage dans les banquets nuptiaux. De plus, malgré le témoignage rendu par le Targum, le Midrash Rabba et la Mekhilta, d'une interprétation allégorique du Cantique des Cantiques comme parabole des relations amoureuses de Dieu et d'Israël, ceux qui discutent sa canonicité allèguent qu'il est difficile de considérer comme divin un ouvrage qui ne mentionne explicitement ni Dieu, ni la Loi, ni les Prophètes, ni les grands événements de l'Histoire sainte. S'agit-il donc d'un ensemble de poèmes nuptiaux profanes et sensuels, purifiés par une interprétation spirituelle ou bien d'une allégorie de l'amour de Yahvé pour la nation choisie et de son union avec elle dans un mariage mystique?

Il semble que Maître Eckhart, dans son commentaire du Cantique des Cantiques, inscrive ce livre dans la lignée des textes prophétiques. L'indice en est que le maître rhénan réfère au moins une partie du verset $C t 1,6$ - Ubi pascas ?immédiatement, c'est-à-dire sans autre glose, au verset Ez 34, 13 : Et pascam eas in montibus Israel.

"Où tu fais paître <ton troupeau > »

De manière active, «sur les monts d'Israël $»^{15}$ etc. $^{16}$

À cet écho explicite du verbe «paître» (pascor) entre les deux passages s'ajoute peut-être implicitement la mémoire de accubare au verset $E z 34,15^{17}$ suscitée par ubi cubas de $C t$ 1, 6. Il s'agit, dans le passage d'Ezéchiel auquel Eckhart fait référence - $E z$ 34, 6-15 notamment - de l'image de Yahvé, berger de son peuple qui le ramènera de la terre d'exil ${ }^{18}$ vers la Palestine où, à l'heure de midi, figure de l'accomplissement de la promesse ${ }^{19}$ et du bonheur eschatologique ${ }^{20}$, il trouvera le repos.

Or, cette référence au prophète Ezéchiel, chapitre 34, verset 13, est significative, dans le commentaire eckhartien du Cantique des Cantiques, dans la mesure où Eckhart ne fait référence à ce passage d'Ezéchiel aucune autre fois dans

témoigne des pratiques matrimoniales syro-palestiniennes. J.-P. Audet y voit, pour sa part, un document de l'institution domestique en Israël, hérité des sources populaires antérieures à Osée. D'autres interprètes insistent sur l'origine païenne du texte qui adapterait en le démythisant des chants d'amour égyptiens (G. Gerleman) ou le culte hiérogamique mésopotamien de Tammuz et d'Ishtar (H. Schmökel, K. V. H. Ringgren, D. Lys).

${ }^{15}$ Ez 34, 13 : Et pascam eas in montibus Israel.

${ }^{16}$ In Cant. § 4, [LW II, 639, 1-2] : «Ubi pascas ? \# Active « in montibus Israel 》 etc.

${ }^{17}$ Ez. 34, 13-15: 13 : et educam eas de populis et congregabo eas de terris et inducam eas in terram suam et pascam eas in montibus Israhel in rivis et in cunctis sedibus terrae.

14 : in pascuis uberrimis pascam eas et in montibus excelsis Israhel erunt pascuae eorum ibi requiescent in herbis virentibus et in pascuis pinguibus pascentur super montes Israhel.

15 : ego pascam oves meas et ego eas accubare faciam dicit Dominus Deus.

${ }^{18}$ Pour la figure du berger qui ramène son peuple de l'exil, cf. par exemple $I S 40,11 ; 49,9$ $10 ; 63,11 ; \operatorname{Jr} 23,3$ et 7-8; surtout : 31,$10 ; 50,19 ; M i 7,14 ; Z a 9,16 ; 10,2-3 ; 11,1-17$; 13, 7-9; Ps 80, 1-8; surtout Ez 34, 7-16.

${ }^{19} \mathrm{Cf}$. l'heure de midi connotant le bonheur, par exemple : Dt 28, 29; $\mathrm{Jb} \mathrm{5,} 14$; Jb 11, 17 ; Ps 37, 6 ; Is 58, 10 ; Is 59, 10.

${ }^{20}$ Cf. Ct 2,$17 ; 3,1 ;$ Is 5, 30;8, 20-9, $1 ;$ Am 5, 18 et 20. 
son œuvre latine. Cette référence n'a donc pas le statut d'un topos exégétique sous la plume de Maître Eckhart. Il s'agit bien plutôt, à ses yeux, d'une inscription délibérée du Cantique des Cantiques dans la veine des livres prophétiques du premier Testament.

De plus, la reprise exacte des termes employés en $G n 37,16^{21}$, lorsque Joseph est envoyé par son père vers ses frères, indique l'inscription du verset $C t 1,6$ dans la tradition comme en une méditation midrashique.

D'autre part, l'acte herméneutique spécifique de Maître Eckhart, par rapport à l'interprétation strictement génétique du Cantique des cantiques, consiste à relier le membre de proposition ubi cubas au verset du Prologue de l'Évangile de Jean, $J n 1,18$, coordonnant ainsi la promesse prophétique à l'annonce évangélique.

De plus, Maître Eckhart confirme son interprétation du Cantique des cantiques comme résonance de la littérature prophétique par l'exégèse de $u b i$ pascas. Lorsqu'il prend cette fois le verbe à la voix passive, il y entend surgir l'image du lys.

« Où tu fais paître < ton troupeau > »

De manière passive, 'parmi les lys $»^{22}$, comme tu le sais ${ }^{2324}$.

Or, précisément à travers la figure du lys évoquée aux versets $C t 2,16 ; 6,2$, s'entrevoit davantage, dans la genèse du texte du Cantique des cantiques et par les termes qui y sont employés, son inscription dans la tradition prophétique. La figure du lys renvoie, en effet, à la finale eschatologique d'Os 14, 6 qui évoque la fertilité rendue à la terre palestinienne au printemps et ainsi au retour des faveurs divines ${ }^{25}$.

Si donc, aux paragraphes 1 et 2 du corps du commentaire en forme d'exégèse, Maître Eckhart semblait suggérer qu'il était impossible de connaître le lieu où demeurait le bien-aimé, il apparaît qu'au paragraphe 4 il indique ce lieu par la simple référence au prophète Ezéchiel. Cette ouverture, à peine esquissée, du point de vue de l'explication du verset s'accompagne d'une décision herméneutique quant à la forme du livre. Il semble qu'aux yeux de Maître Eckhart, le Cantique des Cantiques se déploie comme une glose de la prophétie d'Ezéchiel et ne se comprenne que dans sa relation avec elle ${ }^{26} . \mathrm{Si}$, par suite, le Cantique des Cantiques

${ }^{21}$ Gn 37, 16 : Indica mihi ubi pascant greges.

${ }^{22} \mathrm{Ct} 2$, 16 ; 6, 2. Cf. Os 14, 6 : Ero quasi ros Israhel germinabit quasi lilium et erumpet radix eius ut Libani.

${ }^{23}$ Cf. Guillaume de Saint-Thierry [Guillelmus S. Theodorici], Expositio altera super Canticum canticorum, c. 1, Sources chrétiennes [noté désormais : SC] 82, Paris, 1962, p. 152 : Sponsus et pascit et pascitur ; utrumque enim sonat hac verbum 'pascit'.

${ }^{24}$ In Cant. § 4, [LW II, 639, 3-4] : «Ubi pascas? » Passive « inter lilia », ut nosti.

${ }^{25}$ Cf. A. Robert p.s.s., R. Tournay o.p., A. Feuillet p.s.s., Le Cantique des cantiques. Traduction et commentaire, Études bibliques, Paris, Librairie Lecoffre, J. Gabalda et Cie Éditeurs, 1963, p. 96 et 139.

${ }^{26}$ A. Robert fait l'hypothèse de l'inscription du Cantique des cantiques dans un ensemble de textes prophétiques marqués par une théologie de la conversion et de la rentrée en grâce : Os $2 ; J r 31,17-22$; Is 51,17 et $21-22 ; 52,1-2$ et $7-8$ et 12 ; surtout $54,4-8 ; 61,10-11 ; 62$, 4-5. 
bouleverse les frontières génériques du cantique biblique, c'est peut-être qu'il a, dans la tradition juive, le statut de midrash ${ }^{27}$, selon l'hypothèse de certains exégètes

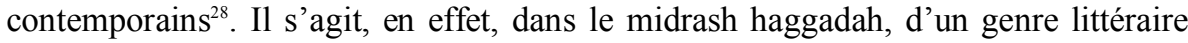
qui consiste en une relecture actualisante d'un texte dont on dégage un sens spirituel ou moral pour les destinataires contemporains, en procédant sur le mode de l'allusion ou du «clin d'œil». Si l'origine de ce genre littéraire est hébraïque, son usage se poursuit de manière commune, dans les commentaires bibliques, jusqu'à l'ère patristique et reste fréquent ensuite dès que l'auteur recourt à un mode parabolique d'explicitation des Écritures.

Or, même si le commentaire du Cantique des Cantiques de Maître Eckhart ne se présente que sous la forme d'une prise de notes allusive, l'hypothèse selon laquelle le maître thuringien aurait considéré ce livre comme la réécriture midrashique de la littérature prophétique semble confirmée par le lieu même où Maître Eckhart annonce par deux fois la ligne directrice de son interprétation de l'ensemble du Cantique des Cantiques: le Livre des paraboles de la Genèse. Or, cette seconde rédaction d'un commentaire du livre de la Genèse est inspirée par la méthode des paraboles ${ }^{29}$ que Maître Eckhart rattache, notamment, explicitement à Maïmonide $^{30}$ dont il cite littéralement, dès le prologue de son commentaire ${ }^{31}$, un

\footnotetext{
${ }^{27}$ Sur la présence de l'exégèse juive, notamment de l'exégèse des métaphores prophétiques et de l'exégèse midrashique, dans l'exégèse chrétienne, $\mathrm{cf}$. G. Dahan, L'exégèse chrétienne de la Bible en Occident médiéval (XII $-X I V^{e}$ s.), Paris, 1999, p. 382-387.

${ }^{28}$ Cf., par exemple, A. Robert p.s.s., R. Tournay o.p., A. Feuillet, op. cit., p. 11 : il s'agit d'un écrit midrashique, c'est-à-dire d'une « recherche du sens des Écritures, entreprise à la lumière de la Bible entière, en vue d'actualiser la portée des textes bibliques, à l'aide de procédés relevant, pour une large part, de l'imagination orientale.»

C'est précisément la détermination de son appartenance au genre littéraire du midrash qui, selon Renée Bloch, «Midrash », in Supplément du Dictionnaire de la Bible V, Pirot, Robert, Cazelles, 1957, col. 1273, permet de tirer l'interprétation du Cantique des cantiques de son ambiguïté et d'en proposer une lecture ajustée : «Si l'exégèse du Cantique a été tant débattue, et si l'on a tant méconnu son sens allégorique, fondé sur l'enseignement prophétique confronté avec l'histoire contemporaine, c'est qu'on a trop souvent négligé l'étude de son genre et de sa structure littéraires. [...] La référence constante aux données bibliques, la dramatisation et la réinterprétation des événements et des aspirations de l'époque qui suit Néhémie, montrent que nous sommes là, sans aucun doute, en face d'un pur midrash. »

A. Robert p.s.s., R. Tournay o.p., A. Feuillet, op.cit., p. 17: Il s'agit d'un midrash allégorique : «le chant d'amour de Yahvé et de son peuple» et «l'amour de l'épouse avec ses hésitations et ses reprises décrit les étapes de la conversion d'Israël en attendant le salut final qui sera l'œuvre de Yahvé. »

${ }^{29}$ Cette «méthode» des paraboles excède les limites du Livre des paraboles de la Genèse. Elle est, en effet, étendue au commentaire de l'Évangile selon saint Jean. Un parallèle de In Gen. II, $\S 5$ se trouve, notamment, en effet, en In Ioh. §174-176, (Jn 1, 15-16), Maître Eckhart, Die lateinischen Werke, Bd. III : Expositio sancti Evangelii secundum Iohannem, ed. K. Christ, B. Decker, J. Koch, H. Fischer, L. Sturlese, A. Zimmermann, Stuttgart, Kohlhammer Verlag, 1936-1989 [désormais noté : In Ioh., LW III], p. 143, 1. 4-p. 145, 1. 4.

${ }^{30} \mathrm{Il}$ n'est pas possible, dans les limites imparties à ce texte, de développer les arguments qui fondent l'influence de Maïmonide, en particulier, sur la méthode des paraboles dans l'exégèse
} 
passage du prologue du Guide des égarés ${ }^{32}$. Or, il appartient également à l'esprit de la parabole ou du midrash auquel recourt l'enseignement rabbinique, tel qu'en témoigne Maïmonide, d'éviter de délivrer un enseignement clair et univoque et de le transmettre plutôt selon le mode de manifestation de la vérité, c'est-à-dire dans une clarté qui dissimule, ainsi que l'exprime le prologue du Guide des égarés: "Car mon but est (de faire en sorte) que les vérités y soient entrevues, et qu'ensuite elles se dérobent $»^{33}$.

La réponse exégétique de Maître Eckhart à la nature parabolique du Cantique des Cantiques - au sens eckhartien inspiré de Maïmonide - ou midrashique - au sens des exégètes contemporains - consiste donc à en obscurcir ou en sceller l'interprétation doctrinale assertorique à l'endroit où le lecteur l'attend, c'est-à-dire sous le titre Commentaire $d u$ Cantique des Cantiques, et à en ouvrir l'intelligence à des endroits inattendus, dispersés dans l'œuvre.

En quoi la forme du commentaire en archipel, adéquate à la nature midrashique du Cantique des Cantiques, selon l'interprétation proposée par Eckhart au moyen du renvoi à la prophétie d'Ezéchiel, offre-t-elle une vision métaphysique cohérente, originale, adéquate au Cantique des Cantiques et en quoi l'apparente fragmentation du commentaire en divers lieux de l'œuvre latine et à l'occasion de différents versets est-elle précisément la possibilité pour Eckhart de déployer une telle métaphysique?

eckhartienne. Ils sont déployés dans l'article suivant : J. Casteigt, «Sous l'écorce de la lettre. De la parabola, comme procédé rhétorique et herméneutique hérité de Maïmonide, à l'opérateur métaphysique qu'est l'imago dans le Livre des paraboles de la Genèse de Maître Eckhart », Maître Eckhart, J. Casteigt (dir.), Les Cahiers d'Histoire de la Philosophie, Paris, Cerf, à paraître. Cf. aussi Y. Schwartz, «Meister Eckharts Schriftauslegung als maimonidisches Projekt », G. K. Hasselhoff et O. Fraisse (dir.), Moses Maimonides (11381204) - His Religious, Scientific, and Philosophical Wirkungsgeschichte in Different Cultural Contexts, Ex Oriente Lux : Rezeptionen und Exegesen als Traditionskritik4, Würzburg, Ergon Verlag, 2004, p. 173-208.

${ }^{31}$ In Gen. II, § 5, [LW I /2, 336, 7-13] : «Le premier genre ou mode des paraboles est quand 'tout mot', ou presque, de la parabole 'démontre quelque chose au sujet de quelque chose séparément. Le second mode est' quand la parabole par elle-même tout entière est 'similitude' et expression 'de la chose' tout entière dont elle est la parabole. Et alors 'de nombreux mots' sont interposés sans donner d'enseignement direct sur quelque chose dont ils sont la parabole, 'mais ils sont posés pour orner la similitude' et la parabole 'ou pour approfondir l'occultation de la chose' dont ils sont la parabole 'à côté de ce qui convient platement à cette similitude' et à cette parabole. "

${ }^{32}$ Moïse Maïmonide, dans Le Guide des égarés suivi du Traité des huit chapitres, Les dix paroles, traduit de l'arabe par S. Munk, préface de C. Birman, nouvelle édition revue par C. Mopsik, Lagrasse, Verdier, 1979, [désormais noté Maïmonide, Le Guide des égarés], introduction, p. 18-19.

${ }^{33}$ Maïmonide, Le Guide des égarés, ibid., p. 12. 
Un commentaire en archipel ou le genre d'une métaphysique du baiser disséminée

En quoi, tout d'abord, peut-on dire que la dissémination des citations du Cantique des Cantiques dans les autres œuvres exégétiques latines constitue un commentaire à proprement parler ?

En un premier lieu, le recensement quantitatif des citations du Cantique des Cantiques dans l'œuvre latine de Maître Eckhart esquisse les grands traits d'une géographie. Du côté du livre du Pentateuque, une île principale semble émerger du côté du verset $C t 1,1-$ «Qu'il me baise d'un baiser de sa bouche»-: dix occurrences $^{34}$ sur les quarante-quatre citations du Cantique des Cantiques, le second verset le plus fréquemment cité étant le verset $C t 1,3$ qui ne présente que quatre occurrences $^{35}$. Les autres versets ne sont cités qu'épisodiquement, une, voire deux fois. Une figure majeure parait, par conséquent, se dessiner autour du verset $C t 1,1$.

Du côté des lieux de l'œuvre eckhartienne où sont distribuées les citations, en revanche, il apparaît qu'elles se concentrent massivement autour du chapitre 3 de la Genèse dans le Livre des paraboles de la Genèse où se trouvent dix citations ${ }^{36} \mathrm{du}$ Cantique des Cantiques. Quatre, sur les six citation $\mathrm{s}^{37}$ inhérentes au commentaire du livre de la Sagesse, surgissent dans la seule exposition du verset $S g$ 7, 11a. Dix-huit ${ }^{38}$

${ }^{34}$ Ct 1, 1 : In Gen.II, Tabula auctoritatum (Gn 3), [LW I, 470, 10]; In Gen. II, § 146, [LW I, 615, 5]; In Ioh. § 118 (Jn 1, 14), [LW III, 103, 10]; In Ioh. § 177 (Jn 1, 14), [LW III, 146, 7] ; In Ioh. §337 (Jn 3, 8), [LW III, 286, 8] ; In Ioh. § 375 (Jn 4, 13-14), [LW III, 319, 12]; In Ioh. §404 (Jn 4, 42), [LW III, 344, 5]; In Ioh. §570 (Jn 14, 8), [LW III, 497, 7]; In Sap. § 105 (Sag. 7, 11a), [LW II, 441, 13]; In Sap. § 107 (Sg 7, 11a), [LW II, 443, 10].

${ }^{35}$ Ct 1, 3 : In Gen. II, Tabula auctoritatum (Gn 3), [LW I, 470, 5]; In Gen. II, § 140, [LW I, 608, 1] ; In Ioh. § 202 (Jn 1, 38), [LW III, 170, 6]; In Sap. § 78 (Sg 6, 17), [LW II, 410, 7].

${ }^{36}$ In Gen. II : [Ct 1, 1] : In Gen. II, Tabula auctoritatum (Gn 3), [LW I, 470, 10]; In Gen. II, $\S 146,(G n$ 3), [LW I, 615, 5] ; [Ct 1, 3] : In Gen. II, Tabula auctoritatum (Gn 3), [LW I, 470, 5]; In Gen. II, § 140, [LW I, 608, 1]; [Ct 2, 10] : In Gen. II, § 152, (Gn 3), [LW I, 622, 11]; [Ct 2, 14] : In Gen. II, § 139, (Gn 3), [LW I, 607, 3] ; [Ct 2, 16] : In Gen. II, § 152, (Gn 3), [LW I, 622, 11]; [Ct 4, 2] : In Gen. II, $\$ 192($ Gn 25, 23), [LW I, 665, 1]; [Ct 5, 6] : In Gen. II, § 139, (Gn 3), [LW I, 607, 4] ; In Gen. II, § 147, (Gn 3), [LW I, 617, 4] ; [Ct 6, 5] : In Gen. II, § 192 (Gn 25, 23), [LW I, 665, 1]; [Ct 7, 10]: In Gen. II, § 152, (Gn 3), [LW I, 622, 12].

${ }^{37}$ In Sap. : dans l'exposition du verset $\operatorname{Sg} 7,11 \mathrm{a}$ : [Ct 1, 1] : In Sap. § 105, [LW II, 441, 13]; In Sap. § 107, [LW II, 443, 10]; [Ct 2, 4] : In Sap. § 108, [LW II, 444, 8]; [Ct 3, 4] : In Sap. § 108, [LW II, 444, 8]; dans l'exposition d'autres versets : [Ct 1, 1] : In Sap. § 78 (Sg 6, 17), [LW II, 410, 7] ; [Ct 8, 5] : In Sap. § 59 (Sg.5, 16), [LW II, 386, 12].

${ }^{38}$ In Ioh. : [Ct 1, 1: ] : In Ioh. § 118 (Jn 1, 14), [LW III, 103, 10]; In Ioh. § 177 (Jn 1, 14), [LW III, 146, 7]; In Ioh. §337 (Jn 3, 8), [LW III, 286, 8]; In Ioh. § 375 (Jn 4, 13-14), [LW III, 319, 12]; In Ioh. § 404 (Jn 4, 42), [LW III, 344, 5]; In Ioh. § 570 (Jn 14, 8), [LW III, 497, 7]; [Ct 1, 3] : In Ioh. § 202 (Jn 1, 38), [LW III, 170, 6]; [Ct 1, 6] : In Ioh. § 209 (Jn 1, 38), [LW III, 177, 7] ; [Ct 2, 11] : In Ioh. § 118 (Jn 1, 14), [LW III, 103, 11] ; [Ct 2, 11-13] : In Ioh. $\S 475($ Jn 8, 36), [LW III, 408, 7] ; [Ct 2, 13] : In Ioh. § 118 (Jn 1, 14), [LW III, 103, 11]; [Ct 4, 11] : In Ioh. § 118 (Jn 1, 14), [LW III, 103, 12]; [Ct 4, 12] : In Ioh. § 691 (Jn 19, 41), [LW III, 607, 1] ; [Ct 4, 15] : In Ioh. § 691 (Jn 19, 41), [LW III, 607, 1]; [Ct 4, 16] : In Ioh. 
citations se trouvent entrelacées au commentaire de l'Évangile selon saint Jean. Loin d'être confronté à une situation d'éparpillement indifférent, neutre du point de vue de la signification, le lecteur note, par conséquent, des lieux d'émergence précis des figures du Cantique des Cantiques.

Mais, cette géographie des citations qui fait apparaître des reliefs à la fois dans le choix des citations et dans les lieux où elles sont distribuées suffit-elle à faire l'hypothèse qu'il s'agit ici d'un véritable commentaire, au moins partiel, du Cantique des Cantiques? Il semble qu'à ces considérations quantitatives, il faille, en un second lieu, ajouter un autre point de vue, à savoir celui de la manière dont opèrent ces citations dans la méthode exégétique eckhartienne. Il me semble que leur mode d'opération relève du procédé propre aux paraboles, tel que Maître Eckhart le trouve développé par Maïmonide, dans le prologue du Guide des égarés notamment. Ce procédé se caractérise, d'une part, par le fait qu'un argument ou une image, précisément parce qu'ils sont importants, ne font que de brèves apparitions dans un discours, à la manière d'un clin d'œil, pour éveiller l'attention du lecteur. Ce procédé est, d'autre part, repérable, par le fait qu'un argument tire sa consistance et sa signification moins de lui-même que du réseau dans lequel il s'intègre. Enfin, il procède en obscurcissant le sens patent, afin d'attirer l'attention du lecteur vers un sens latent.

Observons si ce procédé parabolique est à l'œuvre dans les citations du Cantique des Cantiques dans les œuvres latines d'Eckhart, de telle sorte qu'il constitue ces ensembles de citations en un commentaire en archipel. Or, ces observations sur la forme du discours et son herméneutique propre sont indissociablement mêlées à la question de l'unité de l'interprétation métaphysique du Cantique des Cantiques par Eckhart. Autrement dit, ce qui est en jeu dans la constitution du réseau de citations extraites du Cantique des Cantiques est la formation d'une typologie argumentative caractéristique d'une métaphysique eckhartienne du Cantique des Cantiques.

Est-il donc possible de constituer une typologie argumentative des figures du Cantique des Cantiques à la fois aux niveaux herméneutique et métaphysique ? Pour entrer dans ce réseau de figures, observons comment Maître Eckhart formule sa ligne directrice d'interprétation de l'ensemble du Cantique des Cantiques, aux paragraphes 139 et 152 du Livre des paraboles de la Genèse.

Et, sur cet entretien (confabulatio) de notre $<$ partie $>$ suprême, qui est image de Dieu, avec Dieu et de Dieu avec elle, semble être fondé et procéder le livre du Cantique des Cantiques tout entier. C'est, en effet, l'entretien (confabulatio) entre saint et saint des saints, entre saint et sainteté, entre bon et bonté, entre juste et justice, comme je l'ai remarqué dans l'exposition de ce livre. Quoi d'aussi doux pour le juste en tant que juste que la justice même ${ }^{39}$ ?

$\S 475$ (Jn 8, 36), [LW III, 408, 6] ; [Ct 5, 1] : In Ioh. § 691 (Jn 19, 41), [LW III, 607, 2] ; [Ct 5, 16] : In Ioh. § 48, (Jn 1, 1-2), [LW III, 40, 2]; [Ct 6, 2] : In Ioh. § 292 (Jn 2, 1), [LW III, 244, 9].

${ }^{39}$ In Gen. II, [LW I/1, 607, 5-10] : Et super hac confabulatione supremi nostri, quod est imago dei, cum deo et dei cum illo videtur fundari et procedere totus liber Cantici canticorum. Haec enim confabulatio est inter sanctum et sanctum sanctorum, inter sanctum et 
Deux caractéristiques principales ressortent du paragraphe 139. D'un côté, Maître Eckhart énonce le programme métaphysique dont le Cantique des Cantiques est la figure. Il s'agit de transformer une métaphysique hiérarchique organisée autour de principes supérieurs qui commandent à des réalités inférieures en une métaphysique de l'union. Le levier qui fait passer de l'une à l'autre est la remarque selon laquelle si le supérieur et l'inférieur, certes, se distinguent l'un de l'autre, ils ne s'en touchent pas moins. C'est la figure du baiser ou du toucher. Se laisse ici apercevoir le lien entre la fonction logique et métaphysique d'une telle figure scripturaire, d'un côté, et la concentration massive des citations autour du verset Ct 1,1 .

De l'autre, il s'agit, à travers les citations du Cantique des Cantiques, non pas seulement de bribes d'exégèse éparpillées çà et là, mais bien d'un véritable projet métaphysique, puisque Maître Eckhart transpose les relations entre la fiancée et son bien-aimé, décrites dans le Cantique, en une théorie qui régit les termes généraux, tels que le juste et la justice, le bon et la bonté, etc. Ces derniers constituent, en effet, pour le lecteur d'Eckhart les signaux d'alerte qui marquent le surgissement des énoncés métaphysiques majeurs au cours de ses expositions bibliques.

$\mathrm{Si}$, à partir du paragraphe 139, sont apparues la dimension métaphysique du commentaire et l'unité herméneutique de son projet, il reste à voir comment se constitue, sous les yeux du lecteur, l'argumentation caractéristique du Cantique des Cantiques, selon la méthode des paraboles. Suivons, pour cela, la trace de la figure du baiser à travers le réseau constitué par les citations du verset $C t 1,1$.

Cette figure est décryptée dès l'annonce générale du projet du commentaire du Cantique des Cantiques au paragraphe 139 du Livre des paraboles de la Genèse où elle apparaît.

L'ordre naturel est que $<$ la partie $>$ supérieure de l'inférieur touche $<$ la partie $>$ inférieure de son supérieur ${ }^{40}$.

De quoi est-il question? Pour déchiffrer cette figure, la forme du commentaire en réseau apparaît indispensable, dans la mesure où l'énoncé de la figure du baiser s'avère à la fois bref et obscur du point de vue de son sens patent. C'est pourquoi, seule la prolifération du verset en un rhizome de citations peut en éclairer le sens en mettant en relation différents contextes. Ainsi Maître Eckhart déploie-t-il cette figure dans la suite de l'exposition du troisième chapitre de la Genèse auquel appartient le paragraphe 139. Ce chapitre constitue un lieu majeur pour la géographie des citations du Cantique des Cantiques.

Dans le toucher, la rencontre et l'union suprême et mutuelle du supérieur essentiel avec son inférieur, ils se baisent et s'embrassent d'un amour naturel et essentiel, intime et très doux du supérieur et de l'inférieur, selon cela que l'homme juste qui

sanctitatem, inter bonum et bonitatem, inter iustum et iustitiam, sicut notavi in expositione illius libri. Quid enim tam dulce iusto, inquantum iustus, quam ipsa iustitia?

${ }^{40}$ In Gen. II, § 139, [LW I/1, 605, 14-606, 1]: Ordo autem naturalis est, ut supremum inferioris attingat infimum sui superioris. 
parle à la justice inengendrée à partir de laquelle, par laquelle et dans laquelle il est engendré en tant que juste, désirant s'accomplir tout entier et être transformé sans aucune médiation dit: «il m'a baisé d'un baiser de sa bouche», $C t 1$. Cela est le toucher mutuel par lequel le supérieur regarde l'inférieur et réciproquement. Or, dans ce toucher et cette rencontre, le supérieur et l'inférieur se baisent mutuellement et s'embrassent d'un amour naturel et essentie $\mathrm{l}^{41}$.

Il ressort du rapprochement des paragraphes 139 et 146 que la fonction logique et métaphysique de la figure du baiser semble constituer un levier qui entraîne le retournement de la métaphysique hiérarchique en métaphysique de l'unité, par ce simple constat que la partie inférieure de ce qui commande touche, néanmoins, la partie supérieure de ce qui obéit et, dans ce contact, la conforme à soi. Ainsi le lecteur commence-t-il à percevoir qu'il s'agit, dans le baiser du verset $C t 1$, 1 , d'autre chose qu'une simple locution biblique à expliquer, mais bien d'une image, selon la méthode eckhartienne de la parabole, dans la mesure où cette figure n'est pas circonscrite à l'exposition du chapitre 3 de la Genèse, mais qu'elle surgit au cœur d'autres expositions, comme le sermon latin XIV, qui commente le verset $L c 5$, 1-11, en exerçant, dans l'argumentation, une fonction d'axiome ou de principe métaphysique général qui ne semble pas avoir besoin de démonstration.

De plus, l'être du supérieur affecte son inférieur et l'assimile à lui, le configure, le conforme, selon cela en $C t 1:$ «Qu'il me baise d'un baiser de sa bouche $»^{42}$.

Une fois le caractère nodal de la figure du baiser repéré, c'est selon la méthode des renvois internes au réseau de citations du verset $C t 1,1$ que le lecteur est conduit à identifier la typologie du mode d'argumentation qu'implique la figure $\mathrm{du}$ baiser. Pour esquisser cette architectonique de la figure du baiser, interrogeonsnous sur sa visée. De là découleront les éléments qui y mènent. Or, il apparaît que tous les éléments de l'architectonique du baiser culminent ${ }^{43}$ dans la visée finale qu'est la transformation de l'amant dans l'aimé ou du juste dans la justice, de telle

${ }^{41}$ In Gen. II, § 146, (Gn 3), [LW I/1, 614, 10-616, 1]: Adhuc autem ad evidentiam praemissorum et multorum aliorum rursus notandum quod in attactu, occursu et unione superioris essentialis cum sui inferioris supremo multuo se osculantur et amplexantur naturali et essentiali amore intimo et dulcissimo superius et inferius, secundum illud, quod vir iustus loquens iustitiae ingenitae, a qua, per quam et in qua gignitur inquantum iustus, se toto perfici et absque medio quolibet transformari desiderans ait: "osculetur me osculo oris sui », Cant. 1. Is est ipse attactus mutuus, quo superius aspicit inferius et e converso. In hoc autem attactu et occursu mutuo se osculantur et amplexantur naturali et essentiali amore superius et inferius.

${ }^{42}$ Sermo XIV, 1, § 151, [LW IV, 143, 2-8] : Tertio patris est « unitas ». Hoc autem appetit anima : unum esse cum deo. Quarto anima appetit nullo formari creato, sed solo deo. Unde supremo creato dicimus : " monstra te esse matrem », deo autem: "ostende nobis patrem ». Rursus esse superius afficit suum inferius et sibi assimilat, configurat et conformat, iuxta illud Cant. 1 : "osculetur me osculo oris sui ».

Cf. également In Gen. II, § 146.

${ }^{43}$ Cf. aussi In Ioh. § 177 infra. 
sorte qu'il s'agisse d'une transformation de tout l'être du juste dans celui de la justice en une parfaite unité.

Remarque que celui qui aime quelque chose d'un, par exemple la justice, n'aime pas quelque chose d'autre ou quelque chose de non-juste. Il cherche donc seulement à atteindre parfaitement la justice et à être transformé en elle en son point suprême, en sa source, où, inengendrée, elle enfante et engendre, selon cela: «Montre-nous le Père et cela nous suffit», $J n 14$; et $C t 1$ : «Qu'il me baise d'un baiser de sa bouche $»^{44}$.

Du point de vue du mode d'argumentation, le lecteur observe ici que c'est le rapprochement de la citation de $J n$ 14, 8 avec celle du Cantique des Cantiques qui concentre sur cette union avec le principe de toute justice le but de la transformation, comme en une glose du verset $J n$ 14, 8: "Montre-nous la justice et cela nous suffit ». Ainsi prolifère la méthode exégétique des paraboles et de leurs rhizomes : à l'écho des citations du verset $C t 1,1$ dans les diverses œuvres exégétiques eckhartiennes, comme entre le troisième chapitre de la Genèse, le sermon latin XIV et le paragraphe 177 du commentaire de l'Evangile de Jean, s'ajoute, en effet, le tissage des citations bibliques internes à chaque exposition. Celui-ci confère à la figure du baiser des dimensions supplémentaires inattendues, ici par exemple : celle de la vision du principe divin entendu comme ultime accomplissement du désir.

«Qu'il me baise », dit-il, «d'un baiser de sa bouche». Le juste en tant que juste ne cherche ni ne désire absolument rien d'autre que d'accomplir en lui-même la justice, dépouillé de tout ce qui n'est pas la justice même, ayant rejeté autant le semblable que le dissemblable, jusqu'à ce que le semblable passe dans l'un qui est la justice même et jusqu'à ce que l'imparfait soit évacué à la venue du parfait ${ }^{45}$.

Poursuivons le déchiffrement de la figure du baiser en déployant le réseau du verset $C t 1,1$. Le paragraphe 118 du commentaire de l'Évangile de Jean explicite une condition de l'union impliquée par le baiser. La marque de la transformation parfaite de l'être de l'amant s'avère, en effet, l'intériorité, c'est-à-dire le fait que l'aimé soit en lui. Or, le lecteur se souvient que cette caractéristique majeure de l'interprétation du Cantique des Cantiques se trouve aussi dans l'exposition appelée insulaire du verset $C t 1,6$, avec le recours à Augustin comme une dimension essentielle de la connaissance amoureuse. Ici, au paragraphe $118 \mathrm{du}$ commentaire de l'Évangile de Jean, Maître Eckhart transpose, dans un autre contexte, la dynamique

${ }^{44}$ In Sap. § 105, [LW II, 441, 9-13] Secundo nota quod amans quippiam unum aliquod, puta iustitiam, non amat quidquam aliud nec quidquam non iustum. Quaerit igitur solum se perfecte assequi iustitiam et in ipsam in sui supremo, in suo fonte, ubi est pariens sive gignens ingenita, transformari, secundum illud: " ostende nobis patrem, et sufficit nobis 》, Ioh. 14 ; et Cant. 1: "osculetur me osculo oris sui ».

${ }^{45}$ In Ioh. § 177, [LW III, 146, 9-13] : «Osculetur », inquit, " me osculo oris sui ». Iustus, inquantum iustus, nihil prorsus quaerit nec appetit nisi perfici in se ipso iustitiam, exui ab omni, quod non est ipsa iustitia, abici tam simile quam dissimile, quousque simile transeat in unum, quod est ipsa iustitia, et quousque imperfectum evacuetur veniente perfecto. 
de la connaissance extérieure et de la connaissance intérieure. La figure du baiser tient lieu, notamment, d'argument pour l'interprétation eckhartienne de l'incarnation $\mathrm{du}$ Verbe. Or, nulle autre preuve que la constellation de citations extraites du Cantique des Cantiques ne semble, en effet, apportée à la conception eckhartienne de l'incarnation du Verbe comme ce qui ne s'accomplit qu'en nous et ne trouve pas sa perfection tant qu'il ne survient que comme un événement extérieur. "'Il a habité', dit-il, 'en nous', c'est-à-dire il s'est fait habitus », autrement dit une disposition stable en nous.

«Car le Verbe fait chair» dans le Christ, en dehors de nous, par cela que c'est en dehors de nous ne nous rend pas parfaits, mais après que et par ce fait qu'«il a habité en nous », il nous donne un nom et nous rend parfaits, « de telle sorte que nous soyons appelés fils de Dieu et que nous le soyons », $1 J n 3$. Alors le fils de Dieu, «qui s'est fait chair », habite, en effet, en nous, c'est-à-dire en nous mêmes, Apocalypse: "Voici le tabernacle de Dieu avec les hommes et il habitera avec eux», "et Dieu lui-même sera avec eux leur Dieu», Is. 7: "son nom est Emmanuel», ce qui est «Dieu avec nous»; et 12: «Exulte et loue, Sion, habitation, parce que grand au milieu de toi est le saint Israël ». « Il a habité », dit-il, « en nous », c'est-à-dire il s'est fait habitus ${ }^{46}$. De même, «il a habité en nous », parce que nous l'avons lui-même en nous. Or, à partir de ce qu'une chose a en elle, elle reçoit le nom et l'être. C'est pourquoi l'épouse dans les Cantiques prie en disant: "Qu'il me baise d'un baiser de sa bouche. Une fois qu'elle l'a accueilli, l'hiver se retire et s'en va, la vigne qui fleurit répand son odeur» $(C t 2,11)$; «car ses lèvres sont comme le miel qui distille » $(C t 2,13)$. Il dit donc : «Le Verbe s'est fait chair» et le fils de l'homme est devenu fils de Dieu : "Voyez de quel amour Dieu nous a donné d'être appelés enfants de Dieu et de l'être », 1 Jn $3 .^{47}$

\footnotetext{
${ }^{46}$ Cf. In Ioh. $§ 501$, [LW III, 432, 4-5] : « Habitavit in nobis », id est habitum fecit in nobis et per consequens habitaculum nos sibi fecit.

${ }^{47}$ In Ioh. § 118, [LW III, 103, 1-15] : «Verbum » enim « caro factum » in Christo, extra nos, hoc ipso quod extra nos non facit nos perfectos, sed postquam et per hoc quod " habitavit in nobis », nos denominat et nos perficit, " ut filii dei nominemur et simus », 1 Ioh. 3. Tunc enim filius dei, "verbum caro factum », in nobis habitat, id est in nobis ipsis, Apocalypsis : " ecce tabernaculum dei cum hominibus, et habitabit cum illis », "et ipse deus cum eis erit eorum deus »; Is. 7 : «nomen eius Emmanuel », quod est «nobiscum deus»; et 12: " exsulta et lauda, habitatio Sion, quia magnus in medio tui sanctus Israel ». "Habitavit », inquit, " in nobis », id est habituavit. Item 'habitavit in nobis', quia ipsum in nobis habemus; ab eo autem quod res in se habet, nomen et esse accipit. Hoc est quod orat sponsa in Canticis dicens : " osculetur me osculo oris sui. Quo accepto hiems abiit et recessit, vineae florentes odorem spargunt 》; "favus enim distillans labia » eius. Ait ergo : "verbum caro factum est » in Christo, "et habitavit in nobis », quando in quolibet nostrum filius dei fit homo et filius hominis fit filius dei : "videte qualem caritatem dedit nobis deus, ut filii dei nominemur et simus », 1 Ioh. 3 .

Ab eo autem quod res in se habet, nomen et esse accipit. Hoc est quod orat sponsa in Canticis dicens : "osculetur me osculo oris sui. Quo accepto hiems abiit et recessit, vineae florentes odorem spargunt 》; "favus enim distillans labia » eius. Ait ergo : "verbum caro factum est 》 in Christo, " et habitavit in nobis », quando in quolibet nostrum filius dei fit homo et filius
} 
Une fois indiquée la visée finale de l'architectonique du baiser, à savoir l'union de l'amant et de l'aimé par l'habitation de l'amant dans l'aimé, la question est : par quel chemin y parvenir? Du point de vue doctrinal, le lecteur qui parcourt le réseau des citations du Cantique des Cantiques s'aperçoit que Maître Eckhart propose une voie philosophique pour parvenir à cette unité de l'amant et de l'aimé capable de transformer l'être de l'aimé. Il s'agit, en effet, d'apprendre à discerner l'unité de tous les étants particuliers. L'unité de la justice dans la multiplicité et la diversité des personnes, des paroles et des actions justes est à la fois ce qui unit tout ce qui est juste et le principe, en chacun, de sa justice.

Ainsi donc en n'importe quel un il trouve tout et tous viennent à lui : en un quelconque bien, dis-je, c'est-à-dire là où ce bien-ci et ce bien-là, la justice, la sagesse et les autres de cette espèce sont un. Ceci est un en lequel Dieu habite, en lequel et par lequel nous lui sommes unis. Dans cet un, l'on trouve Dieu, là il enseigne et opère tout ${ }^{48}$.

Du point de vue de la méthode exégétique, Maître Eckhart, en reliant le verset $C t 1,1$ à des propositions logiques et métaphysiques générales, l'éloigne de son contexte biblique et le métamorphose en opérateur logique et métaphysique à son tour. Le même procédé de transformation d'un verset en l'argument philosophique qu'il figure apparaît également au paragraphe 139 du Livre des paraboles de la Genèse. Maître Eckhart le transcrit en différents contextes comme par un glissement métaphorique. Il cite, en effet, Maïmonide ${ }^{49}$, Augustin $^{50}$ et les Psaumes $^{51}$ pour expliciter ce dont il s'agit sous la figure du baiser de l'inférieur et du supérieur. L'herméneutique du réseau qui caractérise la méthode eckhartienne de la parabole permet ainsi d'éviter de fixer un sens univoque à une proposition, mais de faire surgir cette signification dans la circulation entre les domaines et les auteurs qui évoquent des réalités analogues.

Or, l'ordre naturel est que $<$ la partie $>$ supérieure de l'inférieur touche $<$ la partie $>$ inférieure de son supérieur. Or, <la partie $>$ supérieure de l’âme en nous est l'intellect. D'où Rabbi Moïse, au pénultième chapitre de toute son œuvre, dit que «l'intellect qui se diffuse sur nous»-Psaume: «La lumière de ton visage, Seigneur, est marquée sur nous »- l'intellect lui-même, dis-je, « qui nous conjoint au créateur ». Et le créateur, Dieu, «par la même lumière est en rapport avec nous et» « est avec nous », «comme l'a dit David: «Dans ta lumière, nous verrons la

hominis fit filius dei : "videte qualem caritatem dedit nobis deus, ut filii dei nominemur et simus », 1 Ioh. 3.

${ }^{48}$ In Sap. § 106, [LW II, 442, 11-443, 1] : Sic ergo in uno quolibet invenit omnia et veniunt sibi omnia: in uno, inquam, quolibet bono; in uno, id est ubi hoc bonum et hoc bonum, iustitia, sapientia et cetera huiusmodi, unum sunt. Hoc est unum, in quo deus habitat, in quo et quo nos sibi unit. In hoc uno deus invenitur, ibi docet et operatur omnia.

${ }^{49}$ Maïmonide, Le Guide des égarés, III, c. 53.

${ }^{50}$ Augustin, Conf. X, c. 26, n. 37 ; Augustin, Enarrationes in Ps.41, n. 7.

${ }^{51} P_{S} 4,7 ; P_{S} 35,10 ; P_{S} 41,5$. 
lumière $» »$. Et Augustin dit que la raison supérieure toujours tend vers les règles immuables au-dessus d'elle-même, en Dieu, reste attachée à elles, leur est conjointe et les voit directement, selon ceci : «J'ai diffusé au-dessus de moi mon âme » dans le Psaume selon la lettre <d'Augustin>. Et Augustin, dans le livre $\mathrm{X}$ des Confessions, c. 26 : «où t'ai-je trouvé, de telle sorte que j'apprenne à te connaître, sinon en toi au-dessus de moi ? $»^{52}$.

C'est ce mode de production métaphorique de réseaux de signifiants qui autorise l'universalisation du mode de relation dont l'union du juste et de la justice est le paradigme à l'ensemble des éléments d'un système métaphysique, tels qu'être/étant, cause/effet, actif/passif. Le lecteur aperçoit par suite, combien la forme du commentaire en archipel est indissociable, selon la méthode parabolique de production de réseaux de signifiants, du projet métaphysique de Maître Eckhart.

Il n'y a, en effet, absolument rien d'autre, où ils conviennent, où ils se retrouvent, où ils se voient et s'embrassent l'un l'autre-Cantique au début-, l'étant et l'être, la cause et l'effet, l'engendrant et l'engendré, sinon l'être même. Or, l'être se tient toujours dans l'un ${ }^{53}$.

Atteindre la visée unitive de la figure du baiser implique, en suivant le réseau des citations extraites du Cantique des Cantiques, d'entrer dans le parcours métaphysique proposé par Maître Eckhart. Les images s'articulent ainsi aux principes du système métaphysique, le discours exégétique au discours philosophique. Or, ce parcours de citations contribue à forger une métaphysique de l'un - ou hénologie - , plutôt qu'une métaphysique de l'être - ou ontologie. Mais le principe ultime ne semble pas s'apparenter à l'un ineffable et inconnaissable. Il s'agit plutôt d'une unité dynamique sans cesse donnée dans l'attraction de l'amant vers l'aimé, jusqu'à leur union. Là encore, la méthode de la figure qui prend sens à travers les textes et domaines auxquels elle renvoie et la forme générique du commentaire en archipel, en réseau de citations, sont inséparables de cette métaphysique de l'unité dans la différence de relation entre l'actif et le passif, l'amant et l'aimé, en In Ioh. $\$ 177$.

${ }^{52}$ In Gen. II, § 139, [LW I, 606, 1-11] : Supremum autem animae in nobis intellectus est. Unde Rabbi Moyses capitulo paenultimo totius sui operis dicit quod «intellectus, qui effusus est super nos 》 - Psalmus : " signatum est super nos lumen vultus tui, domine 》 - ipse, inquam, intellectus est, "qui nos coniungit cum creatore ». Et creator, deus, " eodem lumine respicit nos et » " est semper nobiscum », "sicut dixit David: 'in lumine tuo videbimus lumen'》. Et Augustinus dicit quod ratio superior semper intendit, subhaeret, coniuncta est et intuetur regulas incommutabiles super se ipsam in deo, secundum illud: "effudi super me animam meam» in Psalmo secundum litteram <Augustini>. Et Augustinus X Confessionum c. 26 : "ubi te inveni, ut discerem te, nisi in te supra me?"

${ }^{53}$ In Sap. § 107, [LW II, 443, 8-11] : Non enim est aliquid aliud prorsus, ubi conveniant, ubi se inveniant, ubi se videant et se invicem osculentur - Cant. in principio - ens et esse, causa et effectus, gignens et genitum nisi ipsum esse. Esse autem semper stat in uno. 
En quatrième lieu : «grâce pour grâce », parce que le visible, en tant que visible, est en vue de la vision et, inversement, la vision est en vue du visible et l'acte des deux est $u^{54}$ : «grâce pour grâce » d'un côté et de l'autre ; et, universellement, le désir et le désiré, l'actif et le passif, Ct 1: "Qu'il me baise d'un baiser de sa bouche ». En général, l'actif et le passif cherchent, en effet, par essence à s'unir l'un à l'autre mutuellement et, en eux-mêmes, ils cherchent l'un ${ }^{55}$, en tant que tel ${ }^{56} .{ }^{57}$

Maître Eckhart emprunte cet argument de l'union en acte du passif et de l'actif au De anima $^{58}$ d'Aristote où il est appliqué au sens et au sensible en acte ainsi qu'à l'intellect et à l'intelligible en acte. Dans le paragraphe 152 du Livre des paraboles de la Genèse, Maître Eckhart reprend l'exemple de l'union en acte du voyant et du vu pour décliner le topos de la communication intime qui a lieu dans le baiser ou dans la parole échangée «face à face» dans l'échange mutuel.

Ainsi, par exemple, tout corps sensible dit ce qu'il est à tous les sensitifs. Mais, l'œil seulement le perçoit sous la raison du coloré ou de la couleur et répond par le fait de voir et parle au corps visible. Et ils se parlent l'un à l'autre le plus naturellement par cette espèce, unique engendrée par l'un et l'autre, dans le rejeton unique, pour cette raison que l'un et l'autre, c'est-à-dire la vue et le visible, sont ce qu'ils sont, en tant qu'ils sont en acte, par cette espèce, comme le dit le Philosophe. Quoi de plus doux, en effet, que l'acte et sa forme? Or, de la même façon, bien que tout corps visible parle aux autres puissances de l'âme ainsi qu'à leurs organes, cependant l'oreille est absolument muette et ne répond pas au corps dans la raison par laquelle il est coloré, mais elle l'entend et le perçoit sous la raison par laquelle il est sonore et elle lui répond "face à face », tous deux tournés l'un vers l'autre échangent mutuellement, c'est-à-dire du mien au tien et du tien au mien, $J n 17:$ : Tout ce qui est mien est tien et ce qui est tien est mien », c'est-à-dire en tant que tel; $C t 2:$ «Mon bien-aimé me parle », et plus bas: «Mon bien-aimé s'adresse à moi et moi à lui »; $C t 7$ : «Moi vers mon bien-aimé et il se tourne vers moi ». Et il en est ainsi de toutes les autres

\footnotetext{
${ }^{54} \mathrm{Cf}$. In Ioh. § 57, [LW III, 48, 2].

${ }^{55}$ Pour l'expression augustinienne unum quaerunt, cf. In Ioh. § 113, [LW III, 98, 11 et 13]; In Ioh. $\S 565$; In Sap. $\S \S 8$ et 300 ; S.XII, 2, § 139; S. XXII, § 209; S. XXX, 2, § 318 ; S. XLVIII, 2, § 503.

${ }^{56}$ Cf. In Ioh. $§ 574$; In Gen. I, § 55 ; §§ 194-200; In Gen. II, § 123.

${ }^{57}$ In Ioh. § 177, [LW III, 146, 4-9]: Adhuc autem quarto : "gratiam pro gratia », quia visibile, inquantum visibile, est propter visum et e converso visus propter visibile, et ipsorum est actus unus : " gratiam pro gratia » hinc inde; et universaliter desiderium et desideratum, activum et passivum, Cant. 1 : "osculetur me osculo oris sui». Generaliter enim activum et passivum se ipsa per essentiam mutuo quaerunt uniri, et in se ipsis unum quaerunt, inquantum huiusmodi.

${ }^{58}$ Aristote, De anima, III, 4, 430 a 3, in Thomas d'Aquin, Sentencia libri de anima, Opera omnia, tome XLV/1, ed. R.-A. Gauthier O.P., Paris, commissio leonina / Vrin, 1984, p. 214 : In hiis quidem enim que sunt sine materia, idem est intelligens et quod est intelligitur. Aristote, De anima, III, 2, 425 b 26, in Thomas d'Aquin, Sentencia libri de anima, ibid., p. 177 : Sensibilis autem actus et sensus idem est et unus, esse autem ipsorum non idem.
} 
puissances de l'âme, aussi bien sensitives qu'intellectives, c'est-à-dire par la vérité à l'intellect et par la bonté à la volonté..$^{59}$

La description de la métaphysique de l'union dans la différence de relation opérée dans le paragraphe 152 du Livre des paraboles de la Genèse introduit le dernier élément caractéristique de la typologie de la figure du baiser. Il consiste à assimiler le mode d'union de la fiancée et de son bien-aimé à l'union du locuteur et de celui à qui il adresse sa parole. Cette dimension verbale parait si constitutive de la figure du baiser qu'elle est d'emblée apparue dans le programme général d'interprétation du Cantique des Cantiques, en In Gen. II, § 139. Elle est amplement développée notamment dans le commentaire de l'Évangile selon saint Jean et aussi, dans d'autres œuvres exégétiques de Maître Eckhart, par le truchement de citations johanniques. Il me semble qu'elle éclaire, enfin, le lecteur sur ce qui est à l'œuvre dans la parole que Maître Eckhart lui adresse. Son acte de lecture, son acte de réception de l'interprétation eckhartienne ne saurait se limiter à la compréhension d'une doctrine exégétique et métaphysique. N'est-elle pas déjà aussi l'acte de sa transformation en ce principe que, par la parole qu'il entend, il apprend déjà à aimer?

Bien plus, ce même toucher mutuel par lequel le supérieur regarde l'inférieur et réciproquement, l'inférieur lui-même considère en retour l'aspect du supérieur, est la voix et le verbe, la parole, la diction et le nom par lequel le supérieur se fait connaître à l'inférieur et s'expose à lui, s'ouvre et se manifeste. Il manifeste, dis-je, tout ce qui est en lui, $J n 16$ : «Tout ce qu'a le Père est mien » et $J n 15$ : «Tout ce que j'ai entendu de mon Père, je vous l'ai fait connaître ». Or, il se manifeste luimême et par lui-même. ${ }^{60}$

59 In Gen. II, §152, Sed et serpens erat callidior cunctis animantibus terrae (Gn 3), [LW I, 621, 12-623,2]: Sic exempli causa corpus aliquod sensibile omne id quod est $<$ loquitur $>$ omnibus sensitivis; sed ipsum sub ratione colorati sive coloris percipit solum oculus et videndo respondet et colloquitur corpori visibili. Et ipsa specie unica genita ab utroque in prole una naturalissime sibi invicem colloquuntur, eo scilicet quod utrumque ipsorum, visus scilicet et visibile, per illam speciem est id quod est, inquantum actu sunt, ut ait philosophus. Quid enim dulcius rei quam actus et forma ipsius? Eodem autem modo corpus visibile quamvis loquatur et aliis potentiis animae et earum organis, auris tamen muta est prorsus et non respondet corpori in ratione qua coloratum est, audit vero et percipit ipsum sub ratione qua sonorum est et ipsi respondet "facie ad faciem » utroque converso vicissim ad se invicem, mutuo, id est meo tuo et tuo meo, Ioh. 17: "omnia mea tua sunt et tua mea sunt », scilicet inquantum huiusmodi; Cant. 2: "dilectus meus loquitur mihi », et infra: 'dilectus meus mihi, et ego illi'; Cant. 7: " ego dilecto meo, et ad me conversio eius 》. Et sic de aliis potentiis animae omnibus, tam sensitivis quam etiam intellectivis, quibus loquuntur omnia tanto dulcius, quanto intimius et quanto sublimius, puta veritate intellectui et bonitate voluntati.

${ }^{60}$ In Gen. II, § 146, (Gn 3), [LW I /1, 614, 10-616, 1] : Quin immo ipse attractus mutuus, quo superius aspicit inferius et e converso ipsum inferius respicit ad aspectum superioris, vox est et verbum, locutio et dictio et nomen, quo innotescit superius inferiori et se illi pandit, aperit et manifestat; manifestat, inquam, omnia quae in se sunt, Ioh. $16:$ "omnia, quae habet pater, 


\section{Conclusion}

La question de la mouvance des genres soulevée par le commentaire eckhartien du Cantique des Cantiques revient donc à la manière de rendre compte de la co-existence d'une annonce explicite de la part d'Eckhart d'avoir composé un commentaire qui propose une interprétation de l'ensemble du livre, d'une part, d'un commentaire fragmentaire et elliptique d'un unique verset sous le titre de l'œuvre exégétique annoncée, d'autre part, et, enfin, d'un commentaire en archipel composé d'un ensemble déterminé de citations du Cantique des Cantiques en des points précis de l'œuvre latine de Maître Eckhart.

Il ne s'agit en aucune façon de se placer ici du point de vue historique. L'état actuel des recherches ne permet pas de trancher la question de savoir si la page de notes qui tient lieu de commentaire du Cantique des Cantiques représente l'esquisse d'un projet que le maître thuringien entend effectivement réaliser ou a réellement composé et qui ne nous a pas été transmis ou bien encore s'il a renoncé à son projet pour préférer au commentaire insulaire une forme en archipel. Il ne s'agit pas non plus de savoir si ce glissement dans le genre littéraire, de l'île à l'archipel, est une intention délibérée de l'auteur ou si cela s'est fait à son insu, s'imposant par la force et la nature mêmes du Cantique des Cantiques qu'il entendait commenter.

La lecture que je propose ici se situe sur un plan strictement herméneutique, en partant des seuls textes dont nous disposons. Il m'est apparu que l'interprétation eckhartienne du Cantique des Cantiques comme appartenant à la tradition prophétique du Pentateuque et en ne prenant sens qu'en relation avec le livre d'Ezéchiel, notamment, s'inscrit au cœur de l'inflexion de sa méthode exégétique et de l'introduction systématique de la méthode des paraboles inspirée de sa lecture de Maïmonide. Dès lors, la constellation des citations du Cantique des Cantiques disséminées dans certaines expositions revêt une fonction herméneutique et métaphysique précise. Ces citations, à la manière du genre midrashique du Cantique des Cantiques, opèrent comme des paraboles qui font basculer l'interprétation du verset d'une métaphysique hiérarchique de principes inférieurs et supérieurs à une «métaphysique du baiser» ou de l'union en acte, en ne cessant de faire appel à l'éveil de l'intelligence du lecteur attentif à ces figures et à leur mise en réseau. Seul ce mode de communication de la vérité qui voile ce qui est patent pour faire apparaître ce qui est latent permet d'interrompre la lecture du monde selon l'ordre des substances séparées, identifiées à leur nature respective, pour y découvrir des relations entre principes actif et passif dont l'union en acte est plus forte que la séparation selon l'existence naturelle. Ainsi s'esquisse, pour le lecteur qui suit patiemment les renvois de verset à verset et les clins d'œil successifs de l'exégète, la possibilité que s'unisse ce qui semblait radicalement séparé : le fiancé et la fiancée, l'actif et le passif, Dieu et l'homme.

Julie Casteigt

Université Toulouse II-Le Mirail

mea sunt»; et Ioh. 15: "omnia, quaecumque audivi a patre meo, nota feci vobis». Manifestat autem se ipso et se ipsum. 


\title{
RM
}

\section{De la chronique au roman courtois: l'épisode de Sérifontaine dans le Victorial de Díaz de Games (Castille, 1436)}

\begin{abstract}
The aim of this paper is to question the relevance of the notion of genre at the end of the Middle Ages. I will do so through an analysis of Chapter 78 of Gutierre Díaz de Games's Victorial (1436), the first biography of a knight written in Castilian. I shall study in particular what distinguishes the chapter from the rest of the treatise. The chapter-about five pages - is situated at the core of the narrative of this Chronicle which the author calls a "treatise" and which is divided into three books, each corresponding to a period in the life of Pero Niño. The chapter itself contains the description of an idyllic place, protected and enclosed, a place where knights and gentlewomen indulge in courtly pleasures. The chapter, the structureof which follows the divisions of the day according to courtly ritual, can be considered as a succession of tableaux evoking the five senses. It also reveals a double trend of the culture of educated noblemen, whether French or Castilian: profane, on the one hand, nourished with literary and artistic references, mostly drawn from Antiquity; religious, on the other hand, with a didactic aim. I posit that these pages contribute to courtly aesthetics, tempered however by Christian morality. This in turn is reinforced by the aim of the work which is to praise the knight, this being a prerequisite of the genre to which the Victorial belongs.
\end{abstract}

Résumé : Il s'agit, à travers l'analyse du chapitre 78 du Victorial de Gutierre Díaz de Games (1436), première biographie chevaleresque écrite en castillan, de s'interroger sur ce qui délimite et différencie ces pages du reste du traité, afin d'évaluer la pertinence de la notion de genre en cette fin de Moyen âge. Le chapitre 78, quelque cinq pages qui se situent au cœur $d u$ récit chronistique, appelé "traité» par l'auteur et divisé en trois livres, chacun correspondant à un âge ou époque de la vie de Pero Niño, est, dans son entier, la description d'un lieu idyllique, protégé et clos, lieu des plaisirs entre chevaliers et gentes dames. Ce chapitre, grâce au découpage de la journée selon le rituel courtois et au recours à l'ecphrasis, peut être considéré comme une succession de Tableaux des cinq sens. Le chapitre serait révélateur d'une double tendance de la culture de ces nobles lettrés tant français que castillans, culture profane, d'une part, nourrie de références littéraires et artistiques, la plupart provenant de l'Antiquité, et culture cléricale à portée didactique d'autre part. Les pages étudiées seraient ainsi au service de l'esthétique courtoise, mais il s'agirait d'une esthétique courtoise contrôlée, dans une certaine mesure, par la morale chrétienne, confortée elle-même par la finalité de l'ouvrage, à son tour pré-établie par le genre auquel appartient le Victorial, faire l'éloge d'un chevalier.

Le Victorial' $^{1}$ est le récit de l'éducation, des exploits et de l'ascension sociale de Pero Niño, chevalier castillan de la première moitié du $\mathrm{XV}^{\mathrm{e}}$ siècle, par Gutierre

${ }^{1}$ G. Díaz de Games, El Victorial, éd. de R. Beltrán Llavador, Madrid, Taurus (Clásicos Taurus $\left.\mathrm{n}^{\circ} 25\right)$, 1994. Pour les citations dans le texte, j'utilise la traduction française : Le Victorial. Chronique de don Pero Niño, comte de Buelna (1378-1453) par Gutierre Díaz de

Cahiers de Recherches Médiévales, 18, 2009 
Díaz de Games qui fut, des années durant, son porte-bannière. Mais, loin d'être une simple chronique particulière, le Victorial surprend par sa structure et la complexité de son écriture. Il s'ouvre en effet sur un long proème, sorte de traité sur la chevalerie, qui s'apparente par les thèmes et sa portée morale au Libre de l'orde de cavalleria $^{2}$ de Raymond Llull et qui a comme fonction de définir le cadre éthique et religieux du récit à venir. De plus, puisant à des sources diverses et nombreuses, l'auteur intercale entre les épisodes de la vie du héros des chapitres qui sont soit des rappels historiographiques - le récit de la lutte fratricide entre Pierre le Cruel et son demi-frère Henri de Trastamare, ou encore les origines de la guerre de Cent Ans...-, soit des narrations brèves, que l'on doit lire comme des exempla, le plus souvent tirées de la mythologie antique. Le Victorial se caractérise donc par une hétérogénéité constitutive parfaitement perçue par ses premiers traducteurs, les comtes de Circourt et de Puymaigre; on lit en effet dans l'introduction de l'édition française de 1867 :

Le Victorial est à la fois un recueil de légendes, traité de chevalerie, sérieux document de l'histoire de l'Espagne et un peu de la nôtre, chronique d'un chevalier que ses aventures ont conduit des côtes de Barbarie, à celles d'Angleterre, de la cour de Castille à celle de France, tableau des idées et des mœurs d'autrefois ${ }^{3}$.

Malgré cette hétérogénéité et ces interférences textuelles, le Victorial a toujours été catalogué comme «biographie chevaleresque», sans doute en raison du but déclaré dès l'incipit: chanter les hauts faits d'un preux chevalier'. La biographie chevaleresque a été étudiée et définie comme un genre littéraire, notamment par Elisabeth Gauchers. La plupart des textes antérieurs au Victorial sont des textes français : L'histoire de Guillaume le Maréchal ${ }^{\mathrm{b}} \mathrm{du} \mathrm{XIII}^{\mathrm{e}}$ siècle - texte fondateur-, La vie du Prince Noir ${ }^{7}$, La Vie de Bertrand du Guesclin ${ }^{8}$ et Le Livre de Boucicaut ${ }^{9}$;

Games, son porte-bannière, traduction et présentation de J. G. Dalché, Turnhout, Brépols, 2001. Désormais Vict.

${ }^{2}$ Ramón Llul, Libre de l'orde de cavalleria, éd. de J. R. de Luanco, Barcelone, 1901.

${ }^{3}$ Comtes Albert de Circourt et Théodore de Puymaigre, Le Victorial, chronique de don Pero Niño, comte de Buelna, par Gutierre Díaz de Games, son alferez (1379-1449), traduit de l'espagnol d'après le manuscrit, avec une introduction et des notes historiques, Paris, 1867, p. VII.

${ }^{4}$ G. Díaz de Games El Victorial,..., p. 207-208.

${ }^{5}$ E. Gaucher, La biographie chevaleresque. Typologie d'un genre (XIII ${ }^{e}-X V^{e}$ siècle), Paris, Honoré Champion, 1994. Cet auteur, même s'il n'établit pas un véritable code, analyse l'ensemble de la production chronistique française, voir notamment le chapitre I «La biographie: un genre littéraire? », p. 37-62. Consulter également R. Beltrán Llavador, «Imágenes de servicio, cortesía y clerecía en la biografía caballeresca medieval : del mundo francés al castellano ", L'univers de la chevalerie en Castille, J.-P. Sanchez (coord.), Paris, Éditions du Temps, 2000, p. 128-143.

${ }^{6}$ L'histoire de Guillaume le Maréchal, éd. P. Meyer, 3 vols., Paris, Renouard, 1891-1901.

${ }^{7}$ La vie du Prince Noir by Chandos Herald, Tübingen, Niemeyer, 1975.

${ }^{8}$ Chronique de Bertrand Du Guesclin, éd. E. Charrière, 2 vols., Paris, Didot, 1839. 
ces deux derniers ouvrages font partie, selon Rafael Beltrán Llavador, des sources, ou des modèles devrions-nous dire, de Díaz de Games. Un caractère commun à ces œuvres semble justifier le regroupement en un genre : la narration de faits donnés comme véridiques. La biographie serait donc avant tout de «l'Histoire ». Cependant, des modifications, des évolutions aussi bien formelles que thématiques peuvent être relevées dans ces récits historiographiques; c'est d'ailleurs ce que reconnaît Elisabeth Gaucher lorsqu'elle écrit que :

La biographie s'intègre donc parfaitement dans l'ambition qui anime tout historien médiéval : dire l'événementiel, une "geste», écrire une historia de rebus gestis [...]. Toutefois, on verra que ce genre tendra, notamment à la fin du Moyen Âge, à élargir le champ de l'histoire au-delà du factuel, en brossant du héros de plus riches portraits $^{10}$.

Le présent travail a donc pour but de situer le Victorial dans cette évolution d'un genre dont la mouvance est en grande partie due à la diversité des sources. Comme les ouvrages qui l'ont précédé, le Victorial se nourrit de la poésie épique, s'enrichit d'influences venues du roman courtois, mais également des livres de voyage ou d'aventures sans dédaigner parfois le recours à l'hagiographie. Il suit certes des modèles français tout en répondant aux attentes d'un public aristocratique castillan imprégné de valeurs chevaleresques ou, plus largement, nobiliaires. S'instaure alors entre l'auteur, membre lui aussi de cette élite militaire et lettrée, et le public visé un pacte de lecture ${ }^{11} \mathrm{~s}^{\prime}$ incarnant dans le protagoniste du récit, le chevalier Pero Niño, archétype du noble castillan. Il y a donc, d'une part, adéquation au genre - tel qu'il est défini par Elisabeth Gaucher-, et, d'autre part, un écart luimême mouvant et fluctuant selon les chapitres par rapport au modèle générique.

J'ai retenu pour l'analyse le chapitre 78 qui me paraît présenter un grand intérêt tant du point de vue thématique que formel. Ces quelque cinq pages se situent au cœur du récit chronistique, appelé traité par l'auteur et divisé en trois livres, chacun correspondant à un âge ou époque de la vie de Pero $\mathrm{Niño}^{12}$. À l'enfance et formation du jeune noble succède l'âge adulte ; Pero Niño est alors capitaine du roi Henri III et s'illustre contre les corsaires berbères en méditerranée puis il entreprend une campagne contre les Anglais qui le mènera jusqu'en Normandie, ou plus exactement jusqu'à la seigneurie de Sérifontaine, sorte de havre de paix ou repos du

\footnotetext{
${ }^{9}$ Le livre des fais du bon messire Jehan le Maingre, dit Bouciquaut, mareschal de France et gouverneur de France, éd. D. Lalande, Genève, Droz (Textes littéraires français, CCCXXXI), 1985.

${ }^{10}$ E. Gaucher, La biographie, op. cit., p. 86.

${ }^{11}$ Pour cette notion consulter H. R. Jauss, Pour une esthétique de la réception, Paris, Gallimard (Bibliothèque des idées), 1978.

${ }^{12}$ À chaque livre et donc à chaque âge de la vie de Pero Niño correspond un épisode amoureux. L'épisode courtois de Sérifontaine constitue une sorte de parenthèse enchantée entre deux mariages «de raison», le premier très formel, et le second qui a donné lieu à une élaboration romanesque différente. Voir à ce propos F. Gómez Redondo, Historia de la prosa medieval castellana. III. Los orígenes del humanismo. El marco cultural de Enrique III y Juan II, Madrid, Cátedra, 2002, p. 3190-3193.
} 
guerrier, cette dernière expression étant à prendre au pied de la lettre. Je m'interrogerai donc sur ce qui délimite et différencie ces pages du reste du traité, afin d'évaluer la pertinence de la notion de genre au Moyen Âge ou plus exactement en cette fin de Moyen Âge. Faut-il en effet penser l'appartenance à un genre comme quelque chose d'inéluctable, de contraignant, et à quel degré d'ailleurs? On peut avant d'entreprendre l'analyse rappeler les conclusions d'Hans Robert Jauss qui écrit à propos de la littérature médiévale :

[...] on ne saurait imaginer une œuvre qui se placerait dans une sorte de vide d'information et ne dépendrait pas d'une situation spécifique de la compréhension. Dans cette mesure, toute œuvre littéraire appartient à un genre, ce qui revient à affirmer purement et simplement que toute œuvre suppose l'horizon d'une attente, c'est-à-dire d'un ensemble de règles préexistant pour orienter la compréhension du lecteur (du public) et lui permettre une lecture appréciative ${ }^{13}$.

Une première lecture du chapitre 78 permet de repérer deux différences majeures, la première affectant la forme, et la seconde le contenu ou ce que l'on pourrait appeler l'objet de la narration. Tout d'abord, on passe de la narration de faits ou d'actions - narration qui est le propre d'une chronique- à la description d'un monde. Toutes références, spatiales, temporelles ou à des événements historiques, disparaissent et le temps semble alors arrêté, ce qui induit forcément un autre rythme de lecture. Ensuite, on assiste à un glissement car, si Pero Niño ne disparaît pas, il passe au second plan, occulté en quelque sorte par le personnage de la dame. On le sait, la biographie chevaleresque suit depuis les origines, c'est-à-dire depuis L'histoire de Guillaume le Maréchal, des principes de composition et de style hérités de l'Antiquité. Ces principes fondent un système, élaboré à partir du commentaire de Virgile par Ælius Donatus, et qui, dès le XIII ${ }^{\mathrm{e}}$ siècle, reçoit le nom de « roue de Virgile $\rangle^{14}$. Dans ce système qui préfigure notre classification en genres, la chronique correspondrait à l'éloquence épidictique, supposerait l'emploi d'un style élevé afin de narrer et aurait pour objet le miles dominans, seul digne d'intérêt pour le chroniqueur. Or, le chapitre 78 s'écarte de cette dernière règle en accordant à la dame un statut supérieur au chevalier qui se transforme non seulement en vassal de la dame - il s'agit là d'un topos de la littérature courtoise ${ }^{15}$ - mais également en spectateur de cette cour raffinée et oisive. Pero Niño rejoint alors à la fois l'auteur, Díaz de Games, vraisemblablement présent lors de ce séjour en France, et le lecteur perdu également dans la description de ce monde de délices. Car tout est écrit, ordonné pour susciter la delectatio depuis la description de la dame jusqu'à l'énumération des passe-temps de cette noblesse frivole. L'hyperbole est ainsi mise au service de la présentation de Madame de Sérifontaine dont il est dit :

\footnotetext{
${ }^{13}$ H. R. Jauss, «Littérature médiévale et théorie des genres », Poétique, 1, 1970, p. 79-101, voir p. 81-82.

${ }^{14}$ Sur cette question consulter G. Genette et T. Todorov, Théorie des genres, Paris, Seuil, 2000, p. 109 ainsi que E. R. Curtius, La littérature européenne et le Moyen Âge latin, Paris, PUF, 1956, p. 324.

${ }^{15}$ D. Boutet et A. Strubel, Littérature, politique et société dans la France du Moyen Âge, Paris, PUF (Littératures Modernes), 1979, p. 217.
} 
La femme de ce chevalier était la plus belle dame qu'il y eût alors en France. Fille $\mathrm{du}$ seigneur de Bellengues, elle appartenait à la plus grande maison et au plus haut lignage de la Normandie. On la louait fort pour des qualités qui étaient celles d'une grande dame. On la tenait pour très avisée et sachant mieux gouverner sa maison que n'importe quelle autre dame de cette province, et pour la mieux parée ${ }^{16}$.

L'écart est donc grand entre les principes qui régissent la chronique particulière et le chapitre étudié. Cependant, il serait faux de croire que cet écart se réduirait à la distance existant entre la biographie chevaleresque et le roman courtois. Le chapitre 78, s'il emprunte certains traits à la littérature courtoise, n'est pas une simple reprise de topiques et de procédés alors fort en vogue. Il innove et se joue des règles et par là même des genres. Ceci pose donc la question d'abord du contenu et, ensuite, de l'écriture du chapitre.

Les thèmes ou motifs développés, bien que divers, présentent une certaine cohérence. La laudatio du chevalier, en une sorte de glose du titre «Le Victorial», ouvre le chapitre; on lit en effet :

Chez Pero Niño, toutes les bonnes manières, les bons enseignements et la politesse lui venaient par nature et il en usa toujours tant qu'il vécût. Son renom vit encore aujourd'hui et continuera de vivre parmi les chevaliers et les nobles ${ }^{17}$.

Puis, sans transition, le narrateur reprend le récit historique pour situer le lieu et présenter en quelques phrases concises les personnages ; on lit : « Il y avait près de Rouen un noble chevalier appelé messire Renaud de Trie, amiral de France. [...] Il fit prier le capitaine Pero Niño de l'aller voir ${ }^{18}{ }^{18}$. Les mentions de dates, de lieux et la présentation sociale des personnages sont un passage obligé tant de la chronique que de la biographie chevaleresque. Ici ces références jouent le rôle de «toile de fond » car le narrateur, pratiquant l'amplificatio, développe ensuite le topos du locus amoenus; la nature, les éléments végétaux, l'eau sont décrits : «Devant la maison coulait une rivière au bord de laquelle il y avait des futaies et de gracieux jardins $»\rangle^{19}$. L'équivalence entre le domaine de l'Amiral, appelé par la suite domaine de Sérifontaine, et le lieu idyllique, protégé et clos, lieu des plaisirs entre amis, est par

\footnotetext{
${ }^{16}$ Vict., p. 231. "Este cavallero avía a su muger, la más fermosa dueña que entonce avía en Françia: hera de la mayor casa e linage que avia en Normandia, fija del señor de Belangas. Hera muy loada en todas las cosas que a grand señora pertenesçían, e tenida por muy sesuda e por de mejor regimiento que otra ninguna grand señora de las de aquella partida, e mejor guarnida », G. Díaz de Games, El Victorial..., p. 393.

17 Vict., p. 229-230. «A Pero Niño todas las buenas maneras e enseñanças e gentilezas le venían por natura, e sienpre usó dellas en quanto él bivió, e aún bive oy su fama, e bivirá entre los cavalleros e entre los nobles ». G. Díaz de Games, El Victorial..., p. 391.

${ }^{18}$ Vict., p. 230. "Hera çerca de Roán un noble cavallero que llamavan mosén Arnao de Tria, Almirante de Françia. [...] Enbió rogar al capitán Pero Niño que le fuese ver », G. Díaz de Games, El Victorial..., p. 391.

19 Vict., p. 230. "Pasava por delante de la casa un río, en que avía muchas arboledas, $e$ graçiosos jardines », G. Díaz de Games, El Victorial..., p. 392.
} 
ailleurs fondée sur les loisirs que pratiquent seigneurs et gentes dames. La chasse bien évidemment donne lieu à de longs développements et explications :

L'amiral avait quarante ou cinquante chiens pour chasser, et des hommes qui les soignaient. Il y avait là jusqu'à vingt montures pour sa personne: destriers, coursiers, bahagnons, hacquenées. Que vous dirai-je encore à propos de tous les approvisionnements, de toutes les commodités? Il y avait tout près, des bois dans lesquels on trouvait tous les gibiers, grands et petits: des cerfs, des daims, des sangliers (qui sont appelés chez nous jabalies). L'amiral avait pour chasser sur la rivière des faucons neblis, que les français appellent gentils, et qui sont excellents héronniers ${ }^{20}$.

Mais, du fait de la prééminence de la figure de la dame, la chasse se mue rapidement en une promenade courtoise :

Ensuite, Madame et ses damoiselles chevauchaient sur leurs haquenées, les mieux harnachées et les meilleures qui puissent être, et avec elles chevauchaient les chevaliers et les gentilshommes qui se trouvaient là. Ils allaient se promener un moment dans la campagne, faisant des chapelets de verdure ${ }^{21}$.

La journée des habitants de Sérifontaine est, dans ce lieu paradisiaque, une suite de plaisirs raffinés, la musique, le chant puis la danse occupant une place importante dans leur emploi du temps. Car c'est bien d'un emploi du temps dont il s'agit. Le narrateur qui s'exprime à la première personne, se donnant comme témoin et garantissant de ce fait la véracité de sa description, précise dès le début : "Je vais vous raconter ce qu'il en était de l'ordre et de la règle que la dame observait $\left.{ }^{22}\right\rangle$. L'insistance, signifiée par la redondance entre les deux termes «l'ordre» et «la règle », est d'autant plus forte que le texte se clôt par la phrase suivante : "Cet ordre que je vous ai dit s'observait tous les jours, suivant la saison, chaque fois que le capitaine et d'autres venaient, selon l'état des personnes $\left.{ }^{23}{ }^{2}\right)$. Les valeurs courtoises,

\footnotetext{
${ }^{20}$ Vict., p. 230-231. "E tenía quarenta o çinquenta canes, con que corría monte, e honbres que los pensavan. Él tenía alli fasta veynte cavalgaduras de su cuerpo, en qué avía destrieres, e cursieres, e bahañones, e facaneas. ¿ Qué más vos diré de todos los abastamientos e cunplimientos? Avía muy cerca de alli bosques en que avía de todos los venados grandes e pequeños. Avía en aquellos montes çiervos, e daynes, e sanglieres, que son xabalies. Él tenía de falcones neblís, que ellos llamman gentiles, para bolar la ribera, muy buenos garzeros ", G. Díaz de Games, El Victorial..., p. 392.

${ }^{21}$ Vict., p. 231. "Cavalgavan luego madama e sus damiselas en sus facaneas, las mejor guarnidas e mejores que ser podrían, e con ellas los cavalleros e gentiles-honbres que ende heran, e yvan a mirar un rato el canpo, faziendo chapeletes de verdura », G. Díaz de Games, El Victorial..., p. 393.

${ }^{22}$ Vict., p. 231. "Contarvos he la orden e la regla que la señora tenía », G. Díaz de Games, El Victorial..., p. 393.

${ }^{23}$ Vict., p. 233. "Esta hordenança que vos he dicho se tenía todos los días, en cada tienpo segund conviene, todas las vezes que el capitán alli venía, e otros, segund sus estados », G. Díaz de Games El Victorial..., p. 395.
} 
la largesse, l'oisiveté, la civilité et le raffinement des plaisirs, sont ainsi déclinés dans une vision figée, répétitive et immuable de la vie qui a cours à Sérifontaine. Le temps semble suspendu - on pourrait parler d'un arrêt sur image - notamment dans la dernière scène décrite, celle du ballet, où dames et chevaliers, se donnant en spectacle, virevoltent à l'envi.

Mais les motifs courtois ne sont pas les seuls à être affectés par ce cadrage ; en effet, sans doute en fonction du public castillan visé, l'accent est également mis sur les pratiques dévotionnelles de la dame dont il est dit que :

Le matin, après son lever, elle allait avec ses damoiselles à un bois qui était près de là, chacune avec un livre d'heures et un rosaire. Elles s'asseyaient à l'écart l'une de l'autre, disaient leurs heures et ne parlaient pas pendant qu'elles priaient. Ensuite cueillant fleurettes et violettes, elles revenaient au palais, allaient à la chapelle et entendaient une messe basse ${ }^{24}$.

L'étiquette, les cérémonies et les rites profanes ou religieux apparaissent alors comme autant de moyens mis en œuvre afin d'assurer la pérennité de ce monde courtois $^{25}$. Cependant, cette vision esthétisante est à considérer comme une réponse à des réalités moins amènes et comme un refus des contingences qui menacent l'harmonie décrite, la seule concession à cette idéalisation étant la mention réitérée de la vieillesse de l'amiral. On lit en effet dans la présentation du seigneur de Sérifontaine «Il était âgé », phrase suivie quelques lignes plus loin de : «L'amiral était un chevalier vieux et malade. Le temps passé sous les armes l'avait brisée ${ }^{26} »$. Cet indice est à lui seul révélateur des potentialités du texte, car au contenu courtois teinté de religiosité, s'ajoute, ou plus exactement se superpose un autre contenu, implicite, empreint d'érotisme. Car, entre les lignes certes, le narrateur laisse supposer à un lecteur averti une entente amoureuse entre Pero Niño et l'épouse de l'Amiral. Comment comprendre en effet la phrase «Le bon vieux chevalier ne pouvait plus chevaucher, mais il les recevait avec tant de bonne grâce que c'était merveille $\aleph^{27}$ lorsqu'on connaît les possibilités sémantiques du verbe «chevaucher»? Les délices évoqués tout au long du chapitre ne seraient alors que des préliminaires à la conquête charnelle de Madame de Sérifontaine. La fin du chapitre laisse d'ailleurs le lecteur dans le doute car, après le rappel du grand âge de l'Amiral et de la finitude de toute vie humaine, il est écrit que :

\footnotetext{
${ }^{24}$ Vict., p. 231. "Levantávase la señora de mañana, con sus damiselas, e yvase a un bosque que hera çerca dende, e cada una un libro de ora, e sus cuentas. E sentávanse apartadas, e rezavan sus oras, que non fablavan mote mientra que rezavan. E después, cogiendo floretas e violetas, ansí se venían al palaçio ; e yvan a su capilla, e oyan misa rezada », G. Díaz de Games, El Victorial..., p. 393.

${ }^{25}$ Consulter à ce propos D. Boutet et A. Strubel, Littérature, politique, op. cit., p. 214.

${ }^{26}$ Vict., p. 230. "El Almirante hera cavallero viejo e doliente; hera quebrantado de las armas », G. Díaz de GamesG. Díaz de Games, El Victorial..., p. 392.

${ }^{27}$ Vict., p. 230. «El buen cavallero viejo non podía ya cavalgar, e reçibiólos con tanta graçia que hera maravilla », G. Díaz de Games, El Victorial..., p. 394.
} 
Pero Niño fut tant aimé, en bonne part, de Madame pour la prud'homie qu'elle voyait en lui, qu'elle lui parlait déjà un peu de ses affaires et le pria d'aller voir son père, un noble chevalier appelé messire de Bellengues, qui vivait en Normandie. Pero Niño partit de là et s'en fut en Normandie. Dans tous les lieux où il passait, les chevaliers venaient le recevoir et lui faisaient beaucoup d'honneur, au bruit de sa renommée ${ }^{28}$.

Le chapitre oscille donc entre deux pôles et il revient au lecteur de donner sens à cette pluralité de motifs. Le texte est à la fois une peinture courtoise, conforme, quant au contenu, aux romans alors en vogue tant français qu'espagnols, et une biographie d'un chevalier qui se joue des codes courtois pour le plus grand bonheur du lecteur. Cette complexité se trouve tout entière signifiée dans le commentaire du narrateur qui est en même temps témoin : «Je vous dis que celui qui a vu cela voudrait que cela durât toujours. Il ne souhaiterait pas un autre paradis ${ }^{29} \gg$. À l'image du locus amoenus hérité de l'Antiquité se superpose celle de l'Eden chrétien. Toutefois, au $\mathrm{XV}^{\mathrm{e}}$ siècle, le mot «paradis » est à considérer dans toute sa polysémie car de quoi s'agit-il au juste: du paradis céleste et donc du lieu de la béatitude ou du paradis terrestre synonyme de gloire et des plaisirs sensuels? Le chapitre peut se clore, il n'en demeure pas moins ouvert en ce qui concerne son contenu.

Il reste à considérer l'écriture même du chapitre et à se poser la question de l'adéquation entre le contenu et la forme. Le chapitre 78 est, dans son entier, une description. Les moyens stylistiques en sont évidents, l'amplificatio et l'acumulatio qui permettent la réitération des motifs et le découpage de la journée à Sérifontaine, un lexique riche, des ellipses et des comparaisons, la topique de l'indicible et enfin, le recours systématique à l'imparfait, temps qui suppose la réalité décrite comme pérenne. Cette description interrompt la narration biographique- nous avons parlé précédemment d'un temps suspendu-; elle est longue et a comme fonction de séduire. Toute description tend à créer un effet de réel, surtout lorsque le narrateur, se donnant comme témoin de cette réalité, non seulement emploie le «je» mais, également, s'adresse par l'hypotypose directement au lecteur afin d'emporter son adhésion :

Vous auriez vu belle chasse et grand contentement ; vous auriez vu nager les chiens, battre les tambours et tourner les leurres, damoiselles et gentilshommes le long de cette rivière prenant tant de plaisir qu'on ne saurait le décrire ${ }^{30}$.

\footnotetext{
${ }^{28}$ Vict., p. 233. "E Pero Niño fue tan amado a buena parte de madama, por las bondades que el él veya, que fablava ella ya con él algo de su fazienda; e rogóle que fuese a ver a su padre, un noble cavallero que llamavan mosén de Belangas, que bivía en Normandía. Partió de alli Pero Niño, e fue a París. Por donde yva, le salian a resçebir los cavalleros, e le fazían muchas honras, oyendo la su fama », G. Díaz de Games, El Victorial..., p. 395.

${ }^{29}$ Vict., p. 232. "Yo vos digo que quien aquello vio querría que sienpre durase, non querría otra gloria », G. Díaz de Games, El Victorial..., p. 394.

${ }^{30}$ Vict., p. 232. "Alli veríades fermosa caça, e grand plazer, alli veríades nadar canes, $e$ tañer atanbores, e rodear señuelos, e damiselas e gentiles-honbres por aquella ribera, aviendo tanto plazer que se non podría dezir », G. Díaz de Games, El Victorial..., p. 394.
} 
L'intention de Díaz de Games est donc de montrer, de faire voir afin de convaincre. Mais que l'on ne s'y trompe pas, la description crée certes une réalité par sa fonction iconique, cependant, dans le cas du chapitre 78 , il s'agit d'une réalité fictionnelle, d'un réel et non du réel.

La description de la cour de Sérifontaine a un sens et, partant, une fonction diégétique : elle fait en effet progresser la narration des faits centrés sur la personne de Pero Niño. Celui-ci reçoit en quelque sorte par la grâce de Jeanne de Bellengues, épouse d'un Amiral de France, la reconnaissance sociale que sous-tend le code de la fin'amor. Le héros est alors hissé au niveau des plus grands nobles et peut, sans crainte, se rendre à Paris où il se distinguera, comme il se doit, lors des joutes et tournois. Le chapitre 78, qui n'est que description, n'est donc pas un ornement détachable du corps du texte ; il est à considérer comme un mode narratif original qui ordonne et infléchit l'œuvre dans son ensemble ${ }^{31}$.

Mais parler de description amène tout naturellement à réfléchir sur la notion d'ecphrasis ${ }^{32}$. À l'origine, dans la rhétorique antique, l'ecphrasis désigne toute description de personne, de faits, de lieux, de temps, capable de mettre avec évidence son objet devant les yeux de l'auditeur ou du lecteur. L'effet visuel de l'ecphrasis doit bouleverser le destinataire et déclencher l'empathie ${ }^{33}$.

Très rapidement, dès le $\mathrm{II}^{\mathrm{e}}$ siècle, l'œuvre d'art se constitue en objet privilégié de l'ecphrasis, en poésie comme en prose. Partant, la figure glisse de la pratique rhétorique vers la pratique littéraire. À la Renaissance, l'ecphrasis nourrit la prose sur l'art et l'on connaît la fortune du genre des Images ou Tableaux de peintures $^{34}$. Il y aurait donc connivence entre la peinture et la fiction ou, plus exactement entre la représentation picturale et la description romanesque. L'on peut alors considérer le chapitre 78 comme une peinture, surtout si l'on prend en compte

\footnotetext{
${ }^{31}$ L'idéalisation de Sérifontaine et de cet épisode amoureux est sans doute destinée à renforcer, outre le prestige du héros, la valeur du renoncement que réalise Pero Niño par la suite : rappelé par son roi, il rendra sa parole à Mme de Sérifontaine. Voir à ce propos M. Pardo, «Biographie et élaboration romanesque : un épisode du Victorial », L'historien et ses personnages. Études sur l'historiographie espagnole médiévale, Cahiers d'études hispaniques médiévales, Annexe 17, ENS Éditions, 2006, p.115-133; du même auteur, « Noblesse et monarchie dans les chroniques biographiques », L'historien et ses personnages, op. cit., p. 175-233, et Antonio Giménez, «El arquetipo del caballero en la crónica de don Pero Niño », Cuadernos Hispanoamericanos, Madrid, juillet 1977, 109, p. 338-352.

${ }^{32}$ Littéralement «exposition faite tout au long ». L'ecphrasis est une figure facile à identifier grâce à son étendue, sa relative autonomie et l'unité que lui confère l'objet auquel elle est en principe dévouée. Voir à ce propos L'inscription du regard. Moyen Âge-Renaissance, Textes réunis par M. Gally et M. Jourde, Fontenay-Saint-Cloud, E. N. S. Éditions, 1995.

${ }^{33}$ Consulter sur cette notion A.-E. Spiga, Savoir peindre en littérature. La description dans le roman au XVII siècle. Georges et Madeleine de Scudéry, Paris, H. Champion (Lumière Classique), 2002.

${ }^{34}$ Voir notamment la traduction de 1597 des Eikones de Philostrate de Lemnos par Blaise de Vinegère, Images ou Tableaux de platte peinture. Consulter également Le défi de l'art. Philostrate, Callistrate et l'image sophistique, textes réunis par M. Constantini, F. Graziani et S. Rolet, Rennes, Presses Universitaires, 2006.
} 
les moyens stylistiques et linguistiques mis en œuvre par Díaz de Games pour créer des effets de visibilité. Ces pages sont d'abord à considérer comme une métaphore lexicalisée, car c'est bien de la peinture d'un personnage et d'un monde dont il s'agit, dans un style tendant vers le naturel, «l'ordre» et privilégiant l'ellipse et le topos de l'indicible. Cette stratégie d'écriture est d'autant plus forte que le narrateur se donne comme témoin - il a vu - et incite le lecteur à imaginer le spectacle décrit ; il n'est que de se rappeler la citation précédente pour s'en persuader : « Vous auriez vu belle chasse... $\|^{35}$ Le lecteur voit alors ce que veut lui faire voir le narrateur, son statut intra-diégétique restreignant le point de vue et agençant le texte en une succession d'images ou de tableaux, chacun correspondant à un moment de la journée passée à Sérifontaine.

Manquerait alors dans ce « livre d'heures courtois » la référence à des œuvres d'art, antiques de préférence, pour que l'ecphrasis soit parachevée. Mais en est-il vraiment ainsi ? Ces scènes courtoises empreintes de sensualité renvoient, selon moi, à une doctrine sur les sens, héritée de l'Antiquité, qui connaît, à la Renaissance, un succès certain, sans doute en raison de l'influence romanesque, et dont la manifestation dans les arts la plus connue reste la Tapisserie de La Dame à la licorne, aujourd'hui au Musée de Cluny ${ }^{36}$. Ces six pièces forment par la conception d'ensemble un tout, c'est-à-dire, ce que l'on nomme communément une tenture, chaque tapisserie mettant en scène un des sens. Cette interprétation, même si elle fait toujours débat, ne peut être remise en cause, notamment en raison du caractère explicite des scènes, du rapprochement avec certains textes médiévaux et du parallèle avec les représentations des cinq sens au tournant du $\mathrm{XV}^{\mathrm{e}}$ au $\mathrm{XVI}^{\mathrm{e}}$ siècle $^{37}$.

Les tapisseries de la Dame à la licorne s'ordonnent selon une hiérarchie prenant en compte l'honorabilité de chaque sens, c'est-à-dire leur proximité plus ou moins grande avec l'âme; on aurait ainsi une progression à partir du Toucher, puis l'Odorat, qui se poursuit avec le Goût, l'Ouïe et enfin la Vue ${ }^{38}$. Durant l'Antiquité, la prééminence revient à la $\mathrm{Vue}^{39}$. Ainsi Horace dans son Art poétique écrit-il : « $\mathrm{Ce}$ que l'esprit reçoit par les oreilles le stimule moins vivement que ce qui apparaît aux yeux, et ce que le spectateur peut voir et croire par lui-même $\mathrm{e}^{40} »$, tandis que le

\footnotetext{
${ }^{35}$ Vict., p. 232. " Allí veríades fermosa caça », G. Díaz de Games, El Victorial..., p. 394.

${ }^{36}$ Consulter à ce propos E. Delahaye, La Dame à la licorne, Paris, Musée de Cluny-Musée National du Moyen Âge, 2007.

${ }^{37}$ Consulter K. E. Gourlay, «La Tenture de la Dame à la licorne : a Reinterpretation», Gazette des Beaux-Arts, sept. 1997, p. 47-71 et E. Bruel, «Les tapisseries de la Dame à la licorne, une représentation des vertus allégoriques du Roman de la Rose », Gazette des BeauxArts, déc. 2000, p. 215-232. Parmi les représentations des cinq sens, citons les gravures illustrant l'édition princeps des Stultiferae naves ou «nefs des folles ", supplément à La Nef des fous de Sébastien Brandt (1494) œuvre rédigée par Josse Bade, ainsi qu'une autre tenture de six pièces dénommée Los Sentidos, achetée en 1539 par Mencía de Mendoza, cités par E. Delahaye, La Dame, op. cit., p. 43-44.

${ }^{38}$ Sur les cinq sens consulter M. Serres, Les cinq sens, Paris, B. Grasset, 1985.

${ }^{39}$ Cette idée est énoncée notamment par Platon : «La vue est pour nous, à mon sens, la cause du plus grand bien... », Platon, Timée, 47a, trad. de É. Chambry, Paris, Garnier Flammarion, 1969 , p. 425.

${ }^{40}$ Horace, Ars poetica, vers 180-182.
} 
christianisme, religion du Verbe, considère l'Ouïe comme supérieure puisque agent de la Révélation ${ }^{41}$. Au $X V^{\mathrm{e}}$ siècle, l'Ouïe et la Vue se trouvent de fait en concurrence.

Le chapitre 78, grâce au découpage de la journée selon le rituel courtois et au recours à l'ecphrasis, peut être considéré comme une succession de Tableaux des cinq sens. Les premiers paragraphes plantent le décor enchanteur et si la Vue est la plus sollicitée, l'Ouïe n'est pas oubliée. Ne lit-on pas « Il y avait là des ménestrels et un trompette qui jouait merveilleusement de son instrument ${ }^{42} \gg$, et, plus loin, dans les lignes consacrées aux promenades dans la campagne « Là, on entendait chanter par des voix diverses et très bien accordées, des lais, virelais, chants, rondeaux, complaintes, balades, chansons du répertoire des Françaiis ${ }^{43} \gg$ ?

À ces délices s'ajoutent les descriptions des collations et des festins qui sont autant d'illustrations du Goût; ainsi les dames se restaurent après avoir dit leurs prières :

En sortant de la chapelle, elles prenaient un plat d'argent sur lequel il y avait des poules, des alouettes et d'autres oiseaux rôtis et elles en mangeaient ce qu'elles voulaient pour leur déjeuner et on leur donnait du $\operatorname{vin}^{44}$.

À midi, tous, gentilshommes et gentes dames se retrouvent :

S'asseyaient à la table l'Amiral, Madame et Pero Niño. Le maitre d'hôtel présidait l'autre table et faisait asseoir l'un à côté de l'autre un chevalier ou un écuyer et une damoiselle. Les mets, très variés, en grand nombre, et fort bien apprêtés, se composaient de viandes, poissons et fruits suivant le jour que c'était ${ }^{45}$.

http : / /www.mediterranees.net /litterature /horace /pisons.html

${ }^{41}$ Saint Ambroise écrit en effet : «La fonction de l'ouie est la plus éminente et son agrément surpasse celui de la vue », saint Ambroise, Hexaemeron, VI-IX, 55, Patrologie Latine, t. XIV, col. 268, p. 146. Consulter à ce propos Par la vue et par l'oüe. Littérature du Moyen Âge et de la Renaissance, textes réunis par M. Gally et M. Jourde, Fontenay-Saint-Cloud, E. N. S. Éditions, 1999, voir l'introduction p. 9-21.

${ }^{42}$ Vict., p. 230. "Avía alli menestrieres, e tronpeta que tocava de bantaja ", G. Díaz de Games, El Victorial..., p. 394

${ }^{43}$ Vict., p. 231-232. "Alli oya honbre cantar lays, e delays, e virolays, e chazas, e reondelas, e conplayntas, e baladas, chanzones de toda el arte que trovan los franceses », G. Díaz de Games, El Victorial..., p. 393-394.

${ }^{44}$ Vict., p. 231. «E saliendo de la capilla, trayan un tajador de plata, en qué venían gallinas, e aluetas, e otras aves asadas, e comían e dejunavan los que querían, e dávanles vino ", G. Díaz de Games, El Victorial..., p. 393.»

${ }^{45}$ Vict., p. 232. "Sentávase a la tabla el Almirante, e madama, e Pero Niño. E el maestre de la sala hordenava la otra tabla, e fazía sentar un cavallero, e una damisela, o un escudero; ansí estavan cada uno. Los manjares, muy diversos e muchos, e de muchos muy buenos adobos, de todas las viandas de carnes, e pescados, e frutas, segund el dia que hera", G. Díaz de Games, El Victorial..., p. 394. 
Le soir, la même scène se répète, prouvant que la largesse et l'abondance règnent à Sérifontaine dans un décor enchanteur où les fragrances florales ravissent l'Odorat et où le Toucher est convoqué non seulement à travers la mention des étoffes des costumes et des frôlements que suppose la danse, mais surtout à travers le baiser de paix que Madame de Sérifontaine accorde au chevalier castillan.

Il reste, enfin, à considérer le chapitre 78 dans son ensemble, car au-delà de l'entrelacement des motifs, des influences stylistiques diverses et des références picturales, ces pages conservent, malgré tout, une cohérence certaine. Quelle lecture prévaut donc? Les cinq sens sont, on le sait, subordonnés au Moyen Âge à un sixième sens, le cœur, qui peut être tout à la fois le siège de la vie morale, la source du libre arbitre et le siège de la passion, du désir charnel ${ }^{46}$. En accord avec cette double conception, la Tenture de la Dame à la licorne comprend une sixième tapisserie intitulée «À mon seul désir» et les critiques débattent encore au sujet de l'interprétation qu'il convient de donner au mot « désir ${ }^{47} »$. L'ambiguïté serait donc de mise et à chacun, spectateur avisé, reviendrait la tâche d'accorder un sens, religieux ou profane à cette tapisserie.

Cette remarque vaut, me semble-t-il, pour le chapitre 78 que nous avons qualifié précédemment de «texte ouvert». Il est en effet peu vraisemblable que le message contenu dans cette description de la cour de Sérifontaine soit univoque. Le chapitre serait ainsi révélateur d'une double tendance de la culture de ces nobles lettrés tant français que castillans, culture profane, d'une part, nourrie de références littéraires et artistiques, la plupart provenant de l'Antiquité, et culture cléricale à portée didactique d'autre part ${ }^{48}$. Les pages étudiées, sorte de variation sur le thème des cinq sens, seraient ainsi au service de l'esthétique courtoise mais il s'agirait d'une esthétique courtoise contrôlée, dans une certaine mesure, par la morale chrétienne, confortée elle-même par la finalité de l'ouvrage, à son tour pré-établie par le genre auquel appartient le Victorial, faire l'éloge d'un chevalier.

La chronique de Pero Niño, écrite par Díaz de Games vers les années 1440, doit donc être considérée comme un creuset, un lieu de confluences littéraires, d'où émerge par moments ce qui sera la prose romanesque et qui, à une époque ultérieure, prendra la forme du roman sentimental, puis du roman pastoral pour déboucher ensuite, sous la plume de Cervantès, sur le roman moderne. L'appartenance du Victorial au genre de la biographie chevaleresque reste cependant relativement contraignante. La meilleure preuve de cela ne réside-t-elle pas dans la brièveté et l'originalité même du chapitre 78 qui n'est qu'une parenthèse enchantée dans un récit résolument historiographique ? La notion d'horizon d'attente telle que la définit Hans Robert Jauss ne peut certes être remise en question. Toutefois les attentes d'un lecteur ne peuvent se réduire à la connaissance du genre car, s'il lui faut connaître

\footnotetext{
${ }^{46}$ Saint Augustin, dans le dixième livre des Confessions, cherche à établir une relation stable entre les plaisirs que procurent les sens et la vérité qui réside en Dieu seul, saint Augustin, Confessions, X, 33, trad. de J. Trabucco, Paris, Garnier Flammarion, p. 237.

${ }^{47}$ E. Delahaye, La Dame, op. cit., p. 48.

${ }^{48}$ Voir à ce sujet Écriture et modes de pensée au Moyen Âge. $V I I I^{e}-X V^{e}$ siècle, textes réunis par D. Boutet et L. Harf-Lancner, Paris, Presses de l'École Normale Supérieure, 1993 ; ainsi que D. Boutet, Formes littéraires et conscience historique. Aux origines de la littérature française 1100-1250, Paris, PUF (Moyen Âge), 1999.
} 
les règles thématiques et formelles lui permettant une lecture appréciative, il désire avant tout être surpris, interpellé et/ou séduit, sinon à quoi bon lire ? L'on peut donc conclure que si, au Moyen Âge comme à toutes les époques, le genre est nécessaire, l'écart ou les écarts ${ }^{49}$ le sont aussi et qu'il n'y a pas de création littéraire ou artistique sans écart(s) par rapport au genre. Le genre ne serait alors qu'un préalable ou, plutôt, une connivence entre l'auteur et le lecteur.

Ghislaine Fournès Université Michel de Montaigne-Bordeaux 3

${ }^{49}$ Sur la notion d'écart en littérature, consulter H. R. Jauss, «Littérature médiéval, art. cit., p. 81 ; et, du même auteur, Pour une Esthétique, op. cit., p. 52-54. 



\title{
酶M
}

\section{Entre encyclopédie et récit : dans la mouvance du Roman de la Rose, le Livre des Échecs amoureux d'Evrart de Conty}

\begin{abstract}
The fact the Livre des Échecs amoureux cannot be reduced to a specific genre, can be explained by Evrart de Conty's intention to compose a poetic work. His text can be considered as a microcosm that encompasses encyclopedic knowledge, philosophic, mythographic, and literary traditions. The analogy with the macrocosm is based on the musical harmony ruling over all aspects of creation. The musical metaphor is central for the interpretation of a work composed by an author who sees himself as a poet as well as a commentator.
\end{abstract}

Résumé: Si le Livre des Échecs amoureux ne se laisse réduire à aucun genre particulier, c'est dans la mesure où Evrart de Conty a souhaité faire ouvre poétique. Son texte se présente comme une sorte de microcosme qui englobe savoir encyclopédique, traditions philosophique et mythographique, mais aussi littéraires. L'analogie avec le macrocosme se fonde sur la recherche de l'«harmonie musicale» qui préside à tous les aspects de la création. La métaphore musicale est centrale pour la compréhension de cette ouvre dont l'auteur se veut autant poète que glossateur.

La prémisse aux réflexions qui vont suivre est la remarque, plusieurs fois répétée par Françoise Guichard-Tesson dans son travail sur le Livre (ou la Glose) des Échecs amoureux, que le commentaire d'Evrart de Conty au poème des Échecs amoureux ne se laisse pas réduire à un genre particulier ${ }^{1}$. Dans la mesure où Evrart juxtapose des sources diverses dont il ne tente pas de faire la synthèse, aucune intention dominante ne se dégage véritablement, même sur des questions morales comme, par exemple, le privilège que, dans une optique chrétienne, on devrait accorder à la vie contemplative sur les vies active et voluptueuse. Sa position fluctue au gré des épisodes qu'il commente et des sources qu'il utilise pour cela. Les contradictions apparentes s'expliquent par le recours aux multiples traditions sollicitées dans cette glose d'une œuvre poétique qui se situe elle-même à la convergence du poétique, du narratif et de l'encyclopédique, d'autant plus que le poème s'inscrit dans la continuité du Roman de la Rose, cette œuvre speculum qui a tenté la synthèse de ces traditions et des discours qui leur sont propres. Dans le Livre des Échecs amoureux (que je désignerai par le terme de Glose), convergent la littérature courtoise, l'héritage philosophique de l'aristotélisme, celui du christianisme, la tradition mythographique, le savoir encyclopédique, notamment lorsqu'il est question de présenter les sept arts, mais aussi celui que véhiculent bestiaires et lapidaires.

\footnotetext{
${ }^{1}$ Cette affirmation est répétée à plusieurs reprises dans sa thèse : F. Guichard-Tesson, $L a$ Glose des échecs amoureux d'Evrart de Conty: les idées et le genre de l'œuvre d'après le commentaire du verger de Déduit, [Montréal,] Université de Montréal, 1980, p. xi, 465, 468.
}

Cahiers de Recherches Médiévales, 18, 2009 
Bien qu'Evrart prétende avoir pour intention de «declairier aucunes choses que la rime contient qui semblent estre obscures et estranges de prime face », la majeure partie de la Glose ne présente qu'un lien assez lâche avec les Échecs amoureux dont elle ne commente que le début et qu'elle ne suit pas de façon linéaire, ne retenant qu'un certain nombre d'épisodes ou de détails ${ }^{2}$. Après un bref prologue où il présente le poème qu'il a l'intention de commenter, Evrart propose une première moralisation du jeu d'échecs comme métaphore de la société civile, de la stratégie militaire et des conflits amoureux qui ont tant en commun avec la guerre. Suivront cinq sections relativement autonomes. La première, où l'acteur se met en route avec Fortune et Nature vers le verger de Déduit, offre le prétexte à des développements sur les quatre éléments et le cosmos, mais également à des considérations d'ordre moral à propos du choix à faire entre Raison et Sensualité. La Glose reprend ensuite au poème le scénario de rencontre avec Mercure et les trois déesses, Pallas, Junon et Vénus, ainsi que la requête faite à l' «acteur» de donner son opinion sur le jugement de Pâris. L'épisode se prête à la présentation et moralisation des figures de seize dieux, de Saturne à Esculape, coupée d'une ample digression justifiée par l'exposition des neuf muses qui accompagnent la figure d'Apollon. On se trouve donc en présence d'une revue des sept arts d'où ressortent les longues explications portant sur l'astronomie et la musique, deux sciences, avec l'arithmétique, dont nous constaterons l'importance dans l'économie de la Glose et son interprétation. Le trajet vers le verger de Déduit se poursuit avec les commentaires positifs de Vénus et négatifs de Diane à propos du jugement de Pâris et les considérations d'ordre moral auxquels ils donnent lieu sur la valeur des trois modes de vie : contemplative, active et voluptueuse. Nous entrons ensuite au verger dont la découverte inspire des commentaires sur les diverses figures allégoriques reprises au Roman de la Rose et dont chacune permet les digressions les plus diverses. Le texte se clôt avec la présentation moralisée de l'échiquier, des pièces et de la partie qui se terminera par la victoire de la dame.

On comprend d'emblée que, du fait de s'appuyer sur deux œuvres littéraires profanes telles que le Roman de la Rose et les Échecs amoureux, Evrart confère à la Glose une dimension narrative et poétique qui est à prendre en compte parallèlement au caractère encyclopédique qui semble la définir à première vue. Autrement dit, si ce texte ne se laisse pas réduire à un genre particulier, c'est qu'il faut non seulement le considérer comme un commentaire, un traité mythographique et une encyclopédie, mais aussi comme une œuvre poétique. Je pense même, et c'est ce que je me propose de montrer, que si la Glose possède une cohérence qu'on ne peut trouver ni dans l'expression d'un point de vue, ni dans l'articulation des éléments qui frappent par leur disparate, elle se révèle dans la volonté affichée par Evrart de faire œuvre poétique. Le recours à la prose, tel qu'il le justifie, traduit sa volonté de s'en servir à la fois comme un outil d'explicitation et comme un instrument d'expression dont l'harmonie peut se mesurer à celle des vers. Certes, il l'utilise parce que «prose est plus clere a entendre que n'est rime», mais aussi parce que,

\footnotetext{
${ }^{2}$ Evrart de Conty, Le Livre des Eschez amoureux moralisés, éd. F. Guichard-Tesson et B. Roy, Montréal, Ceres, 1993, p. 2. F. Guichard-Tesson, La Glose des échecs amoureux d'Evrart de Conty, op. cit. : la Glose ne commente que l'équivalent des 27 premiers folios du ms de Dresde qui en a 144 (p. 86).
} 
affirme-t-il, «il ne doit mie toutesfoiz estre oublié que musique n'est pas tant seulement trouvee es rimes et es mectres, ainz est aussi trouvee en paroles mesmes qui sont mises es proses ${ }^{3} »$. Cela me conduira, après une rapide présentation de la Glose dans ses aspects didactiques, à traiter de cette dimension poétique pour essayer de définir, en conclusion, le travail d'écriture d'Evrart.

On serait tenté, à propos de l'intention explicite d'Evrart de Conty de «déclairier» les choses obscures du «livre rimé», de se demander s'il s'agit bien d'un commentaire. Au-delà de la boutade, on doit bien constater, comme je l'ai indiqué plus haut, que le poème des Échecs sert plus de référence mémorielle que de support à une explicitation fidèle à son déroulement. Si le poème est suivi de façon systématique jusqu'au folio 25 et très présent dans la section sur le verger de Déduit, de nombreuses et substantielles digressions permettent à la Glose de s'émanciper. Ainsi l'exposition des figures des dieux offre l'occasion du développement sur les sept arts libéraux et celle du jeu d'échecs se gonfle en cinquante folios qui correspondent à une rapide description occupant moins de 300 vers dans le poème $\mathrm{e}^{4}$. D'autre part, il ne faut pas s'attendre à y trouver un décryptage des sens sur le modèle exégétique de l'explication littérale et de la mise en évidence des diverses significations allégoriques. L'approche d'Evrart dans la Glose corrobore les utiles remarques d'Armand Strubel dans son ouvrage sur l'allégorie et la littérature au Moyen Âge, lorsqu'il met en garde contre le fait de succomber «à la tentation d'un rapprochement entre des traités d'herméneutique scripturale et les œuvres littéraires $»^{5}$. On chercherait en vain une interprétation religieuse dans la Glose qui, sans s'interdire des considérations morales chrétiennes, les met en perspective avec des points de vue dictés par les exigences de la loi naturelle. Ainsi, la moralisation de Diane, la déesse vierge, tempère l'éloge de la vie chaste par la constatation que l'extrême abstinence serait cause de la fin de l'espèce humaine ${ }^{6}$. En fidèle aristotélicien, Evrart prône la vertu du juste milieu et s'en remet aux théologiens «qui a leur voulenté en détermineront».

Que la perspective théologique ne soit pas la sienne, on peut en trouver un indice manifeste dans le peu d'espace consacré à cette discipline dans l'exposé des sciences attachées aux neuf muses qui entourent Apollon. Une page de l'édition est occupée par la théologie pour affirmer qu'elle dépasse toutes les sciences humaines, et une à la métaphysique qui, dit-il, précède en dignité et en perfection les autres parties de la philosophie ${ }^{8}$. La justification que donne Evrart pour le silence sur deux sciences aussi hautes, circonscrit les limites génériques de son entreprise : «ce sont choses fortes a comprendre et estranges, qui aussi ne sont pas bien seans en françois

\footnotetext{
${ }^{3}$ Evrart de Conty, Le Livre des Eschez amoureux moralisés, op. cit., p. 2, 173.

${ }^{4}$ F. Guichard-Tesson, La Glose des échecs amoureux d'Evrart de Conty, op. cit., p. 92. Les gloses marginales, sans doute d'un autre manuscrit que celui de Venise, fournissent l'essentiel du commentaire sur cette partie (Ibid., p. 93, 98.

${ }^{5}$ A. Strubel, « Grant senefiance $a »$ : allégorie et littérature au Moyen Âge, Paris, Champion, 2003, p. 53.

${ }^{6}$ Evrart de Conty, Le Livre des Eschez amoureux moralisés, op. cit., p. 376.

${ }^{7}$ Ibid., p. 377.

${ }^{8}$ Ibid., p. $230-32$.
} 
pour la plus grant partie $»{ }^{9}$. Il s'en tient donc à la raison naturelle, ce qui ne signifie pas pour autant que, malgré la prédominance de la pensée aristotélicienne et des références à Aristote, il se pose en philosophe ${ }^{10}$. Plus qu'un commentaire qui énoncerait les perspectives propres à son auteur, la Glose se présente à cet égard comme l'un de ces florilèges où il a puisé, par exemple le Manipulus Florum de Thomas d'Irlande ou les Auctoritates Aristotelis ${ }^{11}$. En établissant la lignée des emprunts ou des échos possibles (le De regimine principum de Gilles de Rome, 1'Architrenius de Jean de Hauville, Pierre Bersuire, Alain de Lille), F. GuichardTesson constate qu'il n'y a rien dans les idées exprimées qui ne soit familier à tout lettré de la fin du Moyen $\hat{A} g \mathrm{e}^{12}$. La même observation s'applique à la partie mythographique de la Glose, la moralisation sur les figures des dieux. Le modèle de l'allégorie énumérative permet de proposer une revue de la diversité des significations que peut évoquer chaque dieu. On se trouve ainsi face à une matière considérable, à une succession de petits traités où chacun est à prendre pour luimême car ils ne s'accordent pas nécessairement entre eux. Ceci correspond à la démarche encyclopédique d'Evrart telle qu'il l'explicite :

Et a la verité, les fabuleuses narracions des poetes, quant a toutes leurs clauses, ne sont pas ramenables a tous propos, maiz aucunes a un sens et aucunes a un autre, pour l'equivocacion des noms des dieux qui en pluseurs significacions sont pris $^{13}$.

Sa méthode de travail, son approche de l'allégorie s'apparentent à cet égard à celle qui a été observée pour l'Ovide moralisé, notamment par Ana Pairet: «Il ne s'agit pas d'extraire de la fable un sens caché, mais au contraire de l'envelopper dans les replis du commentaire $\rangle^{14}$. En procédant par associations d'idées, par analogie, par dérivation métonymique ou par synecdoque, on accumule les sens possibles ${ }^{15}$.

Il semble que ce soit dans la tentation de tout exposer, de présenter la richesse du monde et de la pensée que se situe précisément la vision personnelle d'Evrart de Conty. La cohérence qu'on cherche en vain dans l'affirmation d'un point de vue moral ou philosophique ne peut que frapper lorsqu'on constate comment il développe la métaphore de la correspondance entre le microcosme et le macrocosme. Il s'approprie cette notion peu originale pour en faire le modèle même de son texte, en fait de tout travail créateur, selon un strict principe d'analogies. Si

\footnotetext{
${ }^{9}$ Ibid., p. 230.

${ }^{10}$ Sur la prépondérance d'Aristote, voir F. Guichard-Tesson, La Glose des échecs amoureux d'Evrart de Conty, op. cit., p. 251, 287.

${ }^{11}$ Ibid., p. 369 pour le recours au Manipulus florum; p. 289 pour les emprunts possibles aux Auctoritates Aristotelis.

${ }^{12}$ F. Guichard-Tesson, La Glose des échecs amoureux d'Evrart de Conty, op. cit., p. 135.

${ }^{13}$ Evrart de Conty, Le Livre des Eschez amoureux moralisés, op. cit., p. 79.

${ }^{14}$ A. Pairet, Les Mutacions des fables. Figures de la métamorphose dans la littérature française du Moyen Âge, Paris, Champion, 2002, p. 117.

${ }_{15}$ Ibid., p. 117 ; M. Possamaï-Pérez, L'«Ovide moralisé ». Essai d'interprétation, Paris, Champion, 2006, p. 348.
} 
«art est singesse de nature», on peut dire en retour que celle-ci œuvre comme l'artiste, car le ciel et son influence agissent grâce à la lumière des étoiles « qui sont aussi come ly instrument par lesquelz le ciel euvre, en la maniere que la penne est instrument de cellui qui escript ou le pincel du paintre $»^{16}$. Cet énoncé est parfaitement permutable, car une «chaîne dorée » va de l'ordonnance des planètes à celle qui préside à la création artistique :

Car tout aussi que la doloire du charpentier ou le pincel du paintre se meut a la similitude de la main qui l'adresce, et la main se remeut a la similitude de la fantasie, et la fantasie oultre aussi a la similitude de la figure ou de la forme que le ouvrier principal y entend, tout aussi les quatre elemens, le ciel et les estoilles et les intelligences dessusdites, qui ordeneement se entreenssuient tousdis, se meuvent a l'example et a la similitude des ydees et des formes qui sont en la pensee divine. Et c'est ce que aucuns anciens soloient appeller la chayenne doree ${ }^{17}$.

Certes, c'est Dieu qui est la cause efficiente de toute chose et la source de vie. Mais «c'est la main et la doloire après ou le pincel, qui la chose parfait en la vertu des choses devant dites $\gg{ }^{18}$. C'est en cela, je pense, qu'Evrart se veut poète, pour traduire la beauté et l'harmonie de la Nature, en s'appuyant sur le fait que cette beauté et cette harmonie sont fondées sur la science des nombres.

On comprend alors l'importance qu'il a accordée à la musique et à l'astronomie dans sa présentation des sept arts qui eux-mêmes prennent appui sur la première des disciplines du quadrivium, l'arithmétique. Tout dans l'univers traduit l'harmonie des nombres qui régit la création dans tous ses aspects. La figure d'Apollon préside à l'exposé des arts du quadrivium parce qu'elle peut être « exposee a la lectre du soleil », lui qui gouverne l'harmonie des sphères, ainsi que le déroulement du temps ${ }^{19}$. Les mouvements des planètes se font «par musical mesure », d'où découle le principe unificateur de la Glose, le fait que tous les aspects de la nature et des œuvres humaines font preuve d'harmonie musicale ${ }^{20}$. C'est ainsi qu'Evrart explique sa compréhension de l'analogie entre le microcosme et le macrocosme. La «mesure musicale», pour employer son expression, se trouve dans la composition du corps humain :

Pour ceste cause est il a presumer, selon les philosophes anciens dessusdiz, que s'il y a, en cest monde terrestre, complexion ou les elements soient bien proporcioné et bien meslé ensemble par la sutille mesure musical dessusdite, ce doit par raison estre en creature humaine, car autrement ilz ne peussent croire que les .iiij. elemens se

\footnotetext{
${ }^{16}$ Evrart de Conty, Le Livre des Eschez amoureux moralisés, op. cit., p. 134, 132.

${ }^{17}$ Ibid., p. 27. La métaphore de la catena aurea venue d'Homère et exploitée par les Stoïciens, passe au Moyen Âge par le Commentaire au Songe de Scipion de Macrobe. Dans le Roman de la Rose, Nature évoque «La bele chaienne dorée / Qui les .iiij. elemenz enlace » ( v. 1978992).

${ }^{18}$ Ibid., p. 27.

${ }^{19}$ Ibid., p. 86.

${ }^{20}$ Ibid., p. $174-89$.
} 
peussent entreacorder ensemble, s'ilz ne feussent ainsy joint et meslé ensemble par musical mesure ${ }^{21}$.

Avec la volonté d'exhaustivité qui le caractérise, Evrart multiplie les preuves de l'universalité de la musique qu'il fonde sur l'exposé précis des proportions et des intervalles musicaux, le plus parfait étant celui de diapason ou double : « la meilleur consonancie et la plus doulce qui puisse estre et en laquelle les sons mielx se conforment $»^{22}$.

Comme on l'a déjà dit, il procède par association d'idées. Il commence par montrer que la proportion musicale se trouve chez l'enfant dans le ventre de sa mère en fonction des trois périodes qui sont celles de la formation de son corps, de la perfection de ses mouvements et du moment où il est arrivé à maturité pour naître. Puis il renvoie à Galien qui affirme que les battements du pouls se font selon des proportions musicales. D'ailleurs, dit-il ensuite, l'harmonie entre l'homme et la femme correspond à l'accord de diapason. Les proportions musicales se trouvent aussi dans les couleurs, les odeurs, les saveurs. Si l'art imite la nature, c'est dans la mesure où l'œuvre témoigne de ces proportions qui régissent tous les aspects de la création: " art qui enssuit nature devroit ses choses faire par telles proporcions, se elle s'en avisoit, et sy fait elle espoir en pluseurs de ses œuvres qui se moustrent bien faites et plaisans a veoir $»^{23}$.

Le plaisir que procure l'éloquence vient du respect de l'harmonie musicale :

La fleute oultre après que Mercures portoit segnefie la delectacion et la plaisance que ly escoutant prendent en la bele parole, quant elle est bien ordenee a son droit, laquelle delectacion n'est pas mendre de celle que les consonancies musicaulx font a l'ame, ainz samble encor plus grande, car avec ce que la bele parole rethorique atrait les cuers de bon entendement et les esmeut a delectacion come les musicaulx consonancies font, desquelles Aristote dit que l'ame humaine naturelment en elles se delite, y a il oultre une plaisant sentence es paroles comprise, qui font secondement l'entendement grandement delivrer ${ }^{24}$.

Or comme on l'a vu plus haut, la musique se trouve aussi dans la prose, par seulement dans les vers. Toutefois, s'il y a une harmonie à trouver dans la Glose, elle ne réside pas nécessairement dans la recherche des proportions entre les parties comme en témoigne la place démesurée occupée par l'astronomie et la musique (dix folios pour la première et trente pour la seconde) par rapport aux autres sciences rapidement évoquées ${ }^{25}$. Dans la Glose, l'harmonie tient de la tentative de globalisation, de l'effet de microcosme produit par le texte, effet qui est créé aussi

\footnotetext{
${ }^{21}$ Ibid., p. 164.

${ }^{22}$ Ibid., p. 602.

${ }^{23}$ Ibid., p. 189.

${ }^{24}$ Ibid., p. 254.

${ }^{25}$ On trouvera une édition de cette section dans Reginald Hyatte et Maryse Ponchard-Hyatte, L'Harmonie des sphères. Encyclopédie d'astronomie et de musique extraite du commentaire des "Échecs amoureux », New York, Peter Lang, 1985.
} 
bien dans les détails des explications que dans ce qui a trait au genre des œuvres convoquées.

On observe à cet égard, concernant les genres de la littérature vernaculaire auxquels renvoie la Glose, la même impression de se trouver face à un florilège que dans les développements didactiques avec leurs abondantes séries de références aux autorités. Elle est particulièrement nette dans la section sur les figures des dieux qui suit immédiatement la présentation de Nature, au début du texte. Parfois les fables selon le terme utilisé par Evrart - servent d'illustration ou plus précisément de démonstration pour une idée qui vient d'être exposée. Ainsi trois récits soulignent l'importance de naître sous de bons auspices : celui de l'essaim d'abeilles qui vint se poser sur la tête de Platon et repartit sans le piquer, signe qu'il serait un grand philosophe; le rêve prémonitoire que fit Socrate la veille du jour où le père de Platon conduisit son fils auprès du maître; l'anecdote empruntée à l'histoire romaine, de l'aveugle guéri par la salive de l'empereur né avec le pouvoir de guérir les malades $^{26}$. Parfois la narration fonctionne à la manière d'un exemplum raconté puis commenté. L'histoire de l'adultère de Coronis dévoilé par le corbeau qui devint noir, débouche sur la leçon à en tirer contre les calomniateurs ${ }^{27}$. La rencontre de 1'Acteur avec Mercure, puis Vénus et Diane donnera lieu de la part de cette dernière, à des histoires d'amours tragiques pour démontrer le mauvais jugement de Pâris. Se succèdent à un rythme soutenu, les récits condensés de Médée et Jason, Dédale, Adonis, Pirame et Thisbé, Pygmalion, Myrrha et Cynaras, Phèdre et Hypolite, Philomène et Thereus, Enée et Didon, Héro et Léandre. Comme Evrart l'a fait avec les autorités d'ordre philosophique ou encyclopédique, il procède par accumulation, par allusion. En général, il ne s'étend pas sur le récit qu'il suppose connu de ses lecteurs. L'effet produit est double. D'une part, cette collection d'histoires brièvement racontées, fait penser, comme je l'ai dit, à un florilège. De l'autre, par le plaisir pris à leur accumulation et à leur récit, aussi abrégé soit-il, on a l'impression, dans ces sections à forte densité narrative, de se trouver face à un recueil de récits brefs racontés pour leur valeur d'enseignement, mais aussi pour le simple plaisir qu'ils procurent. Si l'association de l'enseigner et du plaire n'a rien de nouveau, la façon dont Evrart la formule dans le prologue à la Glose lui est personnelle. Comme les Anciens, il se propose de parler «en faignant et fabuleusement» de choses qui ne sont pas à entendre à la lettre mais sujettes à «déclaration» car elles cachent une «sentence secrete». Mais s'il veut «sutillement et plaisaument dire», c'est aussi pour procéder comme les poètes,

car en rime et en mectre est la parole assise et mesuree par musical mesure, c'est a dire par nombres ressamblables a ceulx dont les consonances musicaulx despendent, en laquel musical consonance se delite moult l'ame humaine ${ }^{28}$.

Comme on le voit, la métaphore musicale est centrale à la Glose, tant pour la conception du monde qu'elle propose que pour la définition de l'œuvre qui va suivre. De toute évidence, Evrart tient à se présenter en poète, non pas en simple

${ }^{26}$ Ibid., p. 127-133

${ }^{27}$ Ibid., p. 345.

${ }^{28}$ Ibid., p. 3. 
compilateur ou commentateur. D'ailleurs, si le corpus qu'il sollicite dans ces sections qui font largement place au récit, renvoie pour l'essentiel au répertoire de l'Antiquité, celui de la littérature vernaculaire médiévale, en dehors du Roman de la Rose et des Échecs amoureux, n'est pas tout à fait absent. Il mentionne les Isopets, Le Roman de Renart, la Prise amoureuse, l'histoire de Berinus et la Châtelaine de Vergi.

À la façon dont les parties relatives aux dieux, par l'abondante moisson de récits qu'ils permettent de regrouper, donnent l'impression que l'auteur a succombé au plaisir de la narration, les sections du verger de Déduit et de la partie d'échecs finale accordent une large place à l'insertion de citations en vers. La plupart d'entre elles empruntent au Roman de la Rose. Alors que, dans tout ce qui précédait l'arrivée de l'amant au verger de Déduit, Evrart se contentait de mentionner le Roman de la Rose, souvent de pair avec le «livre rimé», c'est-à-dire les Échecs amoureux, il se plaît maintenant à le citer. J'ai compté onze citations de deux vers et plus qui ponctuent le commentaire des dix images à l'extérieur du mur et celui des figures allégoriques rencontrées à l'intérieur. Il faut leur ajouter les citations de quatre chansons et virelais ainsi que deux proverbes dont l'un avait été utilisé par Jean de Meun :

Aussi bien sont amourettes

soubz buriaux come soubz brunetes ${ }^{29}$.

La densité de ces extraits versifiés et le fait qu'ils sont condensés dans la partie qui renvoie au schéma narratif du Roman de la Rose, fait immanquablement penser au procédé de l'insertion lyrique. Certes, en dehors des quelques œuvres que j'ai citées, la littérature vernaculaire est peu présente dans la Glose. L'exposition des connaissances sur l'amour, conforme à la doctrine courtoise, puise largement au De amore d'André le Chapelain et les allusions à la matière bretonne renvoient aux Échecs amoureux et non aux œuvres elles-mêmes ${ }^{30}$. Pourtant avec la place occupée par le florilège de références narratives et versifiées, c'est comme si Evrart avait tenté de faire de la Glose un speculum tant au plan générique qu'à celui du contenu, conformément à la conception de la relation entre macrocosme et microcosme qui est la sienne.

À observer la terminologie qu'il utilise pour réfléchir sur sa pratique d'écriture, on constate que les deux verbes le plus souvent utilisés sont « segnefier» et «feindre». Si le premier correspond à l'activité du glossateur, le second évoque plutôt celle du poète puisqu'il renvoie dans la plupart des cas à l'«aucteur» du « livre rimé » et, pour quelques occurrences, à celui du Roman de la Rose. Comme on le sait, il s'agit dans les deux poèmes d'une figure polysémique : elle désigne le héros du récit, le narrateur qui raconte l'aventure qui lui est arrivée et l'auteur du

\footnotetext{
${ }^{29}$ Ibid., p. 627. À propos de ces chansons et virelais, voir P.-Y. Badel, «Par un tout seul escondire : sur un virelai du Buisson de Jeunesse », Romania 107, 1986, p. 369-379.

${ }^{30}$ Evrart de Conty, Le Livre des Eschez amoureux moralisés, op. cit., p. 407.
} 
texte $^{31}$. Sans se confondre avec eux, celui de la Glose s'inscrit lui aussi dans son texte. Attentif à la régie de son texte, il est en constante interaction, à la première personne avec son lecteur. Il tient à affirmer à plusieurs reprises l'originalité des opinions qu'il présente, notamment à propos du fait que la prose, autant que «les rimes et les mectres » peut être «par mesure musical ordenee» :

Toutes les choses dessusdites des rimes et des mectres et mesmes des proses trouvera estre vrayes cellui qui bien soutillement avisera la dessusdite ymaginacion, qui semble assez nouvelle ; au moins n'ay je pas dusques a cy veu personne qui s'en soit avisee ne qui y ait pris garde, dont $\mathrm{j}$ ' aye eu toutesfoiz congnoissance ${ }^{32}$.

Il va jusqu'à évoquer des souvenirs personnels. C'est d'ailleurs l'un d'eux, celui de l'étourneau qu'Evrart avait entendu chanter à Amiens la mélodie d'un virelai bien connu, qui fut l'une des données probantes de son identification comme auteur de la Glose $e^{33}$. Si l'on adopte les critères avec lesquels Bernard Ribémont distingue une encyclopédie proprement dite d'un poème didactique, le Livre des échecs amoureux, tout en se prétendant un commentaire rédigé en prose, qui est le mode par excellence du discours savant, s'apparenterait plutôt au second. En effet, ce ne sont pas les données encyclopédiques qui préexistent à l'écriture et structurent l'organisation du discours, mais le récit, le schéma narratif offert par l'aventure de l' «acteur $»^{34}$. Du « subtil» agencement de la matière traitée qui en résulte, le jeu d'échecs est la parfaite métaphore, «car ce gieu ne doit pas proceder par fortune, maiz par engin et par soutilleté $»^{35}$.

Madeleine Jeay

McMaster University, Hamilton, Canada

${ }^{31}$ A.-M. Légaré et B. Roy, "Le 'je' d'Evrart de Conty : du texte à l'image », dans Auteurs, lecteurs, savoirs anonymes. 'Je' et encyclopédies, Cahiers Diderot 8, 1996, p. $39-56$ (p. $47-$ 48).

${ }^{32}$ Evrart de Conty, Le Livre des Eschez amoureux moralisés, op. cit., p. 173. Voir aussi p. 223 : «Et ceste ymaginacion est quant a moy nouvelle».

${ }^{33}$ Voir l'introduction au Livre des Eschez amoureux moralisés, op. cit., p. liii.

${ }^{34} \mathrm{~B}$. Ribémont, «L'encyclopédisme médiéval : de la définition d'un genre à son évolution sur la pertinence des notions d'apogée et de décadence», dans Apogée et déclin, éd. C. Thomasset et M. Zink, Paris, Presses de l'Université de Paris-Sorbonne, 1993, p. 27-68 (p. 44-46) ; surtout «Around the definition of an encyclopedic genre in the Middle Ages », Premodern Encyclopaedic Texts, éd. P. Binkley, Brill, Leiden /New York/Köln, 1997, p. 47 61 et «Les encyclopédies du Moyen Âge », Comprendre le XIII siècle, Mélanges M.Th. Lorcin, Presses Universitaires de Lyon, 1995, p. 237-60.

${ }^{35}$ Evrart de Conty, Le Livre des Eschez amoureux moralisés, op. cit., p. 606. 